\title{
Understanding the distribution of introduced mammalian predators in an urban environment using monitoring tools and community trapping
}

\author{
By \\ Cherie Sara Balls
}

\begin{abstract}
A thesis
submitted to the Victoria University of Wellington in fulfilment of the requirements for the degree of Master of Science
\end{abstract}

School of Biological Sciences

Victoria University of Wellington

Te Whare Wānanga o Te Ūpoko o Te Ika a Māui

2019 


\begin{abstract}
Introduced mammalian predators are one of the largest conservation threats to New Zealand native flora and fauna, and there is an increasing concern about their presence in urban environments, coupled with a recognition that cities present a unique opportunity for ecological restoration, due to the availability of a large number of volunteers and options for intensive management of green spaces and gardens. Predator control is an essential step towards the ecological restoration of urban environments, however, it requires an understanding of the factors influencing the distribution of these mammalian predators before successful control operations can be implemented. Few studies have investigated mammalian predators in urban environments, and there is little certainty about what drives their distribution in these environments. This thesis used simple mammal monitoring techniques and trapping data to investigate the distribution of mammalian predators within broad scale urban environments, with the aim of identifying drivers of their distribution.

Chew cards and tracking tunnels collected across three New Zealand cities were assessed for their efficacy as accurate monitoring devices in urban environments. In Chapter 2, monitoring devices were cross-checked between observers to assess the level of consistency in interpretation of chew and tracking marks. The consistency of chew card and tracking tunnel identifications was relatively high overall and were not substantially influenced by the city of identification, or the duration of card exposures. Monitoring devices were also assessed for their change in sensitivity between one and six-night exposures. Both devices were effective at detecting rats, however, tracking tunnels showed greater sensitivity and consistency in detecting mice and hedgehogs, whereas chew cards were better suited to the monitoring of possums. Neither device was particularly effective at detecting mustelids or cats.

In Chapter 3, mammalian predators were monitored across 24 monitoring lines in autumn, 2018, and results were compiled with spring 2017 and autumn 2018 data, pre-collected in two other cities, following the same procedures. There were distinct differences in the broad-scale habitat utilisation of rats, mice, hedgehogs, with possums being the only species to show a strong preference for urban forests. Only two of the tested microhabitat variables had an influence on species distributions. Detection of rats declined with increasing distance to the coast, and the increase in human population size was related to a significant increase in hedgehogs. There was a strong seasonal difference on the influence of local trap density and
\end{abstract}


the detection of mammals. The increase in trap density within $25-50 \mathrm{~m}$ radii was significantly related to a decrease in rat and hedgehog detections. Overall, there are substantial differences between the distributions of species in an urban environment.

Trapping is one of the main methods of predator control in New Zealand, and is already widespread within urban and suburban Wellington. In Chapter 4, I compiled trap data from 22 community trapping groups operating in residential and reserve areas in Wellington City. Residential groups ("backyard trappers") used a high proportion of Victor and various rat and mouse traps, which was strongly linked to their high number of rat and mouse catches. Groups trapping in reserves used a high proportion of DOC 200, Victor and A24 traps, however, fewer hedgehogs were caught compared to residential areas. Catches were significantly influenced by various landscape variables. An increased distance of traps to streams led to significantly higher catches of rats, conversely, proximity to streams resulted in significantly higher catches of mice and hedgehogs. Although few catches of weasels were reported, traps closer to the coast and to forest fragments caught significantly more individuals.

The research in this thesis contributes to the small body of research conducted on mammalian predators within urban environments. The findings in this thesis can assist with the current and future predator management programmes, by highlighting areas of potential significance, particularly in Wellington. 


\section{Acknowledgements}

First and foremost, I would like to thank my supervisor, Stephen Hartley, for without him, I would not have had a project to complete this year. He has been a pleasure to work with and was always ready with support and advice for any problem met. His guidance and expertise in both biology and statistics were invaluable in the competition of this project.

A massive thank you to my partner Michael. He has gone above and beyond to make sure that I completed this thesis with as much ease as was possible. He has been my biggest supporter and my greatest encourager, and without him, the completion of this thesis would not have been possible. He has assisted me both practically and mentally throughout this whole journey and I could not be more grateful for all that he has done.

To all the people who assisted with fieldwork, whether you assisted for just one day or an entire season, thank you for your participation. The fieldwork is collected for the People, Cities and Nature project, however, it was also a large component of my thesis. Without the assistance of all those involved I would have not been able to successfully complete two seasons of fieldwork. Your help has been invaluable.

I would like to thank the People, Cities and Nature project, and Victoria University, for providing me with scholarships to assist with my thesis. It has been a massive help, and one that I am deeply grateful for.

A big thank you to Annemieke, my desk buddy as well as my personal taxi for a great portion of my work. Your carefree and positive attitude has encouraged me to keep working through all the hard times, even when it all seemed too much.

Lastly, I'd like to thank my work colleagues. Part-time work and full-time study is a difficult thing to juggle, and you both made it easier to do so. Thank you Kevin for your understanding and support. You have been so accepting and understanding of all the time I have needed off. And thank you to Adam, for the excessive days where you've covered my shifts, allowing me to complete my fieldwork, and now, my entire thesis.

Overall, I would just like to thank my friends and family, and anyone who had a part to play in the completion of this thesis. I received enormous amounts of support from so many of you, and even the small gestures of kindness have been a light that got me through some of the darker days. 


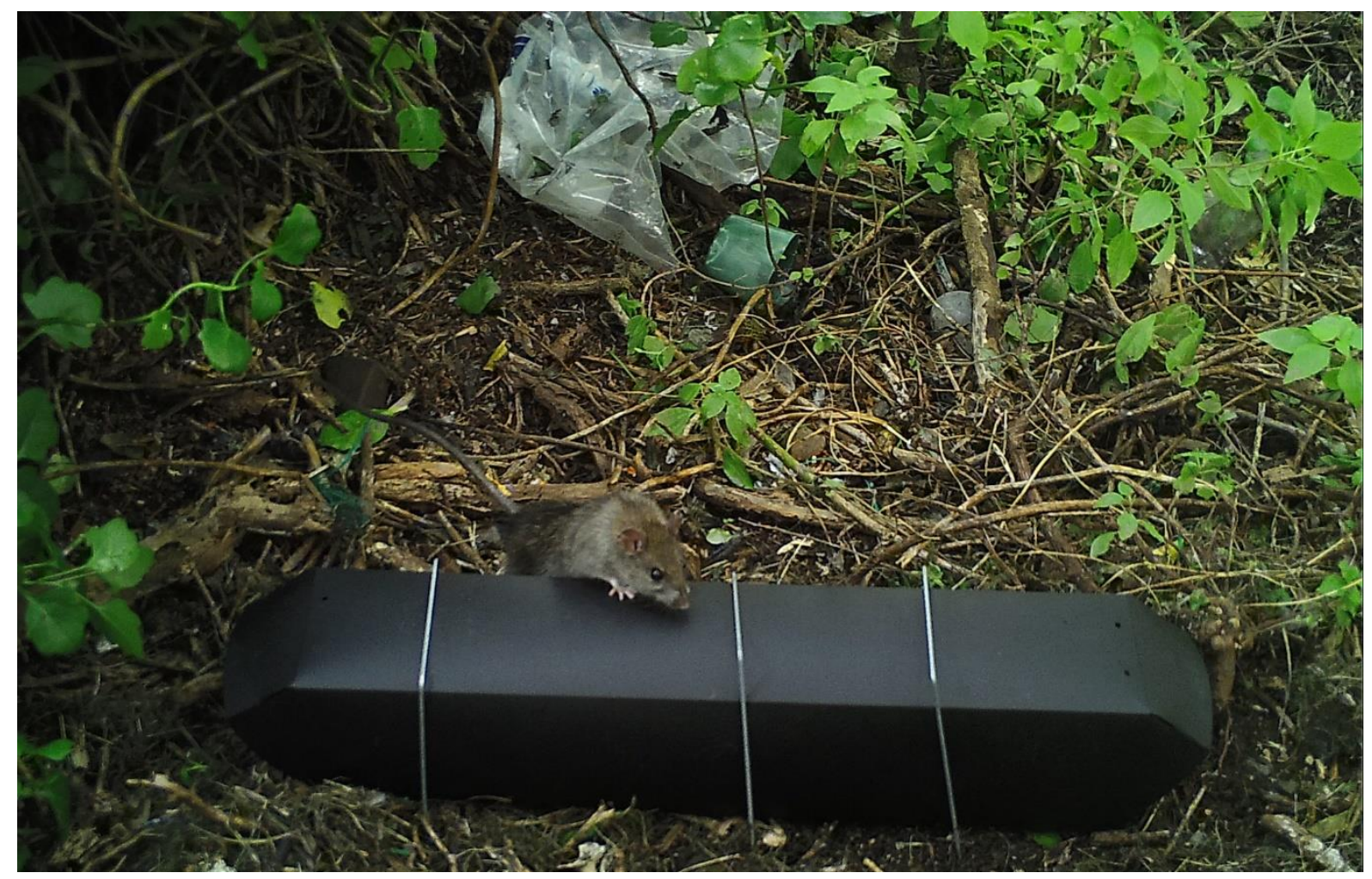

Rat interacting with a tracking tunnel, caught on one of the motion activated cameras in South Miramar amenity, autumn 2018. 


\section{Table of Contents}

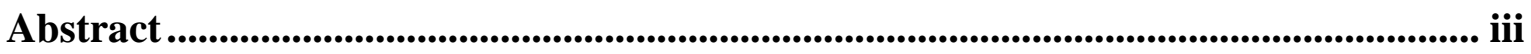

Acknowledgements........................................................................................................................v

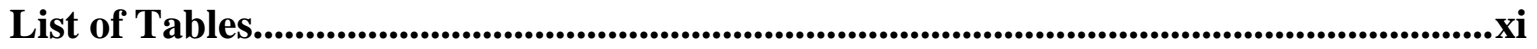

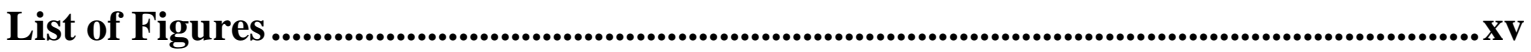

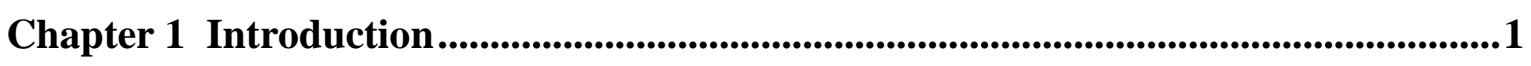

Impacts of mammalian predators in New Zealand ................................................. 2

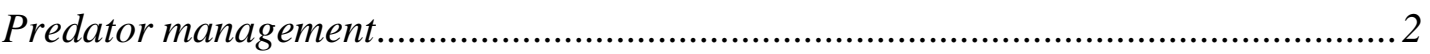

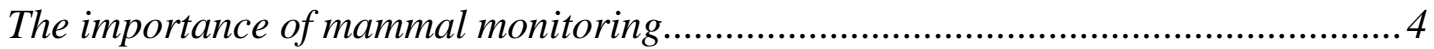

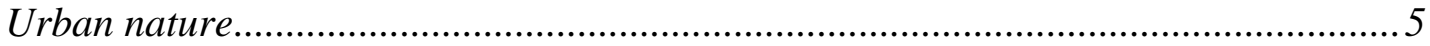

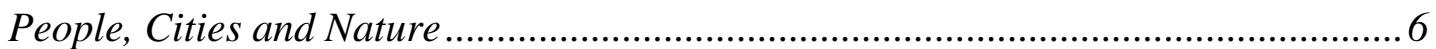

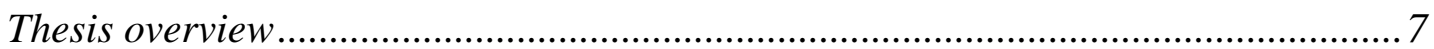

Chapter 2 Assessing the efficacy of chew cards and tracking tunnels for use in urban

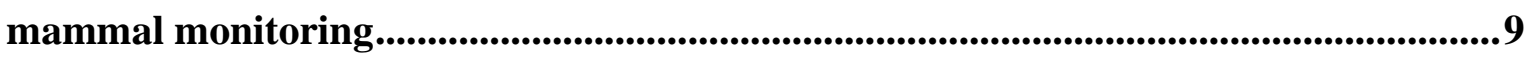

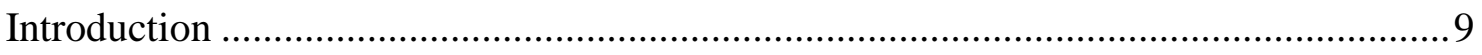

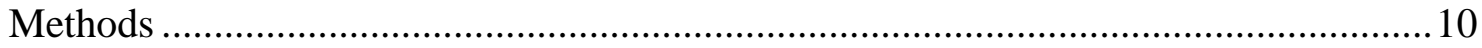

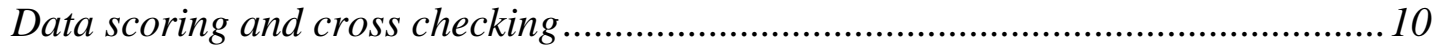

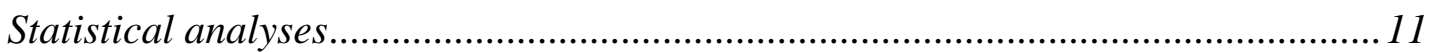

Sensitivity to species detection and the influence of duration of exposure and card

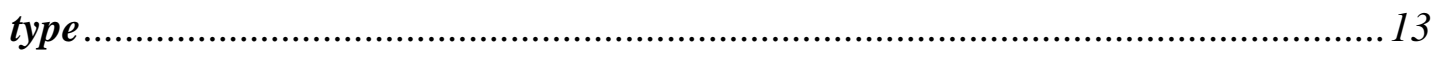

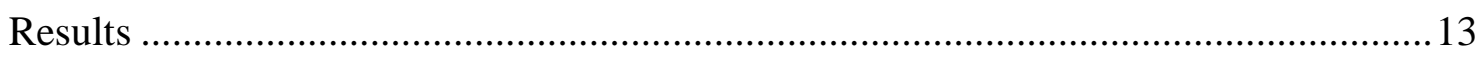

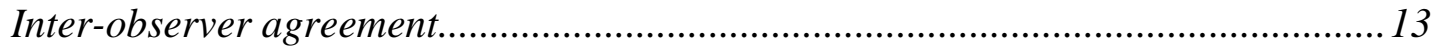

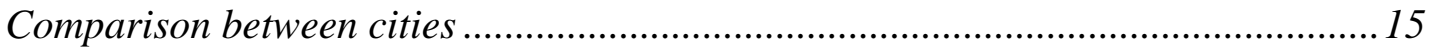

One-night and six-night comparison: chew cards .............................................. 19

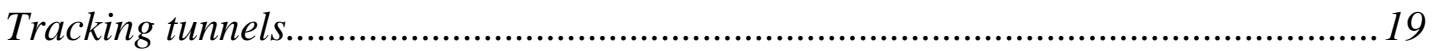

Sensitivity and the influence of duration of exposure and card type ......................2 21

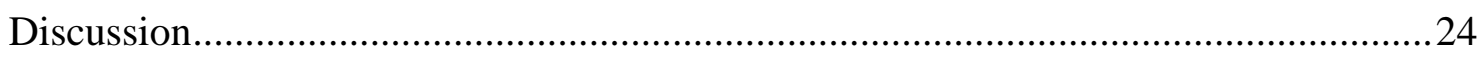

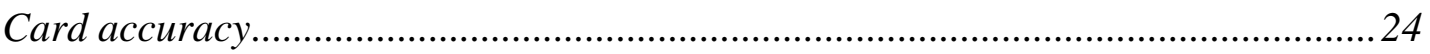

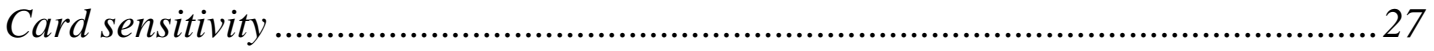

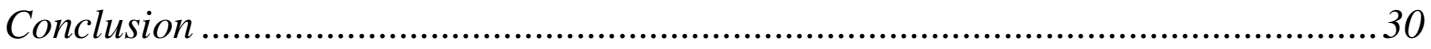

Chapter 3 The distribution of introduced mammalian predators across urban environments, and the influence of trapping intensity and environmental factors ....31

Introduction 


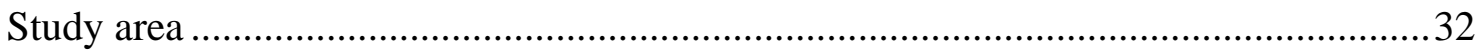

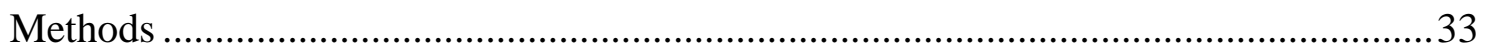

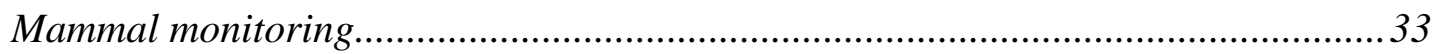

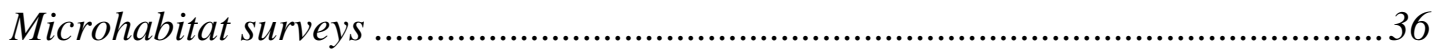

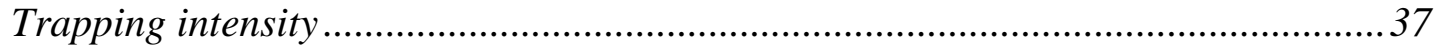

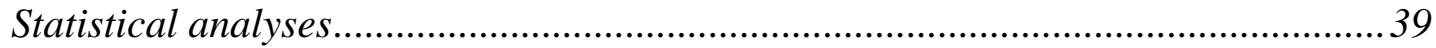

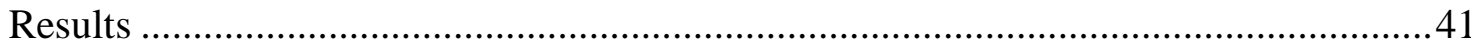

The influence of city, season and habitat type on species distribution......................41

Influence of landscape and microhabitat variables on mammal presence in

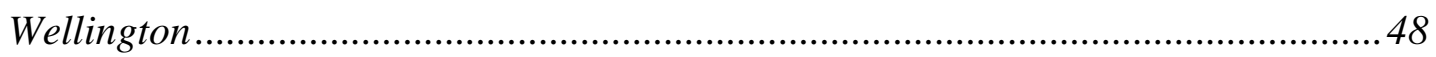

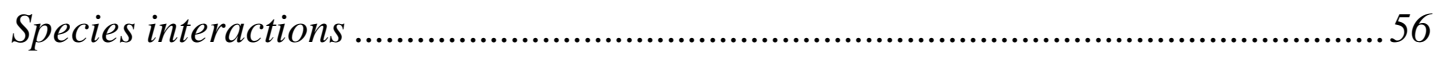

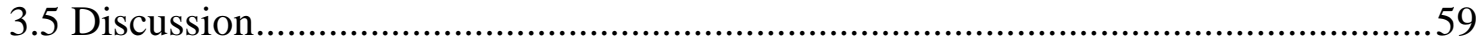

Chapter 4 A summary of council-led and community-led urban trapping in

Wellington, and the influence of environmental variables on trap catches ..................65

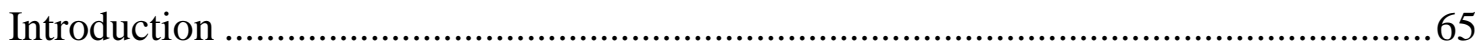

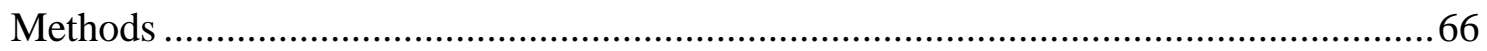

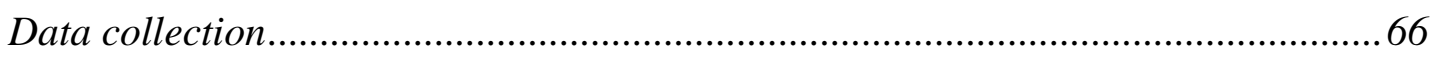

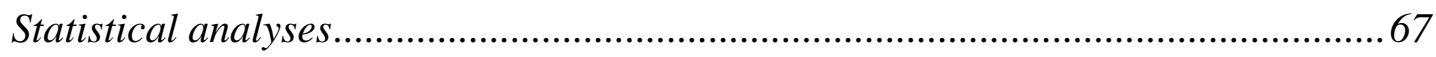

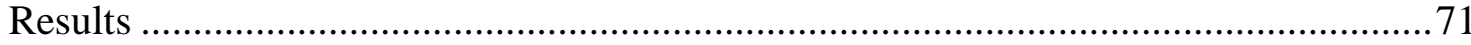

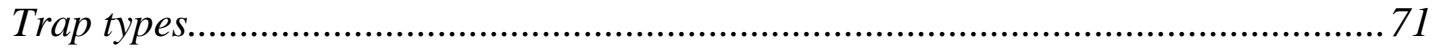

Relationship between trap number and trap catches.............................................. 74

Influence of microhabitat variables and trap type on catches................................. 77

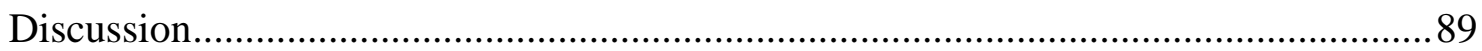

Chapter 5 General discussion...................................................................................95

References ................................................................................................................................................ 105

Appendix A1 Appendices for Chapter 2 ................................................................................. 119

Appendix A2 Appendices for Chapter 3 ................................................................................... 120

Appendix 3 Appendices for Chapter 4 ........................................................................................ 131 


\section{List of Tables}

Table 2.1: A list of the individuals who were responsible for identifying each set of chew cards and tracking tunnels. $\mathrm{N}$ is the total number of observations that were made across both identifiers.

Table 2.2: Confusion matrix for the classifications of marking by species $i$ ( $i=$ animal e.g. rat, mouse, etc) by two separate identifiers. Percent agreement (accuracy) was calculated as $\% \mathrm{~A}=(\mathrm{a}+\mathrm{d}) /(\mathrm{a}+\mathrm{b}+\mathrm{c}+\mathrm{d})$, extended across all species identifications. Cohen's kappa was calculated as $\% \mathrm{~A}-\mathrm{p}(\exp ) / 1-\mathrm{p}(\exp )$, with $\mathrm{p}(\exp )$ calculated as $(\mathrm{a}+\mathrm{c})(\mathrm{a}+\mathrm{b})+(\mathrm{c}+\mathrm{d})(\mathrm{b}+\mathrm{d}) / \mathrm{N}^{2}$, where $\mathrm{N}=(\mathrm{a}+\mathrm{b}+\mathrm{c}+\mathrm{d})$.

Table 2.3: Confusion matrix of the classifications provided to chew cards by two separate identifiers per city. Darker green boxes represent the true positive identifications (true positive $=$ both sets of classifications are consistent $)$.

Table 2.4: Confusion matrix of the classifications provided to tracking tunnel cards by two separate identifiers per city. Darker green boxes represent the true positive identifications. 14

Table 2.5: GLMM summaries for the influence of monitoring duration and card type on the presence of the four listed species. Values are indicative of the difference between one-night and six-night cards, and between chew cards and tracking tunnels. No interactions were included in the analysis.

Table 2.6: Type III ANOVA summaries for the influence of the interaction between monitoring duration and season, and season and card type on the presence of the four listed species. Values are indicative of the combined influence of the two variables.

Table 3.1: The area of a circle for the specified radius buffer zones in the GIS analysis of local trap density.

Table 3.2: Fixed effects for the GLMM model assessing the influence of environmental variables on species presence across Wellington City.

Table 3.3: Type III ANOVA table reporting the results obtained from GLMM models on the influence of season, city and habitat, and their interactions for $a$ ) rats, $b$ ) mice $c$ ) hedgehogs and $d$ ) possums 
Table 3.4: Type III ANOVA table reporting the most significant results obtained from GLMM models on the influence of microhabitat, landscape and management variables for $a$ ) rats, $b$ ) mice and $c$ ) hedgehogs

Table 3.5: Type III ANOVA table for the influence of trap density and specified radii, trap type, and the interaction between trap density and season for rats and hedgehogs. .55

Table 4.1: Fixed effects for the GLMM models assessing the influence of environmental variables on trap catches across Wellington City.

Table 4.2: A list of the 43 recorded trap groups within Wellington City. The right column details what data I have obtained from each trapping group to discern which groups were included in which analyses.

Table 4.3: GLMM table reporting the influences of trap density, and its interaction with land ownership and season, on the catches of mammalian predators. .76

Table 4.4: GLMM table reporting the influence of area and season on the trap catches of rats, mice, hedgehogs, stoats and weasels. Area results are reporting the influence of residential sites in comparison to reserves, and season results are reporting the influence of spring in comparison to autumn catches.

Table 4.5: Type III ANOVA table reporting the influence of microhabitat variables of trap catches of $a$ ) rats, $b$ ) mice, $c$ ) hedgehogs and $d$ ) weasels.

Table A1.1: Consistency of chew card interpretations between initial and cross-check identifiers for the complete dataset of cards.

Table A1.2: Consistency of tracking card interpretations between initial and cross-check identifiers for the complete dataset of cards.

Table A2.1: Spearman correlations between combinations of the six vegetation tiers used in GLMM models

Table A2.2: Spearman correlations between the six vegetation tiers and their relationship with distances from environmental variables used in GLMM models.

Table A2.3: GLMM table reporting the influence of various landscape and microhabitat variables on the three alternative models for rat detections 
Table A2.4: GLMM table reporting the influence of various landscape and microhabitat variables on the three alternative models for mouse detections.

Table A2.5: GLMM table reporting the influence of various landscape and microhabitat variables on the three alternative models for hedgehog detections.

Table A3.1: Results for the Pearson correlation between the total number of catches and the total number of traps within a trap group.

Table A3.2: Linear model results for the association between the total number of catches and the total number of traps within a trap group. $R^{2}$ values represent the adjusted $R^{2}$ reported in the model summary.

Table A3.3: GLMM table reporting the differences between associations of season and area on hedgehog catches. Highlighted variables are the comparisons between residential and reserve sites across the same season. 


\section{List of Figures}

Figure 2.1: Consistency of identifications between observers classifying chew card markings across three cities in New Zealand. Consistency was based on the percentage of agreement, with and without the correction for chance identifications (kappa), between two separate identifiers. Graphs represent the consistencies between cities for $a$ ) rats, $b$ ) mice, $c$ ) hedgehogs, $d$ ) possums, $e$ ) mustelids and $f$ ) no markings.

Figure 2.2: Consistency of identifications between observers classifying tracking card markings across three cities in New Zealand. Consistency was based on the percentage of agreement, with and without the correction for chance identifications (kappa), between two separate identifiers. Graphs represent the consistencies between cities for a) rats, b) mice, c) hedgehogs, d) possums, e) mustelids and f) no markings.

Figure 2.3: Consistency of identifications between observers classifying all one-night and six-night chew card tooth impressions. Consistency was based on the adjusted measure of agreement between two separate identifiers (kappa), accounting for the probability of identifications made by chance.

Figure 2.4: Consistency of identifications between observers classifying all one-night and six-night tracking tunnel card footprints. Consistency was based on the adjusted measure of agreement between two separate identifiers (kappa), accounting for the probability of identifications made by chance.

Figure 2.5: Mean percentage of detection of introduced mammalian predators on chew cards and tracking tunnels across one-night and six-night exposures.

Figure 2.6: Influence of season on card type over one-night and six-night monitoring periods on the mean detection of $a$ ) rats and $b$ ) mice. .24

Figure 3.1: Map of the 24 monitoring lines situated in Wellington City. Yellow markers represent amenity sites, green markers represent forest sites and purple markers represent residential sites. There are three sites located within each of the 8 suburbs identified.

Background image was sourced from LINZ. Map created using ArcMap 10.5.1 .35

Figure 3.2: Diagram depicting the number of traps per hectare for variously spaced regular trapping grids. a) a $25 \mathrm{~m}$ spaced trap grid is equivalent to 16 traps per hectare, b) a $50 \mathrm{~m}$ 
spaced trap grid is equivalent to 4 traps per hectare and c) a 100m spaced trap grid is equivalent to 1 trap per hectare.

Figure 3.3: Mean presence of introduced mammalian species as a percentage of the total chew cards and tracking tunnels collected for $a$ ) rats, $b$ ) mice, the total tracking tunnels collected for $c$ ) hedgehogs, and the total chew cards collected for $d$ ) possums. The detection of rats, mice and hedgehogs demonstrated significant differences across seasons $(\mathrm{p}<0.002) .46$

Figure 3.4: Mean detections of introduced mammalian species across habitat types as a percentage of the total chew cards and tracking tunnels collected for $a$ ) rats, $b$ ) mice, the total tracking tunnels collected for $c$ ) hedgehogs, and the total chew cards collected for $d$ ) possums. Detections of mice, hedgehogs and possums differed significantly across habitat types $(\mathrm{p}<0.02)$, however, only detections of hedgehogs significantly differed between habitats across seasons $(\mathrm{p}=0.012)$.

Figure 3.5: Map depicting the detections of rats at monitoring sites across Wellington, for the spring 2017 and autumn 2018 monitoring seasons. The two highlighted lines represent the sites that had the fewest detections. Background image was sourced from LINZ and used in ArcMap 10.5.1.

Figure 3.6: Map depicting the detections of mice at monitoring sites across Wellington, for the spring 2017 and autumn 2018 monitoring seasons. The two highlighted lines represent the sites that had the fewest detections. Background image was sourced from LINZ and used in ArcMap 10.5.1.

Figure 3.7: Map depicting the detections of hedgehogs at monitoring sites across Wellington, for the spring 2017 and autumn 2018 monitoring seasons. The highlighted lines represent the sites that had the fewest detections. Background image was sourced from LINZ and used in ArcMap 10.5.1.

Figure 3.8: The influence of the distance to the coast on detections of rats. Values have been averaged per line for graphical representation .54

Figure 3.9: The influence of human population size in specified mesh blocks on the detections of hedgehogs. Values have been averaged per line for graphical representation...54

Figure 3.10: The relationship between the mean hedgehog detections and the mean rat detections across monitoring lines in autumn 2018. 
Figure 3.11: The relationship between the mean mouse detections and the mean rat detections across monitoring lines with one-night exposures of cards in spring 2017

Figure 3.12: The relationship between the mean hedgehog detections and the mean rat detections across monitoring lines with six-night exposures of cards in autumn 2018. .58

Figure 3.13: Mean percentage of species-species occurrences at the same site over a onenight and six-night monitoring period in the seasons of spring and autumn.

Figure 4.1: Map of the Wellington City area, depicting the recorded trapping across various residential and reserve sites. Trap density is displayed as a heat map, representing density per hectare over 4 hectare $(200 \mathrm{~m} \times 200 \mathrm{~m})$ grid cells. Sites that only provided trap location data are included on the map to visualise the extent of traps across Wellington. Background image was sourced from LINZ and used in ArcMap 10.5.1

Figure 4.2: The number of each specified trap type occurring across $a$ ) residential sites (n= 11 trap groups) and $b$ ) reserve sites ( $\mathrm{n}=11$ trap groups) within Wellington City. Note the change in scale on the y axis.

Figure 4.3: The total number of occurrences at which just one trap, or more than one trap, was located in a single backyard or reserve site.

Figure 4.4: The influence of the number of traps on the total number of recorded trap catches. Associated $R^{2}$ values are reported at the bottom of each plot.

Figure 4.5: The percentage of species catches in residential sites, reserve sites, and the total percentage of all catches across Wellington City for the five listed species.

Figure 4.6: Total monthly catches across 14 trapping groups in Wellington for $a$ ) rats, $b$ ) mice, $c$ ) hedgehogs and $d$ ) weasels.

Figure 4.7: The percentage of species catches in residential and reserve traps across the four seasons. Both rats and mice consistently have a higher catch rate in residential traps irrespective of season.

Figure 4.8: Rat catch predictions for Wellington City. Map depicts the probability of rat capture within a given location. White line outlines the main boundary between the Wellington core and surrounding forest. Background image was sourced from LINZ. Map created using ArcMap 10.5.1 
Figure 4.9: Mouse catch predictions for Wellington City. Map depicts the probability of mouse capture within a given location. White line outlines the main boundary between the Wellington core and surrounding forest. Background image was sourced from LINZ. Map created using ArcMap 10.5.1

Figure 4.10: Hedgehog catch predictions for Wellington City. Map depicts the probability of hedgehog capture within a given location. White line outlines the main boundary between the Wellington core and surrounding forest. Background image was sourced from LINZ. Map created using ArcMap 10.5.1

Figure 4.11: Stoat catch predictions for Wellington City. Map depicts the probability of stoat capture within a given location. White line outlines the main boundary between the Wellington core and surrounding forest. Background image was sourced from LINZ. Map created using ArcMap 10.5.1.

Figure 4.12: Weasel catch predictions for Wellington City. Map depicts the probability of weasel capture within a given location. White line outlines the main boundary between the Wellington core and surrounding forest. Background image was sourced from LINZ. Map created using ArcMap 10.5.1

Figure A2.3: Map of the buffer zones created around the 240 mammal monitoring stations to assess trap density in Wellington. Buffers measure a $25 \mathrm{~m}, 50 \mathrm{~m}, 100 \mathrm{~m}$ and $200 \mathrm{~m}$ radius around stations.

Figure A2.4: Map of the mesh blocks used to estimate human population within the 240 monitoring stations in Wellington.

Figure A2.5: Map of the various vegetation fragment land cover layers used in the analysis assessing the influence of sites and their proximity to areas of vegetation. The vegetation categories represent those determined in the Land Cover Database, 2013, and are not representative of the vegetation types occurring in residential backyards. Urban areas are uncategorised and this information was not available in the database. 


\section{Chapter 1}

\section{Introduction}

Introductions of predatory mammals to New Zealand occurred as early as the $13^{\text {th }}$ century with the colonisation of human populations (Parkes \& Murphy, 2003; Pickerell et al., 2014). The pacific rat, or kiore, was the first introduced rodent that established with the settlement of Maori and Polynesians (Parkes \& Murphy, 2003). However, it was not until the late $18^{\text {th }}$ century with the arrival of Europeans, that a greater suite of species were introduced (King \& Barrett, 2005; Pickerell et al., 2014). New Zealand now maintains established populations of 31 species of mammals, including rats (Rattus rattus and $R$. norvegicus), mice (Mus musculus), hedgehogs (Erinaceus europaeus), possums (Trichosurus vulpecula) and mustelids (stoats (Mustela ermine) and weasels (M. nivalis)), that occupy a large portion of the mainland (Burns et al., 2012). These predatory species pose some of the greatest threats to the New Zealand native flora and fauna and their impacts have been considered as one of the largest conservation risks (Brooke et al., 2007; Carter et al., 2016; Craig et al., 2000; Pech \& Maitland, 2016; Towns et al., 2006). To conserve our native species, effective pest control programmes are required to reduce the impact that introduced mammalian predators are having on the ecosystem. Many of New Zealand's offshore islands demonstrate the effectiveness that the various predator management programmes can have on the resident species, such as the increase in species populations that were exceedingly endangered (Clout \& Russell, 2006; Towns et al., 2013). However, control can be difficult and implemented with reduced success without first identifying the species of target and their relative abundance within the system (Ruffell et al., 2015a).

The collection of mammal monitoring data through non-invasive techniques may provide useful information on the presence and distribution of species across a landscape. Devices, such as chew cards and tracking tunnels, have been the devices of choice for several mammal monitoring studies in New Zealand. They require minimal effort to put in place, but can provide information on the types of species at a specific location, and if done over a large scale, can provide an insight into the relative presence and abundance of these species (Gillies \& Williams, 2013; Innes et al., 2010b; Ruffell et al., 2015b). 


\section{Impacts of mammalian predators in New Zealand}

Introduced mammalian predators are widespread across New Zealand and have even managed to establish populations on several of New Zealand's offshore islands (Towns et al., 2013). The introduction of mammals has impacted many of New Zealand's native flora and fauna species, largely resulting in declines and extinctions through direct predation and competition for common resources (Blackie et al., 2014; Clout \& Russell, 2008; Towns et al., 2006). New Zealand's native fauna evolved in the absence of mammals, thus resulting in species that are poorly adapted, ecologically and behaviourally, to evade predators (Gibbs, 2009; Lal, 2008). Several native animals are now restricted to offshore islands where pest species are either absent or contains smaller populations of only a few select pest species (Gillies et al., 2003). Declines and extinctions resulting from the introduction of mammals have been recorded for several native birds (Duncan \& Blackburn, 2004; Morgan et al., 2011; O'Donnell \& Hoare, 2012; Sanders \& Maloney, 2002), lizards (Jones et al., 2013), amphibians (Towns et al., 2013; Towns et al., 1997), invertebrates (Gibbs, 2009; Jones et al., 2013; St Clair, 2011) and plant species (Brown et al., 2015; Ruscoe et al., 2005; Towns et al., 2006). Birds are one of the most intensely affected by mammalian predators (Gillies et al., 2003), and at least $41 \%$ of endemic birds having gone extinct since their introduction (Innes et al., 2010a; Towns et al., 1997). The declines and extinction resulting from the introduction of predators has negative effects on the entire ecosystem. The removal of species can lead to interruptions of vital ecological processes, such as pollination and seed dispersal (Innes et al., 2010a; Wright, 2011), with indirect consequences for other species.

The impacts of introduced mammals are not only limited to native flora and fauna. Species, such as possums, can also impact agricultural sectors through the transmission of diseases to livestock (Coleman \& Cooke, 2001) and have general consequences on human health. Overall, the introduction of these species has negatively influenced New Zealand environmentally, ecologically and economically (Clout, 2002; Goldson et al., 2015; Wright, 2011).

\section{Predator management}

Prior to the late 1980's, pest control operations were largely enforced on offshore islands due to their isolation and reduced likelihood of reinvasion (Carter et al., 2016; Gillies et al., 2003). In the case of islands, predator control has focused on eradication, or capture and 
removal, of species where feasible (Courchamp et al., 2003; Towns et al., 2013). On the mainland, complete eradication is difficult to achieve due to the size of populations and their increased likelihood of reinvasion from neighbouring populations that experience no pest control (Carter et al., 2016; Gillies et al., 2003; King et al., 2011). Therefore, the goal remains around maintaining populations below a threshold at which their impacts on flora and fauna are greatly reduced (Brown et al., 2015; Carter et al., 2016; Gillies et al., 2003). Traps and poison baits are the two most common methods of predator control in New Zealand, however, the simultaneous control of multiple species has been proven to be the most effective technique to control mammalian predators (Wright, 2011). As the only native land mammals in New Zealand are three species of bat, multispecies control is usually undertaken with the use of mammal targeted poison baits for the simultaneous control of all targeted introduced mammals (Brown et al., 2015). The control or exclusion of introduced mammalian predators has resulted in several ecosystem benefits including the increases in populations of birds (Gillies et al., 2003; O'Donnell \& Hoare, 2012), invertebrate communities (Ruscoe et al., 2013; Watts et al., 2014; Watts et al., 2011), lizards (Reardon et al., 2012), and the regeneration of vegetation (Gillies et al., 2003; Wilson et al., 2003).

In comparison to trapping, the application of poison baits is a less costly, lower effort, method of control (Wright, 2011). The aerial application of poison baits is the most effective technique of bait control as it can cover hectares of land in one application (Brown et al., 2015; Wright, 2011), however, it is not a feasible option in an open urban ecosystem. The use of ground based poisons is an effective alternative to aerial poisoning, but is also constrained to urban reserves due to the increased risk of contact with domestic mammals and people. Trapping is the most applicable option in an urban environment, however, the energetic and financial requirements to maintain widespread trapping networks can be large (Norbury et al., 2014; Wright, 2011). Urban trapping has already gotten underway in several cities across New Zealand with many individuals and council-led groups getting involved with their local predator free groups. There is currently little formal data summarising the efforts or outcomes of trapping within urban areas in New Zealand. Therefore, mammal monitoring in urban areas is an important step to assess the requirement and efficacy of trapping programmes in specified locations. 


\section{The importance of mammal monitoring}

Mammal monitoring studies use a diverse range of methods, but with the common goal of gaining a relative understanding of species presence and distribution. Monitoring studies have also been proven as an effective method to assess the outcomes of measured ecological exercises, such as trapping (Henry et al., 2008; Ruffell et al., 2015a). In New Zealand, mammal monitoring studies mostly utilise chew cards, tracking tunnels, wax tags and traps to assess mammal populations (Pickerell et al., 2014). In recent years, motion activated cameras have also been trialled as an alternative, multi-species method of monitoring with reasonable success (Anton et al., 2018; Glen et al., 2014). The data that is gained from these studies can provide information on the presence, distribution and abundance of target species. With the simultaneous measurement of landscape and microhabitat variables, monitoring data can also provide information on potential drivers of distribution. Understanding what drives patterns of distribution can lead to predictions on where species may occur, and what degree of impact they may have within a specific location (Ruffell et al., 2015a). In some cases, the identification of environmental drivers had led to predictions on where invasions may occur, and can therefore have control measures in place to limit their impacts (Roura-Pascual et al., 2009; Ruffell et al., 2015a; Zhu et al., 2007). In New Zealand, some investigation has been conducted on the factors that influence the distribution of introduced mammals. Forest composition and structure has been identified as one factor that influences rodent, hedgehog and mustelid distribution, with all species commonly located in undisturbed native forests (Harper et al., 2005; King et al., 1996). Rodents are also commonly located in areas that have dense, low vegetation cover (King et al., 1996; Morgan et al., 2009), are close to bodies of water (Morgan et al., 2009; Ruffell et al., 2015a), at an increasing distance from forest edges (Christie et al., 2009; Ruffell et al., 2014) and in areas of stepper topography and higher elevation (Christie et al., 2009; Rayner et al., 2007; Ruffell et al., 2015a).

A commonality between these studies is that they were all conducted in rural environments. Until recently, monitoring studies have largely been focused within forest and grassland ecosystems (Pickerell et al., 2014), with very few studies on mammalian predators having been conducted in urban ecosystems (Morgan et al., 2009; Morgan et al., 2011). Urban ecosystems are dynamic environments where factors such as fragmentation of resources, and the additional interactions with humans, infrastructure, and domestic animals, are likely to influence patterns of species distribution (Baker et al., 2003; Klimant et al., 2017; Morgan et al., 2009; Pickerell et al., 2014). We cannot be certain that the behaviour of introduced 
mammals is the same across systems, therefore, environmental variables that have previously been identified as influential drivers of distribution in forests, may not have the same influence in urban ecosystems. As previously stated, trapping programmes are already established within urban reserves and suburbs. Pest control, especially via trapping, can be a massive financial and energetic cost, and can only manage to cover a portion of the country. However, without results of mammal monitoring, species presences and relative abundances are unclear and without a proper understanding of the system, targeted pest control can have unexpected consequences due to the release of non-target pests that are normally suppressed by top predators, often with more harmful effects (Ruscoe et al., 2011; Tompkins \& Veltman, 2006). These gaps within the literature point to the importance of monitoring species assemblages in urban areas and identifying potential drivers of distribution. By identifying areas of known trapping intensity, we can also investigate how current trapping efforts are influencing species presences. It is highly beneficial to identify areas where species are present and what potential drivers may be influencing their presence. With this data, resource managers will have greater capabilities to predict areas where mammalian predators are likely to have a high presence or the greatest negative impacts, allowing maximisation of the resources that are available for control (Ruffell et al., 2015a).

\section{Urban nature}

As the world becomes more urbanised, biodiversity faces increased threats through processes of disturbance and fragmentation (Clarkson et al., 2007). At present, more than half of the world's population resides in cities (Goddard et al., 2010; World Health Organisation, 2016) and is expected to increase to $66 \%$ by 2050 . The biggest driver of biodiversity loss is said to largely come from the destruction of habitat (Clarkson et al., 2007), which is a standard process involved in urbanisation (McDonald et al., 2008; McPhearson et al., 2016). As a result of these changes, urban environments are often characterised by the presence of few generalist species that are able to exploit the dynamic environment (Kark et al., 2007), resulting in areas of low species diversity (McKinney, 2002; Shochat et al., 2006).

However, there are cases where urbanisation actually benefits local species. Urban green spaces instead provide a refuge for globally declining taxa, and can result in increased local densities of vulnerable species (Goddard et al., 2010). 
Urban nature also has significant social values. The presence of green spaces has been positively associated with changes to personal wellbeing, reducing feelings of stress and fatigue (Lee \& Maheswaran, 2011; Richardson et al., 2010). Interaction with green spaces has also been suggested to influence physical and mental health (Lee \& Maheswaran, 2011; Richardson et al., 2010). Therefore, restoration of urban biodiversity not only has benefits to the local species, but also people's relationship with nature. However, successful restoration requires an understanding of the processes that occur within urban systems, such as the drivers of species decline.

The management of urban nature can be a complex situation due to the fragmentation and ownership of land, and the social implications of some management methods (Norton \& Roper-Lindsay, 2004). The conservation of urban green spaces is a collaborative effort, requiring cooperation from several areas (Hostetler et al., 2011), and is an important part of successful ecosystem restoration.

\section{People, Cities and Nature}

People, Cities and Nature is an MBIE-funded research programme that was established in 2017, with the intentions of researching and restoring native biodiversity within urban ecosystems. The programme involves several disciplines, both scientific and social, involved in six projects that are spread across several New Zealand cities. Three of the projects aim to understand the social impacts of urban restoration and how governmental and nongovernmental organisations can work together to achieve restoration goals. The remaining three projects aim to gain an understanding of the flora and fauna that occupy urban spaces. My research will align with the introduced predator project, with the aim of understanding the distribution and abundance of rodents, possums, hedgehogs and mustelids across three New Zealand cities (Dunedin, Hamilton and Wellington). The project identifies the need to quantify mammal presence and distribution as it is a key part in the success of urban restoration. A better understanding of urban predators is a necessary step to achieve efficient and successful control, which will assist with the broader goal of making New Zealand predator free. 


\section{Thesis overview}

This thesis comprises of two main objectives related to the overall understanding of introduced mammalian predators in urban ecosystems:

1. An evaluation of current monitoring techniques for accurate identification of species presence suitable for use in an urban setting

2. The collection of monitoring and trapping data to assess the presence and distribution of introduced mammalian predators across an urban ecosystem, and the identification of potential environmental drivers of distribution.

I was able to use collected data by other researchers working in Hamilton and Dunedin. My role was to collect and analyse data from Wellington. In particular, collecting and synthesising trap data from community trapping groups.

The thesis is organised into three data chapters. Chapter 2 investigates the efficacy of chew cards and tracking tunnels for the monitoring of urban mammalian predators, by assessing their ease of use through the level of consistent identifications between cross-check observers, and their difference in sensitivity at detecting species over a one-night and sixnight exposure. Chapter 3 investigates the potential broad scale drivers of distribution for rats, mice, hedgehogs and possums across three New Zealand cities. Furthermore, the influence of various microhabitat, landscape and management variables were assessed on the distribution of rats, mice and hedgehogs in Wellington City. Chapter 4 summarises the community trapping efforts occurring across Wellington and assesses the influence of several environmental variables on species trap catches. 


\section{Chapter 2}

\section{Assessing the efficacy of chew cards and tracking tunnels for use in urban mammal monitoring}

\section{Introduction}

Tracking tunnels and chew cards are two common methods of animal monitoring, capable of targeting a broad range of the introduced mammals that are present in New Zealand (Gillies \& Williams, 2013; Pickerell et al., 2014). These devices monitor the presence of species through the identification of tooth impressions and ink footprint markings respectively, however, devices differ in what they are capable of detecting (Pickerell et al., 2014). The ease of use and cost effectiveness of tracking tunnels make these devices a favoured technique by a broad range of community groups, councils and scientists, and in most cases have been proven to be a reliable index of mammal presence and abundance (Blackwell et al., 2002; Brown et al., 1996; Pickerell et al., 2014; Ruffell et al., 2015b). Chew cards have a shorter history of use in mammal monitoring studies, thus, there have only been a few documentations on their efficacy as monitoring and abundance estimate devices (Burge et al., 2017; Forsyth et al., 2018). Tracking tunnels are capable of detecting a larger portion of mammals, with the exception of larger mammals such as possums, for which the use of chew cards is often essential for targeting the broad range of species (Burge et al., 2017; Forsyth et al., 2018).

There are four desirable properties of any monitoring device: 1) a monotonic relationship with abundance, with acceptable sensitivity at low densities, and low saturation at high densities, 2) minimal inter-observer variability in interpretation, 3) sensitivity for detecting a range of species, and finally, 4) being affordable and logistically easy to use. Although we did not directly test the association of presence/absence measures with actual abundance, tracking tunnels have proven to be a reliable method to gain relative estimates about the distribution and abundance of species in a given area with reasonable accuracy (Blackwell et al., 2002; Brown et al., 1996; Warburton et al., 2004). Chew cards have not been extensively calibrated against abundance and have only been attempted for possum abundance with limited application (Forsyth et al., 2018). However, chew-track cards have been compared to several other methods of detection and have proven to be strongly correlated with alternative methods (Ruffell et al., 2015b; Sweetapple \& Nugent, 2011). 
Cards should be capable of being easily used by a range of people with limited inter-observer variability. The data gained from mammal monitoring studies requires that individual identification of tracking tunnel and chew card markings can be inferred correctly, therefore, monitoring studies are only as informative as the device identifications. A useful device should be informative across a range of expertise.

Devices should also be capable of accurately detecting the presence or absence of a range of species. Efficiency of these monitoring devices is largely dependent on the target species and the environment in which they are being monitored (Pickerell et al., 2014). Studies detailing the efficient use of these devices has been largely limited to rural environments where onenight exposures are sufficient (Blackwell et al., 2002; Pickerell et al., 2014; Ruffell et al., 2015b; Sweetapple \& Nugent, 2011), but the type and duration of exposure for these devices in alternative environments, such as urban, has not been well documented (Morgan et al., 2009; Pickerell et al., 2014).

Chew cards may be preferential for mammal monitoring in an urban context due to their ease of set up and removal across various landscapes. Chew cards may also be preferable in areas of high disturbance as they are less likely to be interfered with by dogs or people.

Traditionally chew cards have been the less favoured monitoring device and do not have a long history of use. There is a smaller body of research on the efficacy of chew cards in monitoring studies (Burge et al., 2017; Forsyth et al., 2018; Ruffell et al., 2015b; Sweetapple $\&$ Nugent, 2011), therefore, their use at assessing the presence of target species requires further validation. The aim of this chapter was to assess the efficacy of chew card and tracking tunnel identifications for the monitoring of urban introduced mammalian predators. I will test the consistency of chew card interpretations using a recently developed identification guide by Sweetapple and Nugent (2017), and compare with the consistency of tracking tunnel card identifications. This study is a step towards identifying their use in future monitoring studies. Additionally, I will assess the difference in sensitivity of species detections between one-night and six-night device exposures.

\section{Methods}

Data scoring and cross checking

Chew cards and tracking tunnel cards collected in Dunedin, Hamilton (12 monitoring lines, 480 cards) and Wellington (24 monitoring lines, 960 cards) between May and mid-June 2018, 
were initially scored by individuals in the cities of collection (refer to Methods in Chapter 3 for detailed information on device setup). In total, five observers were involved in interpretation of cards across the three cities: one in Wellington (myself) and two in each of Dunedin and Hamilton, working as a pair. A pair of observers from the same city will be treated as a single classifier in analyses. The degrees of expertise varied between identifiers and across devices, however, all had at least one monitoring seasons' worth of previous experience in identifying card markings. All identifications were made with the advice and examples obtained from the mammal footprint and tooth impression identification guide by Sweetapple and Nugent (2017). Species were recorded with either a 1 or a 0 if they were interpreted, through tooth impressions and footprints, as either present or absent at a given site. A set number of categories were selected for identification, encompassing the main species to mark cards. Insects were given a criterion (three tarsal pads $>2 \mathrm{~mm}$, or a gait $>1 \mathrm{~cm}$ ) that was standardised across observers. Cards were later exchanged between the three cities for reassessment by a different identifier. The cross-checker did not have access to the original identifications, therefore, all observations were made independently. Overall, cards received two interpretations: one in the city of origin and one from either of the remaining two cities so that a second independent classification was obtained (Table 2.1). Data were compiled into a single spreadsheet and used for further analyses.

Table 2.1: A list of the individuals who were responsible for identifying each set of chew cards and tracking tunnels. $\mathrm{N}$ is the total number of observations that were made across both identifiers.

\begin{tabular}{lcccc}
\hline \hline Card type & City of origin & Initial identifier & Cross check identifier \\
\hline Chew card & Dunedin & Hayley Ricardo \& Kim Miller & Cherie Balls \\
Chew card & Hamilton & Neil Fitzgerald \& John Innes & Cherie Balls \\
Chew card & Wellington & Cherie Balls & Hayley Ricardo & John Innes \\
Tracking tunnel & Dunedin & Hayley Ricardo \& Kim Miller & Kim Miller \\
Tracking tunnel & Hamilton & John Innes & 1102 \\
Tracking tunnel & Wellington & Cherie Balls & John Innes \\
\hline \hline
\end{tabular}

\section{Statistical analyses}

All statistical analyses were conducted in $\mathrm{R}$ version 3.5.2. To estimate the accuracy of chew card and tracking tunnel identifications, data were organised into a confusion matrix where 
independent identifications were compared. Confusion matrices are commonly a two by two table for which predicted values are compared against known values to assess accuracy (Table 2.2). Using the Caret package in $\mathrm{R}$ (Kuhn, 2008), we ran a multiclass confusion matrix which compared two sets of observations for each species marking, expanding on the traditional 2x2 matrix (Table 2.3). Calculations were made to assess the accuracy of chew card and tracking card classifications across the whole suite of detected species. Multi-taxon accuracy refers to the overall proportion of identifications that were consistent between identifiers from the full multiclass confusion matrix. Separate $2 \times 2$ matrices were created for rats, mice, hedgehogs, possums and mustelids, whereby metrics of accuracy (also called percent agreement), Cohen's kappa and McNemar's test were calculated on a species basis. When prevalence is very high or very low it is possible to get fairly high levels of agreement simply by repeatedly recording all presences or all absences, respectively. Cohen's kappa is a measure of accuracy, adjusted for prevalence and relative to what would be expected if identifications were assigned at random (McHugh, 2012). A value of 0.5 represent random classification for a given prevalence and a value of 1 represents perfect agreement. McNemar's test examines the sensitivity of identifiers and reports whether there are significant differences between identifiers. These measures were used as they did not require that one set of identifications was assigned as the reference data or "truth". Cards were identified by different people across cities, therefore, the specified measures of accuracy were also calculated on a city basis. All missing cards were removed from analyses.

Table 2.2: Confusion matrix for the classifications of marking by species $i$ ( $i=$ animal e.g. rat, mouse, etc) by two separate identifiers. Percent agreement (accuracy) was calculated as $\% \mathrm{~A}=(\mathrm{a}+\mathrm{d}) /(\mathrm{a}+\mathrm{b}+\mathrm{c}+\mathrm{d})$, extended across all species identifications. Cohen's kappa was calculated as \% A - p(exp) / 1-p(exp), with p(exp) calculated as $(\mathrm{a}+\mathrm{c})(\mathrm{a}+\mathrm{b})+(\mathrm{c}+\mathrm{d})(\mathrm{b}+\mathrm{d}) / \mathrm{N}^{2}$, where $\mathrm{N}=(\mathrm{a}+\mathrm{b}+\mathrm{c}+\mathrm{d})$.

Identifier 2 classifies $i$ as Identifier 2 classifies $i$ as present absent

Identifier 1 classifies $i$ as present a b 


\section{Sensitivity to species detection and the influence of duration of exposure and card type}

Comparisons of card sensitivity were made by conducting summaries on one-night and sixnight presence scores that were provided by the initial card identifier, to assess if the exposure period of cards, and the type of card deployed, influenced what species were detected. As the current methods of monitoring are somewhat time intensive (Sweetapple \& Nugent, 2017), understanding the sensitivity of cards in detecting the widest array of species could benefit future monitoring. Two different bait types (peanut butter and Erayz, a rabbitbased meat paste) were used over the two exposure periods of tracking tunnels. Erayz was used over the six-night duration as it is a longer lasting lure that is also attractive to mustelids, therefore, attempting to target a wider array of species. Generalised linear mixed models (GLMM's) were fitted for rats, mice, hedgehogs and possums, to assess the influence of monitoring duration, card type, and their two-way interactions with each other and season, on species detections, with line fitted as a random effect.

\section{Results}

\section{Inter-observer agreement}

Six classes of species were identified as present on cards, with an additional class reporting no markings. The multiclass identifications of chew card markings across all cities were in 91.79\% agreement (Table 2.3). Agreement of identifications was largely influenced by the species tooth impressions present on the cards. On chew cards, agreement of presence and absence was highly consistent between identifiers, with over $96 \%$ multiclass agreement. However, the accuracy when correcting for chance species identifications varied considerably. Possum identifications reported the highest consistency between identifiers, with a 98.6\% agreement of presence and absence scores, and an adjusted accuracy (kappa) of 91\%. The lowest consistency between identifications occurred for mustelids. Mustelids were extremely rare on cards, with only one interpreted presence, so there was a $99.8 \%$ agreement largely due to the agreement of a large number of non-presences. However, accuracy dropped to $49.9 \%$ when chance identifications were considered. The adjusted accuracy of mouse and hedgehog identifications were between $70-80 \%$ and also reported a significant difference in sensitivity between identifiers (McNemar's test: mouse, $p<0.01$; hedgehog, $p=0.03$ ). There was a $92.8 \%$ agreement of cards that were identified as having no markings, with a slight decrease to $85 \%$ by chance. 
The multiclass identifications of card markings across all cities were in $89 \%$ agreement for tracking tunnels (Table 2.4). The presence of rats, mice and hedgehogs were consistently identified in more than $98 \%$ of occurrences, with a maximum of $5 \%$ contributed to chance identifications (Table A1.1 and A1.2). However, sensitivity in the interpretation of hedgehogs differed between identifiers ( $p=0.02$ ). The agreement of possum footprints was substantially reduced on tracking tunnels, with kappa $=49.2 \%$ agreement based on chance identifications. Cards with no markings were consistently identified $89.9 \%$ of the time which decreased by $10 \%$ when identifications were considered as chance. Furthermore, there was a significant difference between identifiers categorising cards with no marks $(p<0.001)$.

Table 2.3: Confusion matrix of the classifications provided to chew cards by two separate identifiers per city. Darker green boxes represent the true positive identifications (true positive $=$ both sets of classifications are consistent).

\begin{tabular}{|c|c|c|c|c|c|c|c|c|c|}
\hline & & \multicolumn{8}{|c|}{ Classifications of cross-check identifiers } \\
\hline & & Rat & Mouse & Hedgehog & Possum & Mustelid & Invertebrate & No Marking & $N$ \\
\hline \multirow{8}{*}{$\begin{array}{l}\text { Classifications of } \\
\text { original indentifiers }\end{array}$} & Rat & 137 & 2 & 0 & 1 & 1 & 0 & 10 & 151 \\
\hline & Mouse & 4 & 119 & 0 & 0 & 0 & 2 & 16 & 141 \\
\hline & Hedgehog & 0 & 0 & 9 & 0 & 0 & 0 & 2 & 11 \\
\hline & Possum & 0 & 0 & 0 & 78 & 1 & 0 & 2 & 81 \\
\hline & Mustelid & 0 & 0 & 0 & 0 & 1 & 0 & 0 & 1 \\
\hline & Invertebrate & 0 & 0 & 0 & 0 & 0 & 0 & 0 & 0 \\
\hline & No Marking & 9 & 12 & 5 & 10 & 0 & 5 & 573 & 614 \\
\hline & $N$ & 150 & 133 & 14 & 89 & 3 & 7 & 603 & 999 \\
\hline
\end{tabular}

Table 2.4: Confusion matrix of the classifications provided to tracking tunnel cards by two separate identifiers per city. Darker green boxes represent the true positive identifications.

\begin{tabular}{|c|c|c|c|c|c|c|c|c|c|c|}
\hline & & \multicolumn{9}{|c|}{ Classifications of cross-check identifiers } \\
\hline & & Rat & Mouse & Hedgehog & Possum & Mustelid & Cat & Invertebrate & No Marking & $N$ \\
\hline \multirow{9}{*}{$\begin{array}{l}\text { Classifications of } \\
\text { original indentifiers }\end{array}$} & Rat & 148 & 2 & 1 & 0 & 0 & 0 & 0 & 5 & 156 \\
\hline & Mouse & 0 & 251 & 2 & 0 & 0 & 0 & 0 & 13 & 266 \\
\hline & Hedgehog & 1 & 2 & 254 & 3 & 0 & 0 & 0 & 9 & 269 \\
\hline & Possum & 0 & 0 & 0 & 13 & 0 & 1 & 0 & 16 & 30 \\
\hline & Mustelid & 0 & 0 & 0 & 0 & 0 & 0 & 0 & 0 & 0 \\
\hline & Cat & 0 & 0 & 0 & 5 & 0 & 0 & 0 & 0 & 5 \\
\hline & Invertebrate & 0 & 0 & 0 & 0 & 0 & 0 & 227 & 88 & 315 \\
\hline & No Marking & 7 & 5 & 1 & 1 & 0 & 0 & 20 & 580 & 614 \\
\hline & $N$ & 156 & 260 & 258 & 22 & 0 & 1 & 247 & 711 & 1655 \\
\hline
\end{tabular}




\section{Comparison between cities}

The accuracy of chew card identification did not vary greatly between cities, with all identifiers demonstrating an agreement between 88-94\%. The identifiers of the Hamilton chew cards had the highest total agreement (93.85\%), followed by Wellington (92.5\%) and Dunedin (88.31\%). The overall accuracy of identifications was high between cities, with all individual species identifications consistently identified with over 95\% agreement (Figure 2.1). However, kappa values varied considerably between species identifications in differing cities. Overall, the identifications of Wellington chew cards had the highest consistencies. The lowest accuracy was reported for mice, with only $84.2 \%$ of identifications consistent across identifiers. However, the consistency in identifications of all remaining species was greater than $90 \%$, with identifications of hedgehogs, possums and mustelids in $100 \%$ agreement. Identifications of mice represented one of the more frequent inconsistencies on chew cards. There were significant differences in the sensitivity to interpreting the presence of mice between cross checkers of Hamilton and Wellington cards ( $p=0.02$ and 0.005 respectively), and in both cases, accuracy (kappa) was lower than $85 \%$ when chance identifications were considered. Across all cities, there was a consistently low agreement of non-marked cards. All identifiers had an agreement below $88 \%$, with significant differences in identifications occurring between cross checkers in Hamilton. The lowest overall agreement was reported for mustelids, between identifiers of Dunedin cards where a $0 \%$ agreement was reported.

The accuracy of tracking tunnel card identifications demonstrated a greater degree of variation in comparison with the chew card results, however, the agreement of identifications was still between $85-94 \%$ for all cities. The initial and cross-check identifiers of Hamilton cards demonstrated the highest level of agreement (93.29\%), followed by Dunedin (89.13\%) and Wellington (85.97\%). The accuracy of identifications was high between cities, with all identifiers consistently identifying species presence and absence with over $90 \%$ agreement (Figure 2.2). There were high consistencies across identifications of rats, mice and hedgehogs, with over $97 \%$ agreement and only a $4-5 \%$ adjustment due to potential chance identifications (Figure 2.2). There was a low level of agreement in the interpretation of potential possums on tracking tunnels. The highest level of agreement was between the cross checkers of the Hamilton cards, consistently identifying possums on $39.2 \%$ of occasions. Dunedin and Wellington reported a $0 \%$ agreement on possum identifications, however, possums rarely occurred on cards. The categorisation of tracking cards recorded as having no 
markings had a consistently low accuracy across cities, with significant differences occurring between initial and cross-checker identifiers of the Dunedin cards and the Wellington cards $(p=0.01)$. Overall, the identifications of non-marked cards were consistently identified between $74-89 \%$. 

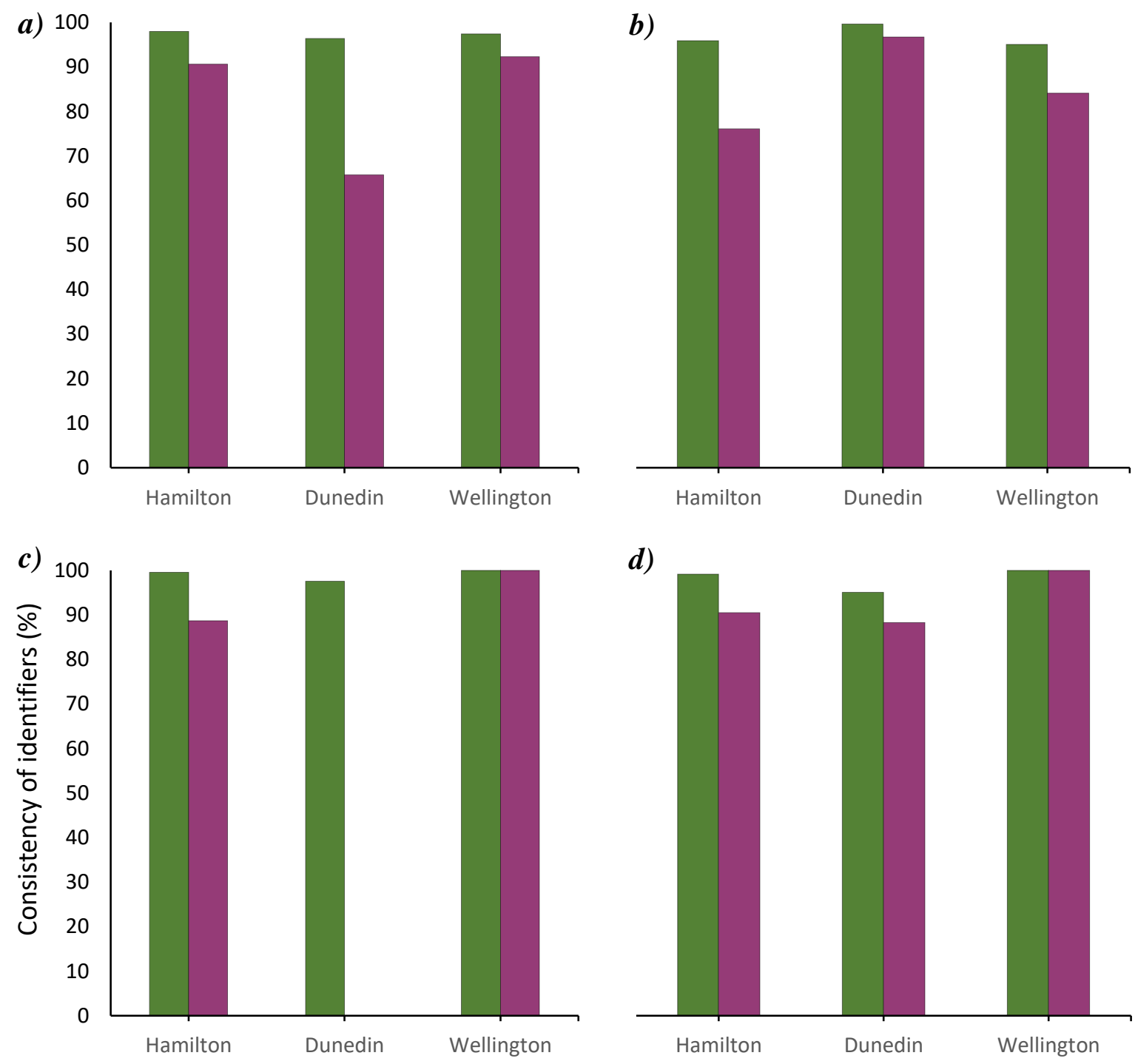

e)

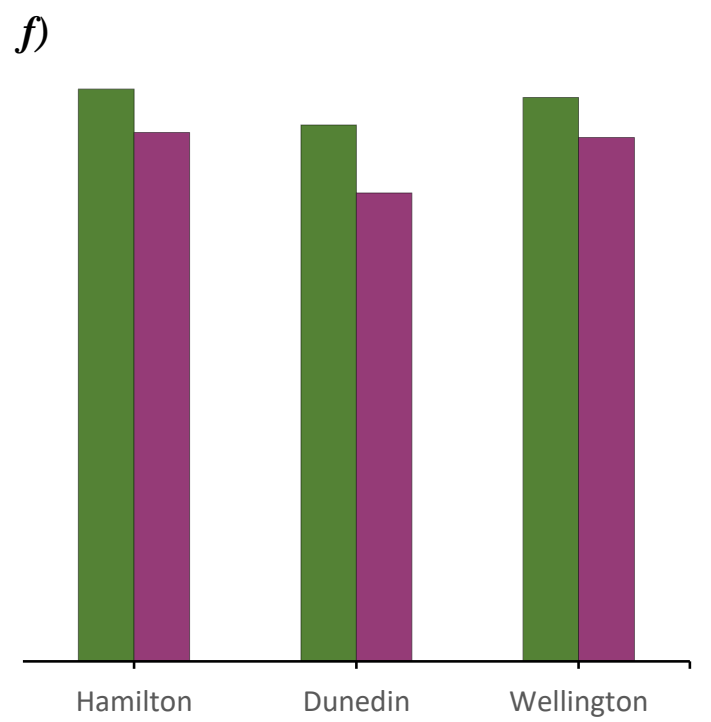

Figure 2.1: Consistency of identifications between observers classifying chew card markings across three cities in New Zealand. Consistency was based on the percentage of agreement, with and without the correction for chance identifications (kappa), between two separate identifiers. Graphs represent the consistencies between cities for $a$ ) rats, $b$ ) mice, $c$ ) hedgehogs, $d$ ) possums, $e$ ) mustelids and $f$ ) no markings. 

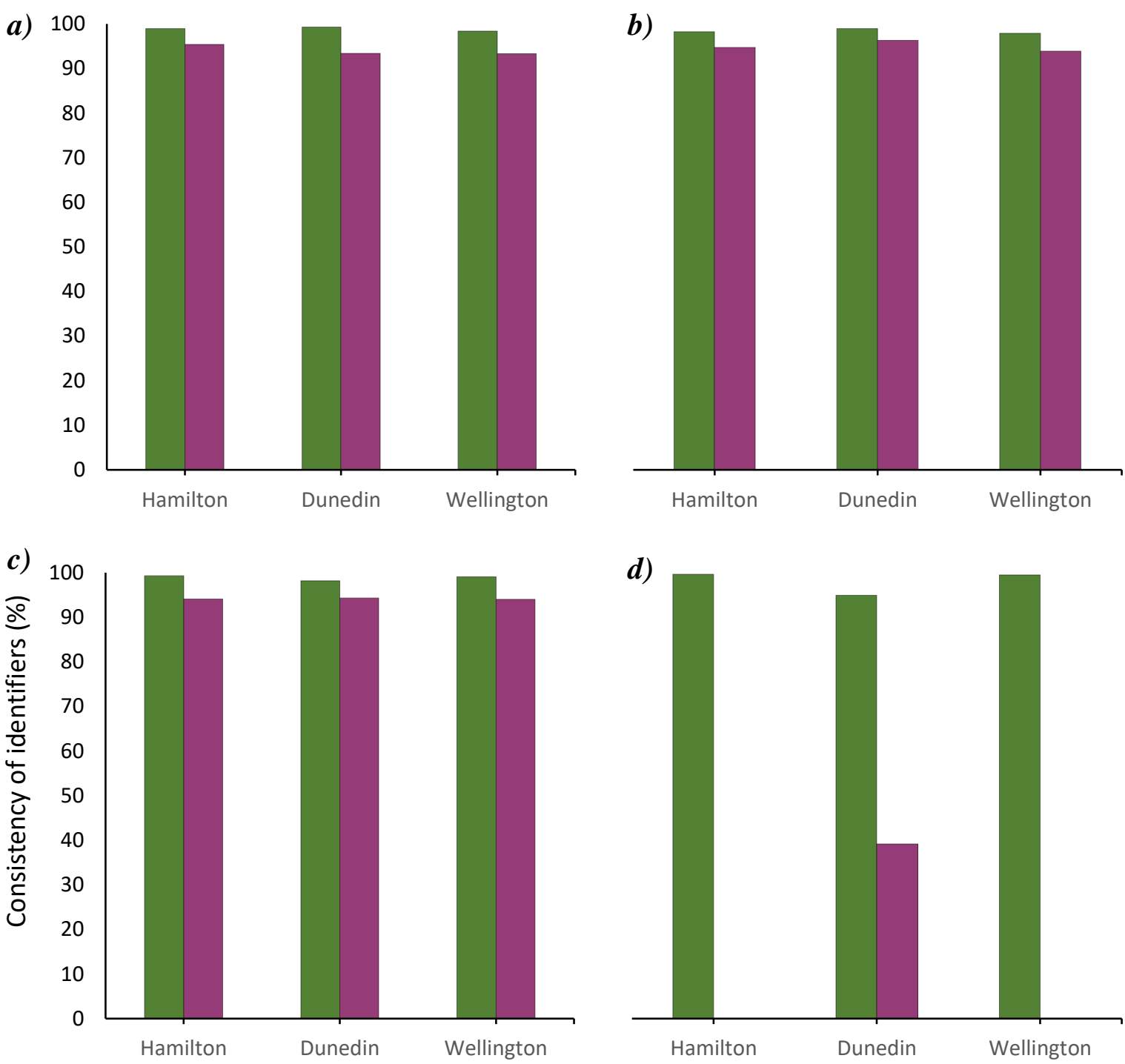

e)
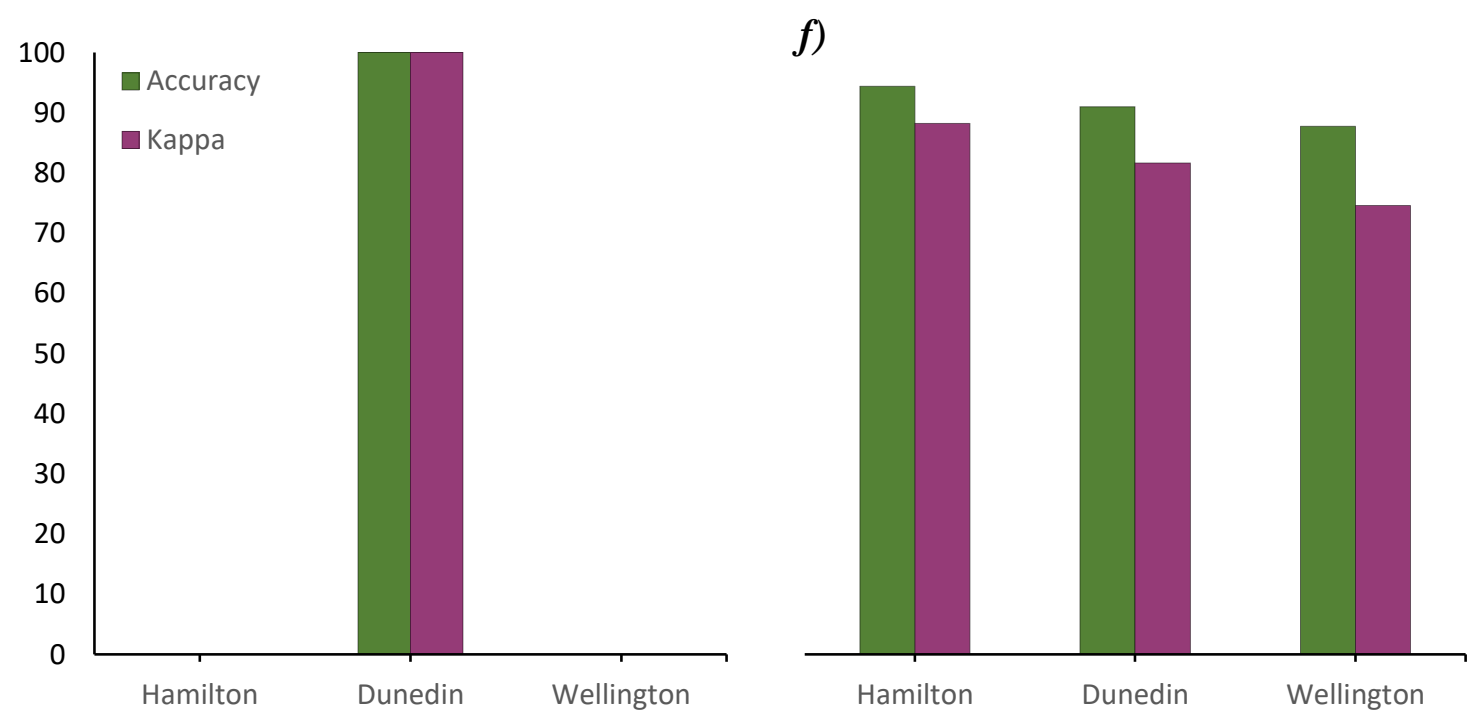

Figure 2.2: Consistency of identifications between observers classifying tracking card markings across three cities in New Zealand. Consistency was based on the percentage of agreement, with and without the correction for chance identifications (kappa), between two separate identifiers. Graphs represent the consistencies between cities for a) rats, b) mice, c) hedgehogs, d) possums, e) mustelids and f) no markings. 


\section{One-night and six-night comparison: chew cards}

There were consistent differences between the accuracy of identifications of one-night and six-night chew cards. There was a higher general agreement of identifications on one-night chew cards $(94.2 \%)$ compared to identifications on six-night cards $(89.4 \%)$. This was the case for rats and mice, whereby identifications on one-night cards had a $91.6 \%$ and $87.4 \%$ agreement, with a decrease in agreement of approximately $4 \%$ on 6 night cards (Figure 2.3). However, significant differences in mice identifications were observed between identifiers on six-night cards $(p=0.01)$. The identifications of hedgehogs and possums reported the opposite pattern, and instead had a higher level of identification agreement on six-night cards. In fact, the identifications of hedgehogs on one-night cards reported no agreement between identifiers. The consistency of possum identifications increased by approximately $10 \%$ between one and six-night cards and had an overall agreement of 94.8\%. Mustelids were rarely observed on either one-night or six-night cards, however, there was a higher agreement of mustelid identifications on 1 night cards $(66.6 \%)$.

\section{Tracking tunnels}

The overall accuracy of one-night and six-night tracking tunnel card identifications corroborates the findings of chew card accuracy. One-night tracking cards reported a higher agreement of identifications (91.16\%) compared with six-night cards $(87.07 \%)$. The identifications of hedgehogs were the only group to report a higher agreement on six-night cards for tracking tunnels. However, identifications of rats, mice and hedgehogs were relatively similar across both exposures (Figure 2.4). Possum identifications demonstrated a marked decrease in agreement on six-night cards, falling from $43.5 \%$ to $19.5 \%$. Cards specified as having no markings also reported a marked decrease in agreement on six-night cards, falling from $84.4 \%$ to $70.4 \%$. However, over all the cross check identifications, none were significantly different, suggesting that differences in identifications are largely between one and six-night cards. In this section, possums, mustelids and cats are not reported on as they rarely occur in both samples, either through a lack of presence or a misidentification of markings, therefore, measures were not always obtainable. 


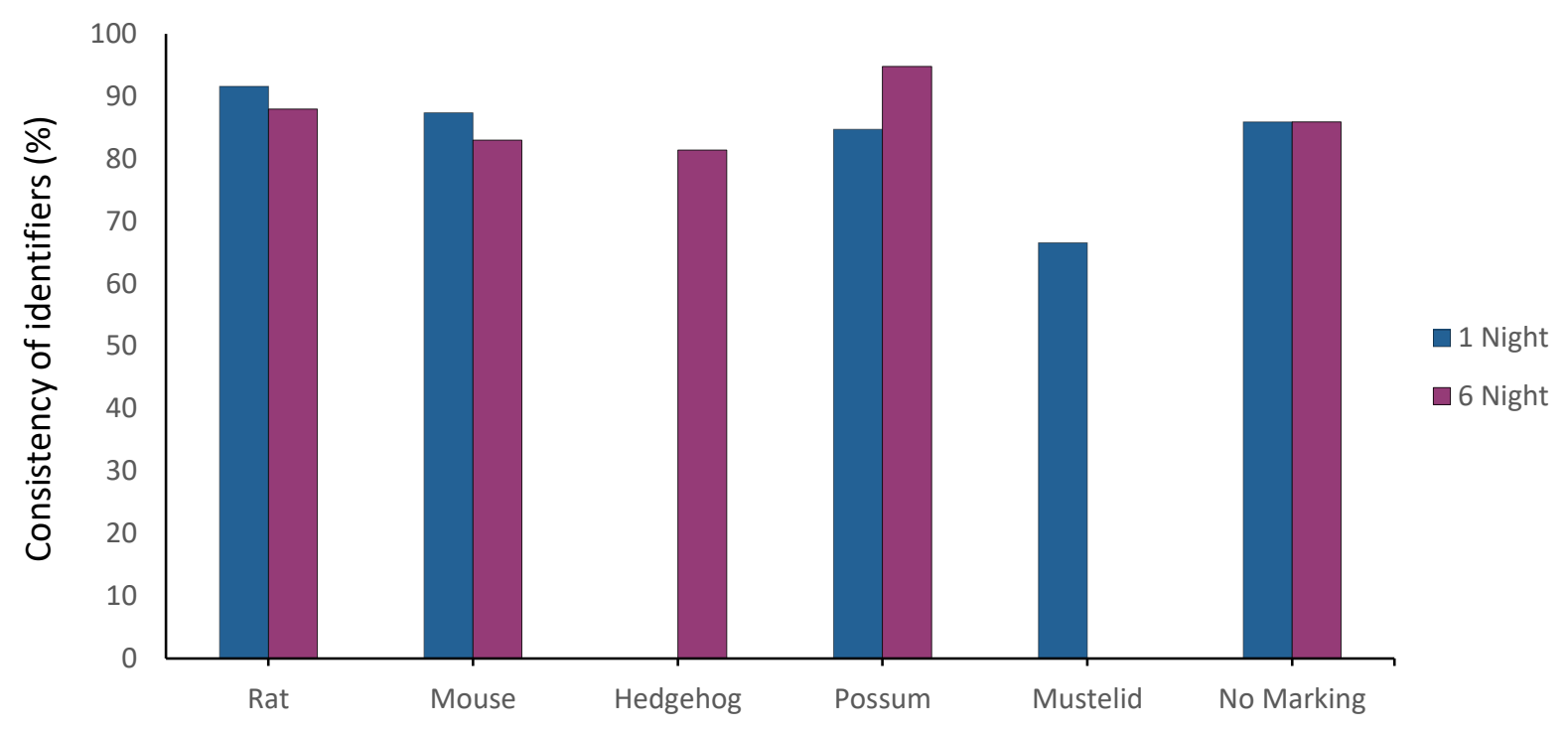

Figure 2.3: Consistency of identifications between observers classifying all one-night and six-night chew card tooth impressions. Consistency was based on the adjusted measure of agreement between two separate identifiers (kappa), accounting for the probability of identifications made by chance.

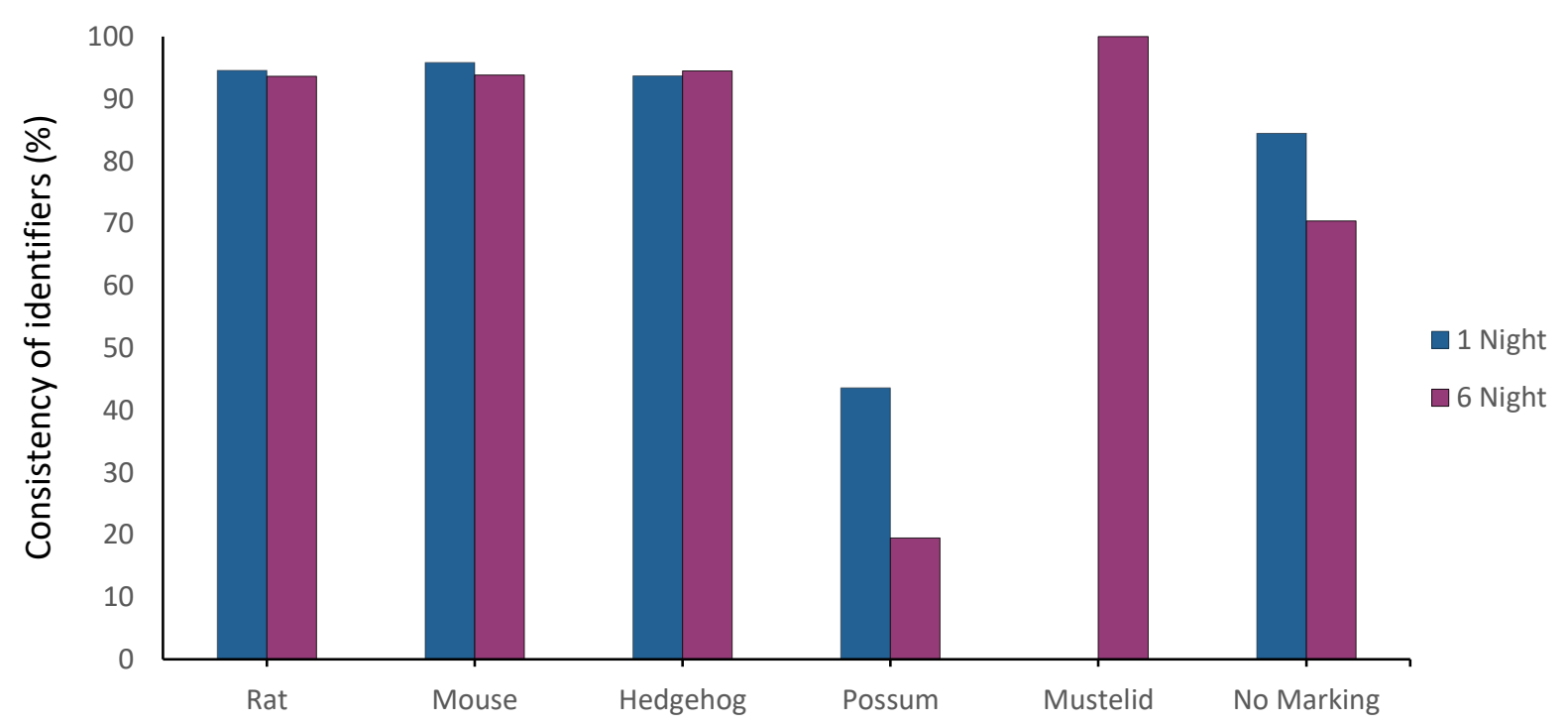

Figure 2.4: Consistency of identifications between observers classifying all one-night and six-night tracking tunnel card footprints. Consistency was based on the adjusted measure of agreement between two separate identifiers (kappa), accounting for the probability of identifications made by chance. 


\section{Sensitivity and the influence of duration of exposure and card type}

The comparison of one-night and six-night cards demonstrates that across rats, mice and hedgehogs, monitoring duration has a significant influence on the detection of species (Table 2.5). There is an increase in the percentage of species detections on both tracking tunnels and chew cards with the switch to six-night cards (Figure 2.5). Possum detections did increase between one and six nights, however detections were only apparent on chew cards. The decrease in detections on tracking tunnels over this period likely influenced the importance of this variable in possums (Figure 2.5, Table 2.5).

It is evident that the type of card used in monitoring had a significant influence on what species were detected. The detections of rats on the two card types were relatively similar, however, there were significant differences in the detection rates of mice, hedgehogs and possums across card types (Table 2.5). Chew cards and tracking tunnels had a relatively equal detection of rats on one-night cards, with chew cards providing a $4 \%$ higher detection of rats on six-night cards (Figure 2.5). Both 1 night and 6-night tracking tunnels provided a higher percentage of detection for mice and hedgehogs, with a 5-20\% detection difference between sets of cards (Figure 2.5). Chew cards consistently had higher detections of possums over both the one-night and six-night duration, with 4-12\% more interactions captured compared to tracking tunnels.

The interaction between monitoring duration and card type had a strong influence on the sensitivity of monitoring devices (Table 2.5). Results indicate that the highest detections are a species-specific combination of card type and monitoring duration. There were no significant differences in rat detections using tunnels compared to chew cards, however, chew cards over a six-night period were demonstrated to have captured the highest detections of rats in this study. The six-night exposure of tracking tunnels was identified as the most appropriate method of monitoring mice and hedgehogs to detect the most occurrences. The six-night exposure of chew cards was identified as the more sensitive method of monitoring possums. 
Table 2.5: GLMM summaries for the influence of monitoring duration and card type on the presence of the four listed species. Values are indicative of the difference between one-night and six-night cards, and between chew cards and tracking tunnels. No interactions were included in the analysis.

\begin{tabular}{lcccc}
\hline \hline $\boldsymbol{a})$ Rat & Estimate & Std. Error & z value & $\operatorname{Pr}(>|\mathbf{z}|)$ \\
\hline Monitoring duration & 0.26764 & 0.03386 & 7.903 & $p<0.001$ \\
Card type & -0.17842 & 0.11255 & -1.585 & 0.1130 \\
\hline \hline
\end{tabular}

\begin{tabular}{lcccc}
\hline \hline $\boldsymbol{b})$ Mouse & Estimate & Std. Error & z value & $\operatorname{Pr}(>|\mathbf{z}|)$ \\
\hline Monitoring duration & 0.19222 & 0.02842 & 6.763 & $p<0.001$ \\
Card type & 0.56503 & 0.10482 & 5.39 & $p<0.001$ \\
\hline \hline
\end{tabular}

\begin{tabular}{lcccc}
\hline \hline $\boldsymbol{c})$ Hedgehog & Estimate & Std. Error & z value & $\operatorname{Pr}(>|\mathbf{z}|)$ \\
\hline Monitoring duration & 0.243353 & 0.042859 & 5.678 & $p<0.001$ \\
Card type & 2.498229 & 0.168931 & 14.788 & $p<0.001$ \\
\hline \hline $\boldsymbol{d}$ ) Possum & & & & $\operatorname{Pr}(>|\mathbf{z}|)$ \\
\hline Monitoring duration & Estimate & Std. Error & z value & 0.0636 \\
Card type & 0.10971 & 0.05915 & 1.855 & $p<0.001$ \\
\hline \hline
\end{tabular}

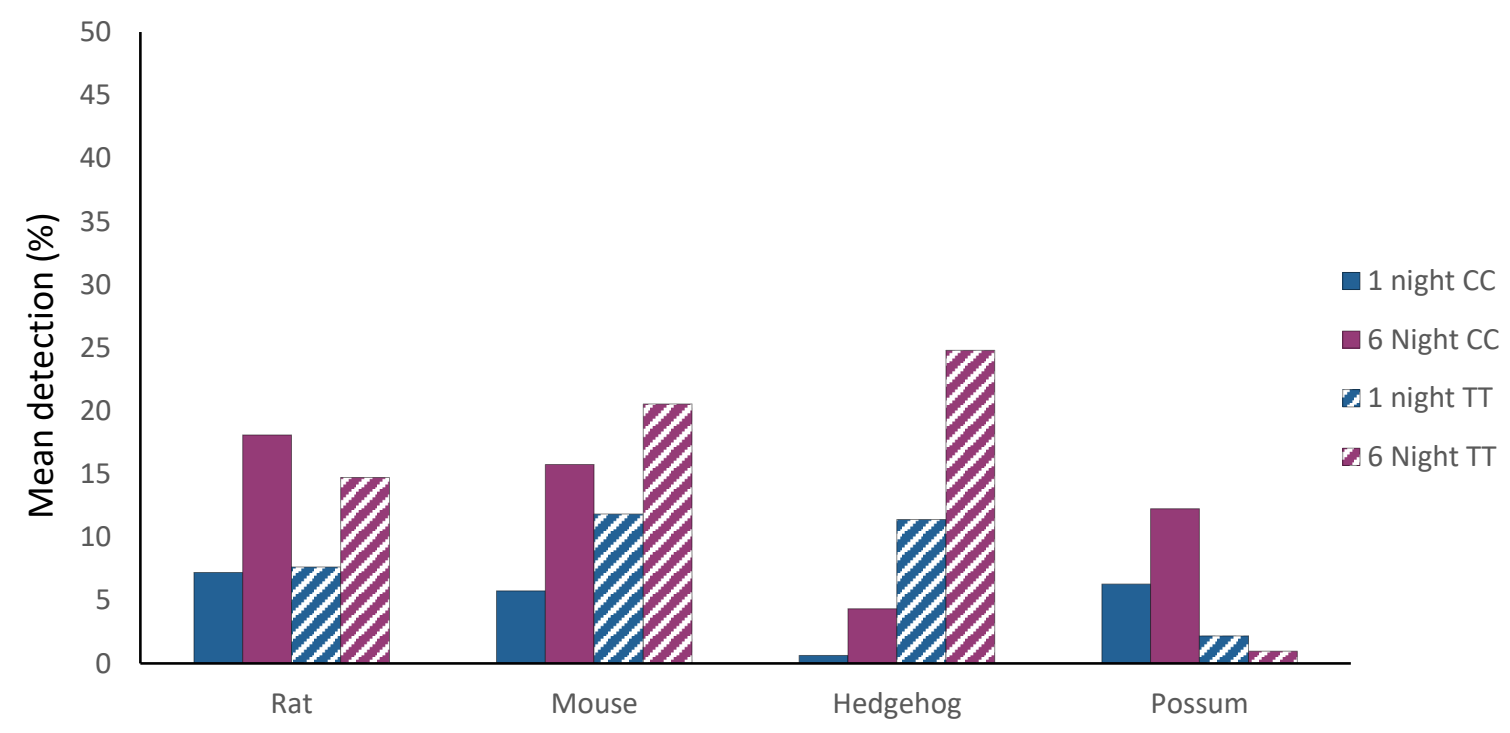

Figure 2.5: Mean percentage of detection of introduced mammalian predators on chew cards and tracking tunnels across one-night and six-night exposures. 
The change of season over monitoring studies did not have an influence on species detections over one and six-night exposure, however, season did influence the detections of species over the two card types. The most notable influence of season to assess is those that occur between card types from the same season. Although all species are capable of being present on either monitoring device, rats and mice are the only ones recorded that are equally targeted by either device, and therefore were the only ones where a difference was of interest. Interestingly, there was a higher detection of rats and mice on tracking tunnels in autumn, however, this was only significant in mice. The opposite pattern occurred for both species in spring, whereby detections of the two species were higher on chew cards, and were consistent across both of the monitoring durations (Figure 2.6)

Table 2.6: Type III ANOVA summaries for the influence of the interaction between monitoring duration and season, and season and card type on the presence of the four listed species. Values are indicative of the combined influence of the two variables.

\begin{tabular}{lcc}
\hline \hline $\boldsymbol{a})$ Rat & $\boldsymbol{W}$ statistic & $\operatorname{Pr}(>|\mathbf{W}|)$ \\
\hline Monitoring duration*Season & 2.07 & 0.149 \\
Season*Card type & 18.79 & $p<0.001$ \\
\hline \hline
\end{tabular}

\begin{tabular}{lcc}
\hline \hline $\boldsymbol{b})$ Mouse & $\boldsymbol{W}$ s tatistic & $\operatorname{Pr}(>|\mathbf{W}|)$ \\
\hline Monitoring duration*Season & 0.88 & 0.349 \\
Season*Card type & 101.11 & $p<0.001$ \\
\hline \hline
\end{tabular}

\begin{tabular}{lcc}
\hline \hline $\boldsymbol{c})$ Hedgehog & $W$ statistic & $\operatorname{Pr}(>|\mathbf{W}|)$ \\
\hline Monitoring duration*Season & 0.03 & 0.871 \\
Season*Card type & 1.52 & 0.2171 \\
\hline \hline
\end{tabular}

\begin{tabular}{lcc}
\hline \hline $\boldsymbol{d})$ Possum & $\boldsymbol{W}$ s tatistic & $\operatorname{Pr}(>|\mathbf{W}|)$ \\
\hline Monitoring duration*Seasn & 2.63 & 0.105 \\
Season*Card type & 0.93 & 0.3351 \\
\hline \hline
\end{tabular}




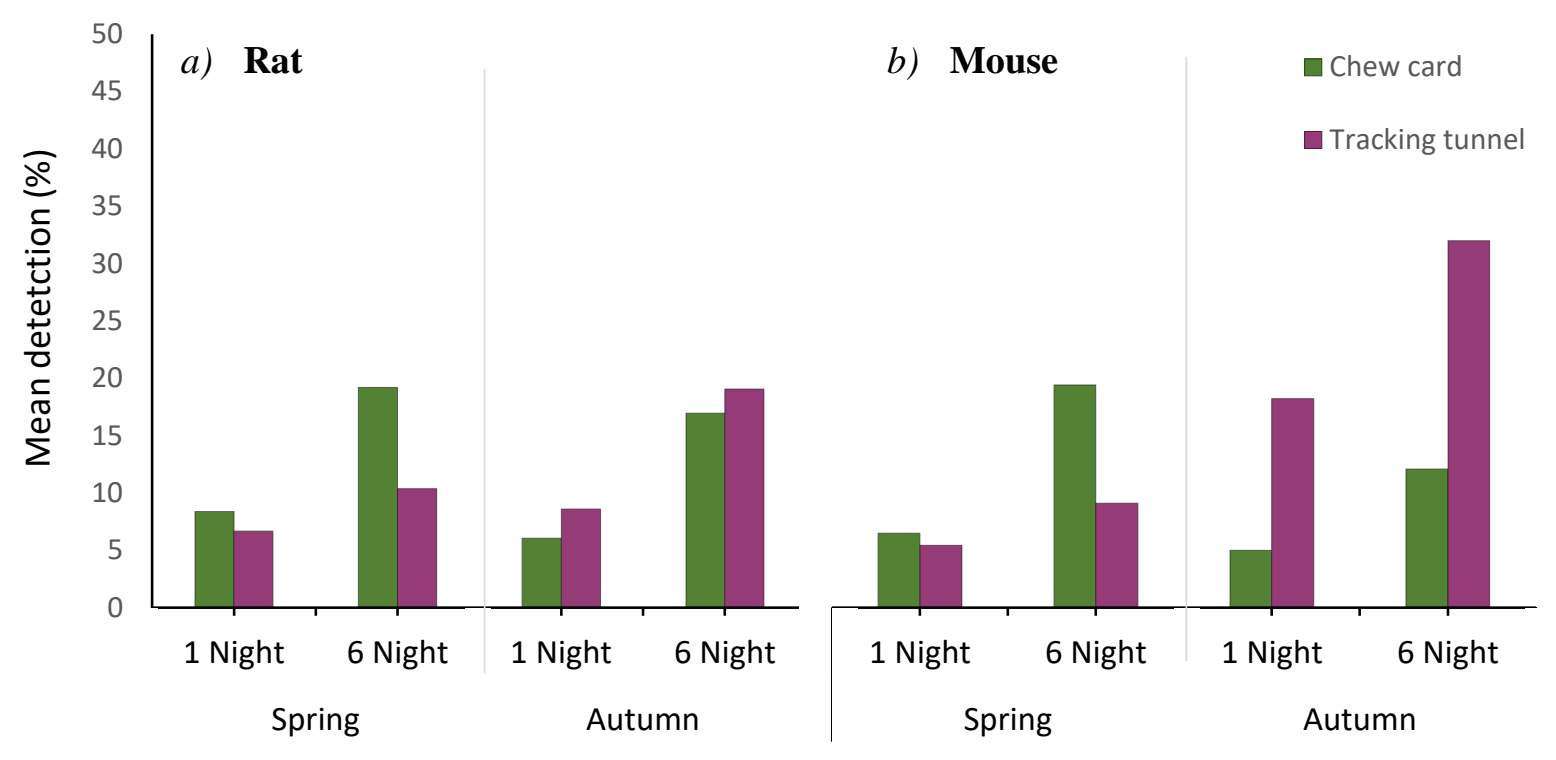

Figure 2.6: Influence of season on card type over one-night and six-night monitoring periods on the mean detection of $a$ ) rats and $b$ ) mice.

\section{Discussion}

\section{Card accuracy}

The consistency of chew card and tracking tunnel card identifications were relatively high across all analyses and demonstrates their ability to successfully inform researchers about the introduced mammals occupying urban spaces. The consistent identifications across all species was somewhat higher on chew cards than on tracking tunnels across the majority of analyses. This is potentially attributed to the fact that chew cards are targeted at fewer species (Burge et al., 2017; Sweetapple \& Nugent, 2011), so there is a reduced chance of misidentification error.

The three most common species to be detected by chew cards were rats, mice and possums, however, mouse presence and absence identifications were substantially lower on chew cards compared to tunnels. Rat and mice chew markings are occasionally mistaken for one another, as the small bite marks of rats along card margins can often appear similar to the small gnawing marks of mice if tooth impressions are not visible (Sweetapple \& Nugent, 2011). Sweetapple et al (2011) reported that they could always be distinguished by the experienced observer, however, the identifiers in this study all had differing levels of experience. Furthermore, due to the small size of their chew marks, detections of mice can be missed entirely, which could have resulted in the differences observed between identifiers. 
Tracking tunnel card identifications for all species still reported a high level of agreement, however, the percentage of agreement was largely based on the consistent identifications of rats, mice and hedgehogs. Unlike chew cards, more species are commonly detected in tracking tunnels, including rats, mice, hedgehogs, invertebrates, and occasionally other small mammals. A substantial portion of the total disagreement likely arose due to the strong inconsistencies in the identifications of invertebrates on tracking tunnels. Identifiers commonly reported potential insect prints as no markings, possibly due to their small size and their likelihood of being overlain with other prints, or, misidentified as drag marks (Hasler et al., 2004). Although the focus of this study is on mammal predators, the variability in invertebrate identifications was still an important aspect to detail the overall use and accuracy of tracking tunnels for monitoring studies.

Rats, mice and hedgehogs are the three species most commonly detected on tracking tunnel cards and maintained a high level of agreement for identifications of over 93\%, higher than that reported for chew cards. When footprints are clearly visible, there is a large size distinction between the three species (Sweetapple \& Nugent, 2011). Although rats and mice have a similar pattern of prints, their size difference is often sufficient to distinguish them from each other (Gillies \& Williams, 2002; Sweetapple \& Nugent, 2011).

In several cases, the consistency of card identifications does appear to reflect the presence of select species. For example, there was a much higher agreement of possum markings on chew cards, where their large crushing tooth impressions are very distinct (Sweetapple \& Nugent, 2011). However, on tracking tunnels, potential possum markings were often recorded as cat or hedgehog, with no definitive consensus on the correct conclusion. Possums are too large to enter tracking tunnels, and often pull cards out to acquire the bait (Clapperton et al., 1999). In these cases, prints are often smudged. There are clear distinctions between cat and possum footprints, such as their size and general shape, and misidentifications have not previously been reported (Gillies \& Williams, 2002). However, both cat and possum prints are not particularly common in tracking tunnels (Gillies \& Williams, 2002), therefore misidentifications were potentially a result of inexperience with these prints.

One of the more pressing concerns is the consistency at which identifiers reported no markings. Without the use of a magnifying device, some markings are inherently more difficult to see (Sweetapple \& Nugent, 2011). Studies highlighting inter-observer variation on card identifications has not been formally tested, therefore there are no specific hypotheses in 
the literature as to why the variations occur. However, there are instances when species only leave light markings, particularly on chew cards, that have the potential to go unnoticed (Sweetapple \& Nugent, 2011).

Between cities, the accuracy of chew card and tracking tunnel identifications remained relatively consistent, with all scores falling within 6-10\% of each other. As well a minimal inter-observer variability, the comparison between cities also represents minimal inter-study variability. The high agreement of the prior mentioned species remained consistent between cities, but again, the inconsistencies in mouse identifications were reported for identifiers of chew cards across all three cities, with significant differences between identifiers. It is unknown whether these inconsistencies arose due to the presence of false positive or false negative identifications, but it highlights the need for a more comprehensive identification system for mouse markings. There is an opportunity to utilise cameras in these situations to observe the true set of visitations. Cameras trained on the chew cards can identify when an individual has been present in the area, regardless of whether they left a marking, and can provide information on the occurrence of false negative results.

A common issue that arises with the use of monitoring devices is the interference and saturation of cards. Markings can become so numerous that it is often hard to disentangle individual species. Many species can occur on the same card within the time of exposure, thus, there is a trade-off between species detections and minimising effects of saturation and interference (Burge et al., 2017). Overall, there was a higher agreement of identifications on one-night cards compared with six-night cards for both chew cards and tracking tunnels, however, this varied for individual species.

On chew cards, consistent identifications of rats and mice were higher over one-night exposures. The increased exposure of chew cards increases the likelihood that cards will get saturated, even in sites with moderate pest densities (Burge et al., 2017). However, one-night cards in non-forest environments have also been associated with a higher rate of false negative presences, therefore, there is a slight trade-off between increased accuracy and increased reliability of indexes (Burge et al., 2017). The consistency of identifications is likely higher on one-night cards as there are fewer markings. Rats have been hypothesised as neophobic to chew cards over the first few days of exposure (Burge et al., 2017; Innes, 2001), likely resulting in the reduction of markings. Our data suggests neophobia is stronger for 
chew cards than for tunnels, as the difference in detection rates rose more for chew cards over exposure periods.

Interference is known to occur between rats and possums, whereby the initial presence of one species will often result in the reduced presence of the other species (Burge et al., 2017). It seems unlikely that the severe gnawing of cards by rats resulted in unrecognised possum tooth impressions. Possums are known to lightly chew cards, however, these are still commonly identifiable (Sweetapple \& Nugent, 2011). Again, like mice, it could be related to the sensitivity of the identifier, however, without a further understanding of the misidentifications it is unclear how this issue can be reviewed in future studies.

The results from this chapter have demonstrated the accuracy of identifiers, highlighting the level of confidence that we can have when reporting further analyses. The depth of experience between identifiers varied considerably, particularly across devices. The level of confidence appears to be most dependent on the type of card used when reporting results for specific species, as well as the duration in which the cards were deployed. It is unsurprising that species identifications on chew cards are lower than tracking tunnels. Chew cards are a newer method of mammal monitoring and identification guides continue to be developed to accurately identify markings. One potential limitation to consider is that although accuracy values were high, there was a possibility that both identifiers could have incorrectly identified the same marking. Although this seems unlikely due to the previous experience in identification from all observers, there may be a small percentage of observations that were incorrect due to the obscurity of markings. The same identification guide was used across observers, however, there were still discrepancies detected across many observations which is likely due to the difficulty of some markings. Overall, we can report with a high level of confidence that the results from further analyses are largely consistent and provide a valid account of introduced mammals in urban environments. The results reported in this chapter likely correspond to community groups that have a couple of years of experience in card identification, and therefore, any recommendations made are subject to the experience of the identifier.

\section{Card sensitivity}

The use of chew cards and tracking tunnels for mammal monitoring following the one-night standard procedure (Gillies \& Williams, 2013) has been utilised across a number of 
monitoring studies and proven to be a relatively effective measure of species presence and distribution (Blackwell et al., 2002; Brown et al., 1996; Forsyth et al., 2018; Warburton et al., 2004). The mammal monitoring conducted in this study utilised one-night and six-night exposures of tracking tunnels and chew cards in an attempt to monitor the array of species occupying Wellington. This also presented the opportunity to assess the sensitivity of cards in an urban context.

The detection of species typically increased over six-night exposures. The duration of monitoring for effective records of detection is largely based on the density of the monitored pest population (Burge et al., 2017). In areas of high pest density, one-night cards are most appropriate for determining pest species presence and abundance as they reduce the likelihood of interference and saturation (Brown et al., 1996; Burge et al., 2017; Ruffell et al., 2015b; Sweetapple \& Nugent, 2011). However, it is unlikely that pest populations in urban environments reach the high densities that are recorded in rural sites, thus one-night cards may limit the sensitivity of monitoring (Burge et al., 2017). Results consistently indicate that six-night cards report higher estimates. There is a higher probability that an individual will interact with a device if it is exposed for a longer period, therefore reducing the likelihood of false absent results (Burge et al., 2017). However, longer monitoring durations can also result in saturation of cards, whereby the markings left by species entering the tunnel later in the monitoring period might mask what was left by earlier species (Burge et al., 2017; Ruffell et al., 2015b). The presence scores and increase between one-night and six-night cards appears consistent between exposures, therefore it is unlikely that species populations were high enough for saturation to be an influential factor (Burge et al., 2017; Ruffell et al., 2015a). An alternative hypothesis for the higher detections of species on six-night cards could be explained by the movement of species. Hedgehogs in particular have large home ranges that have been reported to average between 2-20ha in rural environments (Moss \& Sanders, 2001). Over the six-night exposure, there is a possibility that a single individual could be interacting with multiple devices. I did not locate any reported cases of this in the literature, however, it is a plausible outcome that should be considered.

The change from one-night tracking cards to six-night tracking cards also came with a change of bait from peanut butter to Erayz. The limitation of the change is that we are unable to disentangle whether the increased detections of species in tracking tunnels is a result of 
duration of exposure, or bait, and is therefore something that needs to be considered with interpretation.

The most effective card type at detecting individuals is shown to be strongly species dependent. Both chew cards and tracking tunnels have been proven useful to monitor species (Brown et al., 1996; Ruffell et al., 2015a). Chew cards were shown to be the most efficient at capturing the presence of possums and rats. Very few possum prints were recorded in tracking tunnels as tunnel size does not permit the entrance of possums, thus making chew cards the more accessible device (Pickerell et al., 2014). Although tracking tunnels had high detections of rats, chew cards have been proven to be a more sensitive device at detecting rats in non-forest habitats (Burge et al., 2017). Tracking tunnels were shown to be the most efficient at detecting mice and hedgehogs and this was consistent across both one-night and six-night exposures. It has not been extensively investigated whether tracking tunnels provide a good estimate of hedgehog presence and abundance, or the duration at which estimates are most reflective of the population (Gillies \& Williams, 2013). However, large tracking tunnels and longer monitoring periods were demonstrated to capture the greatest number of hedgehog detections in a non-forest habitat (Pickerell et al., 2014), and is corroborated in the findings here.

As chew cards were deployed approximately $30 \mathrm{~cm}$ above the ground, cards may have been inaccessible to hedgehogs which could provide the reasoning for their higher detections in tunnels. There are two potential reasons why mice were detected more in tracking tunnels. The analysis only investigated the relationship between monitoring duration and card type across the total dataset and did not consider line variation in detections. When rat populations are low, there is an increase in the utilisation of tracking tunnels by mice (Brown et al., 1996). Furthermore, it has been postulated that mice become attracted to baited tunnels with frequent contact (Brown et al., 1996). However, this is unlikely the case in this study as only two trials were run over a season.

Seasonal differences in card use were not apparent for hedgehogs and possums, however, there was a marked shift in the use of monitoring devices by rats and mice over the spring and autumn monitoring seasons. In autumn, the highest detections of rats and mice occurred on tracking tunnels over both exposures. It was observed that in the hot summer weather, the six-night bait did not remain fresh. Often the rabbit-based bait would get dry and in a number of cases was maggot-ridden. There have only been documentations on the palatability of 
Erayz in wetter months where the growth of mould was an issue (Harper et al., 2011;

Hopkins, 2008). However, no documentation on the palatability of these baits in summer months was located.

The disturbance of tunnels could have resulted in the increased detections on chew cards, which reported little to no disturbance. Tunnels were often disturbed by dogs, either by eating the bait or interfering with tunnel placement. We were unable to detect on which night the tunnels were disturbed, only if they had been on collection. Therefore, we were unable to identify how long tunnels had been in action for. However, results on tunnel disturbance with season indicate that there were a higher number of disturbance events occurring in spring (Appendix A2.1).

\section{Conclusion}

Overall, six-night card exposures were the most effective at capturing the presence of a wide array of introduced mammalian species. One-night exposures tended to only capture half of the presences that six-night exposures achieved. Both chew cards and tracking tunnels were effective at detecting rats and mice, tracking tunnels were more effective at detecting hedgehogs, and, chew cards were more effective at detecting possums. Neither device was shown to be effective at detecting mustelids. Depending on the goal of monitoring, it seems most effective to utilise both chew cards and tracking tunnels simultaneously to provide the greatest chance of capturing the wide array of species. 


\section{Chapter 3}

\section{The distribution of introduced mammalian predators across urban environments, and the influence of trapping intensity and environmental factors}

\section{Introduction}

New Zealand is currently home to 31 introduced mammal species (Burns et al., 2012), many of which cause declines and local extinctions of a range of native biodiversity (Brown et al., 2015; Towns et al., 2013; Towns et al., 2006). Understanding the distribution of species assemblages is a key step towards the successful control of mammalian predators.

Mammal monitoring studies play a key role towards the understanding of species distributions. Monitoring focused on the distribution of mammalian predators has been extensively conducted in rural ecosystems, often dominated by stands of native or exotic forest or grasslands, with little to no human habitation nearby (Clout, 2001; Pickerell et al., 2014). Factors such as habitat structure and composition, distance to bodies of water and forest edges, climate, elevation and topography have been identified as some of the leading drivers of species distribution in these systems (Christie et al., 2009; King et al., 1996; Ruffell et al., 2015a). However, fewer studies have focused on mammal distribution within an urban environment (Baker et al., 2003; Morgan et al., 2009), particularly in New Zealand.

The urban environments of New Zealand are commonly a mixture of green spaces, such as forests and parks, and areas of infrastructure, such as town centres and residential suburbs (Clarkson et al., 2007). The green spaces are rarely continuous, and are instead smaller fragments of vegetation located within broad areas of infrastructure. Residential backyards vary in the extent of artificial structures and vegetation. Backyards can broadly be categorised as complex areas of fragmented vegetation with a varying degree of native and exotic plant species that contain a varied extent of artificial structures (i.e. fences, concrete paths, decking) and maintenance. Although backyards are highly diverse, the presence of vegetation provides potential habitat for mammalian predators. The fragmentation of habitat and resources, accompanied by the increased interactions with infrastructure, people and domesticated animals, are all factors that are of little consideration within rural environments, but could potentially influence the distribution of mammalian predators within urban environments. There is evidence to suggest that habitat fragmentation and domestic 
predators, such as cats, influence the abundance and distribution of small mammal species occupying urban spaces (Baker et al., 2003). It is also possible that an increase in accessible food sources (e.g. compost bins) and the presence of local, non-standardised methods of trapping, could have an influence on their distribution.

Predator control via trapping can be expensive, and the energetic investment to deploy and maintain traps is relatively high (Brown et al., 2015; Norbury et al., 2014; Wright, 2011). If resources are limited, predator control can be implemented with limited success if prior knowledge is not first obtained (Morgan et al., 2009; Ruffell et al., 2015a; Wilson et al., 2007). Urban mammal trapping regimes are already in place in several cities, particularly in Wellington, although there is little published data on how much trapping is needed to make a measurable impact on pest species in urban environments. Understanding what potential factors influence the distribution of the key predators can enhance current and future trapping regimes by identifying potential areas of high predator abundance. Information on preferred habitats could have real potential in wide scale urban projects, such as Predator Free Wellington.

The aim of this chapter is to assess patterns of distribution of introduced mammals across three New Zealand cities in relations to season and broad habitat type. Furthermore, I aim to identify additional management, landscape and microhabitat variables that might potentially influence species' distributions within Wellington City. Specifically, I will quantify trapping intensity across residential suburbs and reserves and relate it to species distribution.

\section{Study area}

The People, Cities and Nature project includes a programme of mammal monitoring across five New Zealand cities: Wellington, Hamilton and Dunedin (biannual monitoring), and Tauranga and Nelson (with a one-off monitoring occurring in 2019). I personally undertook and coordinated monitoring in Wellington in late-autumn and late-spring 2018, however, all aspects of the methods are standardised for consistency and comparison across the five cities involved. Within Wellington, monitoring was conducted across a total of 24 sites distributed across 8 Wellington suburbs (North Miramar, South Miramar, Lyall Bay, Roseneath, Brooklyn, Karori, Wadestown, Ngaio, see Figure 3.1). I will be utilising monitoring data from November 2017 and May 2018 for the 24 sites in Wellington, and the 12 sites each in Hamilton and Dunedin. 


\section{Methods}

\section{Mammal monitoring}

Mammal monitoring data were conducted across Wellington City, Dunedin and Hamilton from early November to mid-December (spring) and late April to mid-June (autumn), 2017/18. There were three monitoring lines set in each suburb each sampling one of three distinct habitat types: urban forests, amenity and residential. The forests sites were areas of primary or secondary growth and could contain both native and exotic plant species. Amenity sites were public areas, such as parks and coastal walkways, which contained a mixture of open areas, shrubs and occasional trees. Monitoring lines in amenity areas were typically along the fringes of vegetated areas where human interaction was considered a factor. Residential sites consisted of the backyards of properties in which permission was given, as well as if the property contained established vegetation that had the potential of supporting native species. Households were initially recruited in spring of 2017. The recruitment process was initiated with a letter sent out to households within selected streets, outlining background information and project intentions, followed by a period of door knocking to sign up willing participants. Door knocking was continued in subsequent seasons if previous recruits were no longer able to participate. Sites were selected based on their potential to contain a transect, the state of vegetation and their accessibility. The sites were also intended to be selected based on the criteria that half of the sites were located in areas designated to receive an intensification of predator control effort.

Each site contained a monitoring line that was approximately 450 metres long, containing ten monitoring stations. Monitoring stations were spaced 50m apart as per the standard procedure for the monitoring of mammals with tracking tunnels in forests (Gillies \& Williams, 2013). The monitoring equipment included plastic chew cards pre-baited with an aniseed based possum dough (traps.co.nz), and "Black Trakkas" tracking tunnels with "Gotcha" pre-inked cards (gotchatraps). One chew card and tracking tunnel were deployed, 2-5 metres apart, at each of the ten monitoring stations. Tracking tunnels were pegged into the ground in a vegetated area with both tunnel openings free of obstructions. Chew cards were folded in half and either nailed onto a stable surface $30 \mathrm{~cm}$ above the ground, or when no suitable surfaces were available, they were threaded onto a tracking tunnel peg and placed in the ground of a vegetated area. Two periods of tracking tunnels and chew cards were run in succession per monitoring season: a one-night exposure followed by a six-night exposure. One-night 
exposures are the standard procedure for tracking tunnels and chew cards when monitoring possums and rodents in forest environments, however, longer periods are often used to detect species present at low densities e.g. mustelids in forest habitat (Gillies \& Williams, 2013). For the one-night exposure, tracking tunnels were baited at the two ends of the card with a small portion of peanut butter as it is a substance that has been proven to be a successful attractant for a majority of the target species (Hice \& Velazco, 2013; Patric, 1970) and is the standard protocol used in a majority of studies. After one-night, the tracking tunnel card and chew card were replaced for the next six nights. Six-night exposures of tunnels were baited with Erayz paste, placed at the two ends of the tracking card. Erayz is a rabbit-based paste intended to target mustelids, while still being highly attractive to rodents. On collection of the monitoring equipment at the end of each trial, any missing or disrupted equipment was noted to account for the lowered probability of detection for the monitoring line in subsequent analyses. In total, 960 data points were collected each season across Wellington using the two standard monitoring devices across the two different lengths of exposure (i.e. 240 monitoring stations x 4 methods) (Figure 3.1).

To supplement the standard monitoring equipment, two Bushnell Aggressor motion triggered cameras (model 119777) were deployed at two of the stations within each transect, placed at least $250 \mathrm{~m}$ apart. Cameras were attached to a stable structure, such as a tree or fence, and were set facing the tracking tunnel. The placement of tracking tunnels was dependent on the amount of surrounding vegetation. Tracking tunnels were preferably placed in locations where moving vegetation was minimal, however, any remaining problematic vegetation immediately surrounding the tracking tunnel was trimmed back to reduce the number of false triggers. Cameras were set approximately $1.5 \mathrm{~m}$ from the tunnel and angled down at $20^{\circ}$ (following (Anton et al., 2018). The angle allows both sides of the tracking tunnel to be observed and the distance allows the entire tracking tunnel to be in view and ensures that small species such as mice are still detectable (Anton et al., 2018). The camera was set to a high sensitivity and a medium shutter speed to increase the probability of detecting all target species. Each trigger resulted in three photos being recorded, approximately 0.5 seconds apart. There was a set delay of 30 seconds between successive triggers to reduce the number of photos that were captured of the same individual. The camera flash was set on low to reduce the probability of scaring animals away from the tunnels, while maintaining visibility of individuals in the captured photos. 


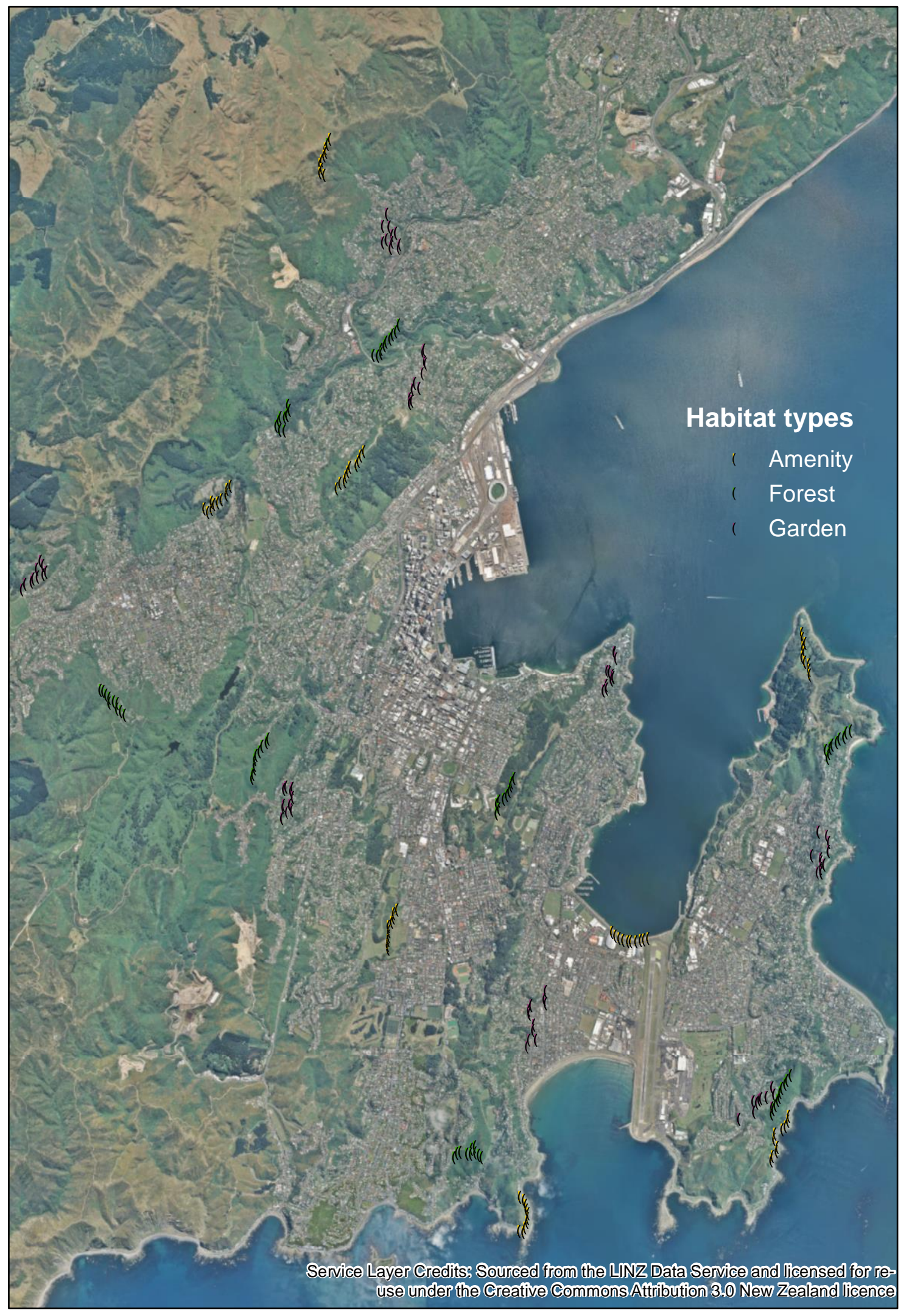

Figure 3.1: Map of the 24 monitoring lines situated in Wellington City. Yellow markers represent amenity sites, green markers represent forest sites and purple markers represent residential sites. There are three sites located within each of the 8 suburbs identified. Background image was sourced from LINZ. Map created using ArcMap 10.5.1. 
All sites were established in spring 2017 with some turnover in the precise residential addresses due to the loss of permissions when residents moved. The spring 2017 monitoring data and the data collected in autumn 2018 formed the dataset that is used in my analyses.

\section{Microhabitat surveys}

Vegetation and ground cover surveys were conducted in autumn 2018 at each sampling station. The two surveys were conducted at each of the 240 stations, with an additional survey conducted in the residential backyards.

The vegetation survey was a modified version of the traditional Recce method (Hurst \& Allen, 2007), and included the vegetation that was in a 10x10m quadrat centred on the tracking tunnel. Plant species were recorded with their six letter vegetation code (National Vegetation Survey Databank, 2018) and placed within tiered height categories: an herb layer (0-30 cm from the ground), a shrub layer (30cm-2m), a sub-canopy layer (2-5m), a lower (5$12 \mathrm{~m})$, mid (12-25m) and/or high (>25m) canopy layer. Only the three most abundant species in each tier were recorded and a single species could occupy more than one tier. Each of the recorded species were numbered between 1 and 6 which was associated with a specific abundance percentage range: $1(<1 \%), 2$ (1-5\%), 3 (6-25\%), 4 (26-50\%), 5 (51-75\%), 6 (76$100 \%)$. The total vegetation cover in each height tier was also recorded. Within $5 \mathrm{~m}$ of the tracking tunnel, the species of tree with the largest trunk was recorded and a DBH measurement was taken (see example data sheet in Appendix A2.2).

The percentage cover of eight components of ground cover within a 10x10m quadrat centred on the tracking tunnel were also assessed using the same six-point abundance scale as above. The eight ground cover variables were: leaf litter, rocks, bare soil, woody debris $(>1 \mathrm{~cm}$ in diameter), mown grass $(<10 \mathrm{~cm}$ in height), water, buildings and low artificial cover such as decking or concrete.

Additional variables were recorded in the 80 garden stations located in residential areas. Unlike the previous surveys, the backyard survey assessed various categories within either the entire backyard or a 20x20m quadrat centred around the tracking tunnel, dependent on which measure was smaller. Four variables were measured: the ratio of native vegetation cover to exotic vegetation cover, percent cover of artificial hard landscaping features, percent cover of lawn and the percent cover of garden beds. These four categories were measured 
using a numbering system from 1 to 6 , but using a symmetric scale, different to that used above. The numbers were each associated with a specific percentage range: $1(<10 \%), 2(10-$ $25 \%), 3(26-50 \%), 4(51-75 \%), 5$ (76-90\%), 6 (>90\%). The maintenance level of the garden was also recorded. Maintenance was recorded from 1 to 3 which represented a low to high level of maintenance. The criteria of a highly maintained garden was evidence of mown lawns, pruned trees and weeded flower beds. Finally, as rats and mice have commonly been observed around compost bins, the presence of compost bins, as well if they were open or closed, was recorded.

All the aforementioned surveys were estimated by myself and just one other observer after a period of cross-referencing to minimise excessive variation due to observer error.

\section{Trapping intensity}

Trapping intensity refers to the number of traps that occupy a specified area (Gillies, 2002b; Gillies et al., 2003; Ruffell et al., 2015a). For example, one trap per 50m on a regular grid (i.e. 4 traps per hectare) is considered a high trap intensity for the control of rats and mice (Gillies, 2002a; NZ Landcare NZ Landcare Trust, 2016). Using trap location data provided by the Wellington City Council and coordinators of various trap groups (Trap.NZ), I aimed to quantify trap intensity for the Wellington sites. Sampling stations were GPS located during the field monitoring season and from this a map was created using ArcMap version 10.5.1. Using the buffer tool, a 25m, 50m, 100m and 200m radius buffer was created around each sampling station to determine the number of traps that occurred within the area of the circle centred on the 240 monitoring sample stations (Figure A2.3 and Table 3.1). A spreadsheet containing trap location and type was imported into ArcMap and individual points were created and symbolised based on trap type. The spatial join tool was used to combine the buffer datasets with the trap datasets to acquire the number and type of traps that fall within each buffer zone around the monitoring points. As there are often several different trap types residing in one buffer zone, I recorded the most common type of trap to occur within a specified buffer zone. If two trap types were equally common, then the trap type closest to the monitoring point was selected to represent trap type for the site. Additional trap types were recorded but not included in analyses for model simplification.

I did not have information on how often the traps were reset or rebaited, therefore I can only report on how the local density of known traps and trap type may influence species presence 
recorded by nearby monitoring. Trap number was calculated separately for two time points: number of traps within an area before November 2017, and the number of traps before April 2018. Any traps that were deployed after these dates were removed as they would have not had an influence on species presence over the two monitoring periods. However, trap deployment dates were not specified for the Karori, Otari and Wadestown residential datasets, therefore, all recorded traps were assumed to have been in place for both monitoring periods.

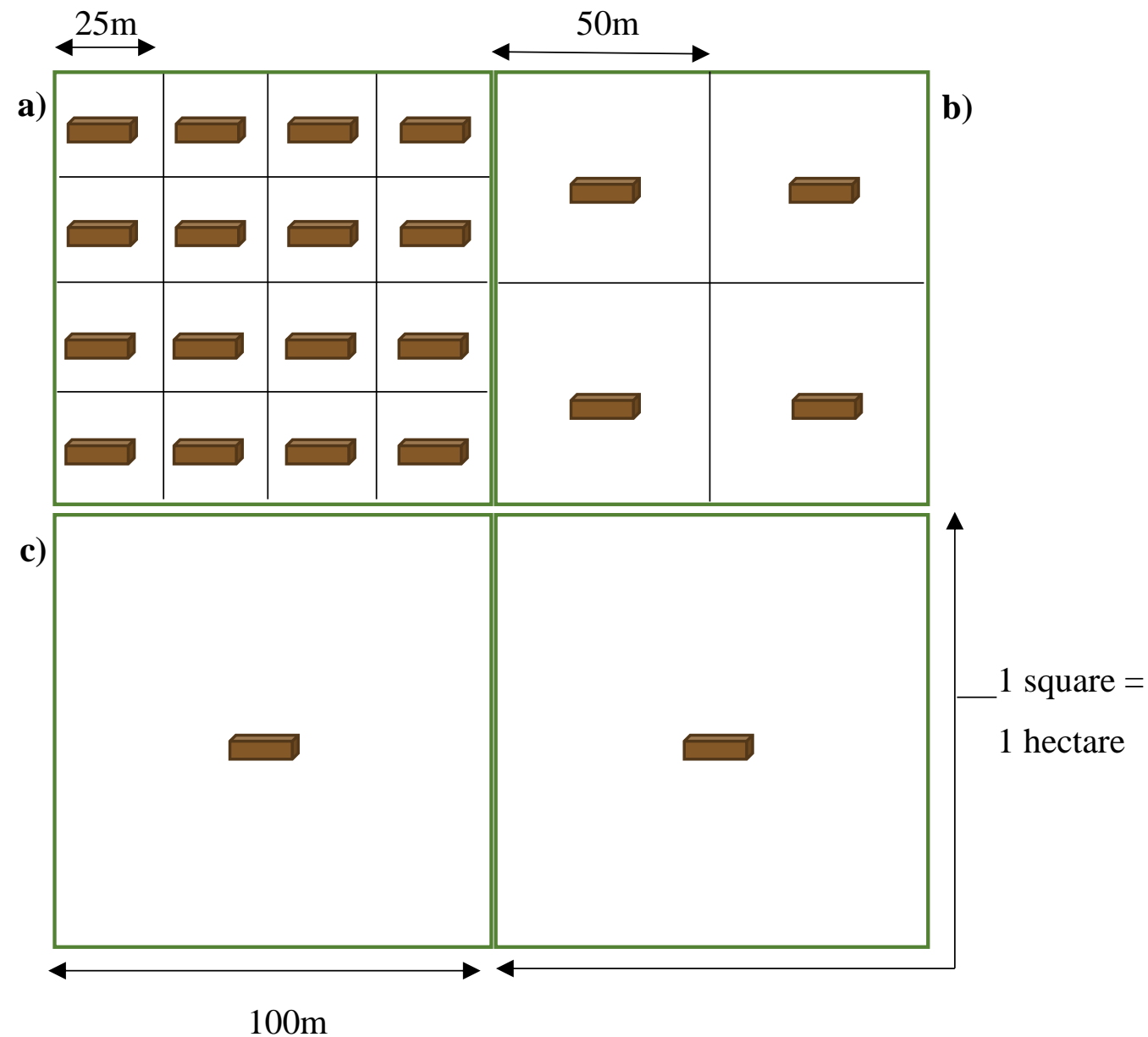

Figure 3.2: Diagram depicting the number of traps per hectare for variously spaced regular trapping grids. a) a $25 \mathrm{~m}$ spaced trap grid is equivalent to 16 traps per hectare, b) a $50 \mathrm{~m}$ spaced trap grid is equivalent to 4 traps per hectare and c) a 100m spaced trap grid is equivalent to 1 trap per hectare. 
Table 3.1: The area of a circle for the specified radius buffer zones in the GIS analysis of local trap density.

\begin{tabular}{lcc}
\hline \hline B uffer $(\mathbf{m})$ & Area $\left(\mathbf{m}^{2}\right)$ & Hectares $(2 \mathrm{dp})$ \\
\hline 25 & 1963 & 0.20 \\
50 & 7854 & 0.79 \\
100 & 31415 & 3.14 \\
200 & 125663 & 12.57 \\
\hline \hline
\end{tabular}

\section{Statistical analyses}

For all chew cards and tracking tunnels over the spring and autumn monitoring seasons, the presence or absence of all target species was recorded, and this formed the main dataset for analyses. Presence and absence data from Wellington, Hamilton and Dunedin formed a single dataset and simple summaries were conducted to assess the mean percentage of species presence across season, city and broad habitat. Although the tracking tunnels recorded species such as invertebrates, lizards and other small mammals (such as cats), results were only reported for rats, mice, hedgehogs, possums and mustelids as they are the key introduced mammalian predators that occur within New Zealand. The mean presence scores per line were calculated individually for each species for use in the summaries. The means of one-night and six-night chew cards and tracking tunnels were calculated for rats and mice. The means of the one-night and six-night tracking tunnel scores only were calculated for hedgehogs and mustelids, and the mean of the one-night and six-night chew card scores only were calculated for possums. Hedgehogs, mustelids and possums rarely occurred on the alternative monitoring devices and therefore were excluded from the summaries as they would dilute the results. All means are presented as percentages, therefore, when I report the change in means in percentages, it is referring to the difference in values and not the difference as a percentage of the values.

\section{Reduced models for Hamilton, Dunedin and Wellington}

All of the remaining statistical analyses were performed in $\mathrm{R}$ version 3.5.2. Generalised liner mixed models (GLMM) were performed on the Hamilton, Dunedin and Wellington dataset to assess if season, city and habitat were significant factors influencing the presence or absence of species, whilst accounting for line as a random effect. The presence scores of all four 
monitoring devices were combined so that if one of the four devices detected a species, then that species would be scored a 1 for detection at that station over the entire seven-night monitoring period. The interactive effects of both season and city, and season and habitat, were assessed to identify if there were strong seasonal influences within these variables. Mustelids were removed from the analyses as they did not have a sample size large enough to form any meaningful conclusions. Using the car package, Type III ANOVA's were performed on the resulting models to obtain omnibus p-values for factors using a Wald chi square test. For all individual significantly reported factors from the models, a post-hoc Tukey $z$-test was run to identify which categories within the factors were significantly different from which other. When interaction of two factors were significant, the two variables were consolidated into a single factor so that the post-hoc tests could be run.

\section{Microhabitat models for Wellington}

GLMM's assessing the influence of various landscape and microhabitat factors on species presence were only conducted for Wellington. All four devices were combined as previously mentioned, and the models were performed on the binary, presence per station scores of each species. Presence scores were tested against 10 fixed effects (Table 3.2), whilst accounting for the random influence of line. All fixed effects were tested for a correlation or association prior to running the models as correlated data can influence model performance and result interpretation (Harrison et al., 2018). The height tiers were consolidated into two groups, and all scores were added on a 2-12 point scale that defined vegetation cover under $2 \mathrm{~m}$, and all vegetation between $2-25 \mathrm{~m}$. Tiers were consolidated to reduce complexity within the model and these groups were specified based on their correlation and likelihood to influence presence. All calculations of trap density in increasing radii were strongly correlated as the larger buffer areas necessarily overlap with the smaller buffer areas. Thus, separate models were run for each of the trap distance categories, and in total, four models were run per species. Trap type within different buffer zones were used for each model when capable of convergence. Human population was obtained from census data collected in 2013 (Statistics New Zealand) and square root transformed for inclusion in the models. Mesh block data containing population information were displayed on the GIS map, and the spatial join tool was used to identify the human population of the mesh block within which our monitoring points resided (Figure A2.4). Distance data were obtained using the near tool in ArcMap (Figure A2.5. All distances were logged, and count data square rooted, so that values were on 
similar scales, allowing the models to converge successfully. Marginal $\left(R^{2}{ }_{m}\right)$ and conditional $\left(R^{2}{ }_{c}\right)$ r-squared values were calculated for models to assess the fit of fixed effects, both separately and with random effects, on the presence of species.

\section{Models for species associations in Wellington}

It was not uncommon for multiple species to be present on the same cards, but we do not know to what degree these species interact behaviourally. To assess species-species interactions, GLMM's were performed on various two-way species presence scores for Wellington data, accounting for suburb as a random variable. Models were performed on line means to assess site specific interactions following the formula:

$$
\text { glmer(RatAutumn MouseAutum + (1|Suburb) }
$$

GLMM's were fitted to determine if the presence of one species may have influenced the overall presence of another species and therefore, the interpretation of previous results. Separate analyses were performed for the two seasons to account for variation in seasonal presences, whilst removing individual impacts of season and species on resulting model variability. Analyses were also run to assess influences of monitoring duration and habitat type as these variables had the potential to influence results. Summaries recording the percentage of occasions where two species were present at the same site were reported to accompany results.

\section{Results}

The influence of city, season and habitat type on species distribution

\section{Rats}

Species detections varied considerably across city and season (City*Season interaction, $p<0.001)$. Across all cities, there was a general increase in the detection of rats in autumn (Figure 3.3). Rat detections increased by 5-7\% between spring and autumn, however, the magnitude of change did not greatly differ between cities (Table 3.3). Wellington recorded the highest detection rate of rats across both seasons, with a detection rate of $12 \%$ in spring, rising by $7 \%$ in autumn (Figure 3.3). 
Table 3.2: Fixed effects for the GLMM model assessing the influence of environmental variables on species presence across Wellington City.

\begin{tabular}{lccc}
\hline \hline Fixed effects & Median & Min & Max \\
\hline Total vegetation (Tier 1 + 2) & 3 & 0 & 6 \\
Total vegetation (Tier 3+4+5+6) & 0 & 0 & 6 \\
Distance to bush fragment (m) & 7.3 & 0 & 657.0 \\
Distance to coast (m) & 993.9 & 7.6 & 4563.1 \\
Distance to stream (m) & 376.9 & 0.1 & 1754.6 \\
Human population (sqrt) & 10.7 & 0 & 15.1 \\
Traps 25m & 0 & 0 & 4 \\
Traps 50m & 0 & 0 & 9 \\
Traps 100m & 2 & 0 & 28 \\
Traps 200m & 8 & 0 & 81 \\
\hline & Categories & $N$ \\
\hline Trap type & Victor, DOC 200, A24, rat & 6 \\
Season & trap, Snap E Rat, Unspecified & \\
Habitat & Spring, Autumn & 2 \\
\hline \hline
\end{tabular}

Habitat was not a significant predictor of rat detections, neither as a main effect, nor in the two-way interactions tested (Table 3.3). Rats were detected in all three habitat types across all cities in at least one season of monitoring. Hamilton recorded the highest detection of rats in forest sites, with a detection rate of $17 \%$ in spring, and $26 \%$ in autumn. Wellington recorded the highest detections of rats in both amenity and residential sites. The detection rate of rats in amenity sites was $15 \%$ in spring, and $19 \%$ in autumn. In residential sites, detection rates were $7 \%$ in spring, and $11 \%$ in autumn (Table 3.3 and Figure 3.4 ).

Mice

There was a general increase in mouse detections in autumn across all cities, although the increase also varied significantly between cities (City*Season interaction $p<0.001$, Figure 3.3). Mouse detections were between $2-10 \%$ in spring, and rose to $10-25 \%$ in autumn, although the exact magnitude of the increase varied between cities (Table 3.3). Wellington 
had the highest overall detections of mice, with 9\% detected in spring, and $24 \%$ in autumn, demonstrating a 15\% increase between seasons (Figure 3.3).

Mouse detections strongly differed between habitat types across all cities (Table 3.3). Mice detections increased between $4-22 \%$ in forest sites, $14-18 \%$ in amenity sites and $2-15 \%$ in residential sites between spring and autumn (Figure 3.4). In five out of six cases, mouse detections were highest in amenity sites and had consistently higher detections in this habitat, regardless of the city or season. Overall, Wellington had the highest mouse detections in amenity sites, with a detection rate of $15 \%$ in spring, and $33 \%$ in autumn.

\section{Hedgehogs}

Unlike rats and mice, there is a general decrease in hedgehog detections in autumn across all cities. Hedgehogs were detected between $14-46 \%$ in spring, and declined by $7-23 \%$ in autumn (Figure 3.3), however, there was minimal variation in detections between Hamilton and Wellington across seasons (Table 3.3). Dunedin had the highest detections of hedgehogs overall, with $46 \%$ in spring and $23 \%$ in autumn, resulting in a $23 \%$ decrease between seasons (Figure 3.3).

Hedgehogs do not appear to have a distinct pattern of distribution based on habitat type (Table 3.3 and Figure 3.4). Hedgehog detections did not differ greatly between habitat types in spring, with detection rates all within less than $10 \%$ of one another. However, in two out of three cases in autumn, hedgehog detections were higher in amenity sites. Dunedin had the highest detections of hedgehogs, with a detection rate of 51\% in amenity sites in spring, and $30 \%$ in residential sites in autumn (Figure 3.4). Although hedgehogs weren't detected more in one specific habitat type, their use of habitats did differ seasonally. In most cases, hedgehogs had a higher detection rate in all habitat types in spring.

\section{Possums}

Possums showed large differences in detection rates between cities (Table 3.3), being almost absent from Wellington (just one detection in autumn 2018). Dunedin had a five times higher mean detection rate of possums compared to Hamilton $(z=-4.562, \mathrm{df}=1908, p<0.001$, Figure 3.3), however, the difference in detections between seasons was minimal.

Possum detections strongly differed between habitat types across all cities (Table 3.3). The highest possum detections occurred in forest sites and did not substantially differ seasonally 
(Table 3.3 and Figure 3.4). Dunedin recorded the highest possum detections in forest sites, with $78 \%$ of all sites detecting possums.

\section{Mustelids}

Due to the limited occurrence of mustelids, models could not sufficiently explain the factors contributing to mustelid detections, therefore results were excluded. Only one event of mustelid detection occurred in spring 2017 in one of the Wellington forest sites. These results do not necessarily reflect that mustelids are not present within the cities, however, their neophobic nature likely lead to the avoidance of monitoring equipment and therefore their limited presence in the dataset (Gleeson et al., 2010; King et al., 2009). 
Table 3.3: Type III ANOVA table reporting the results obtained from GLMM models on the influence of season, city and habitat, and their interactions for $a$ ) rats, $b$ ) mice $c$ ) hedgehogs and $d$ ) possums.

\begin{tabular}{lccc}
\hline \hline a) Rat & Chisq & df & $p(>$ Chisq $)$ \\
\hline Season & 9.26 & 1 & 0.002 \\
City & 5.04 & 2 & 0.081 \\
Habitat & 2.22 & 2 & 0.330 \\
Season*City & 20.12 & 2 & $<0.001$ \\
Habitat*Season & 1.67 & 2 & 0.434 \\
Habitat*City & 5.41 & 4 & 0.248 \\
\hline b) Mouse & & & \\
\hline Season & 12.17 & 1 & $<0.001$ \\
City & 2.49 & 2 & 0.288 \\
Habitat & 7.39 & 2 & 0.025 \\
Season*City & 28.31 & 2 & $<0.001$ \\
Habitat*Season & 1.69 & 2 & 0.430 \\
Habitat*City & 3.07 & 4 & 0.546 \\
\hline $\boldsymbol{c}$ ) Hedgehog & & & \\
\hline Season & 38.32 & 1 & $<0.001$ \\
City & 11.15 & 2 & 0.004 \\
Habitat & 2.06 & 2 & 0.358 \\
Season*City & 5.14 & 2 & 0.077 \\
Habitat*Season & 8.82 & 2 & 0.012 \\
Habitat*City & 0.84 & 4 & 0.934 \\
\hline $\boldsymbol{d})$ Possum & & & \\
\hline Season & 1.30 & 1 & 0.255 \\
City & 0.1209 & 2 & 0.9493 \\
Habitat & & 2 & 0.007 \\
Season*City & 21.70 & 2 & $<0.001$ \\
Habitat*Season & & & \\
Habitat*City & & 2 & 0.000 \\
\hline \hline
\end{tabular}




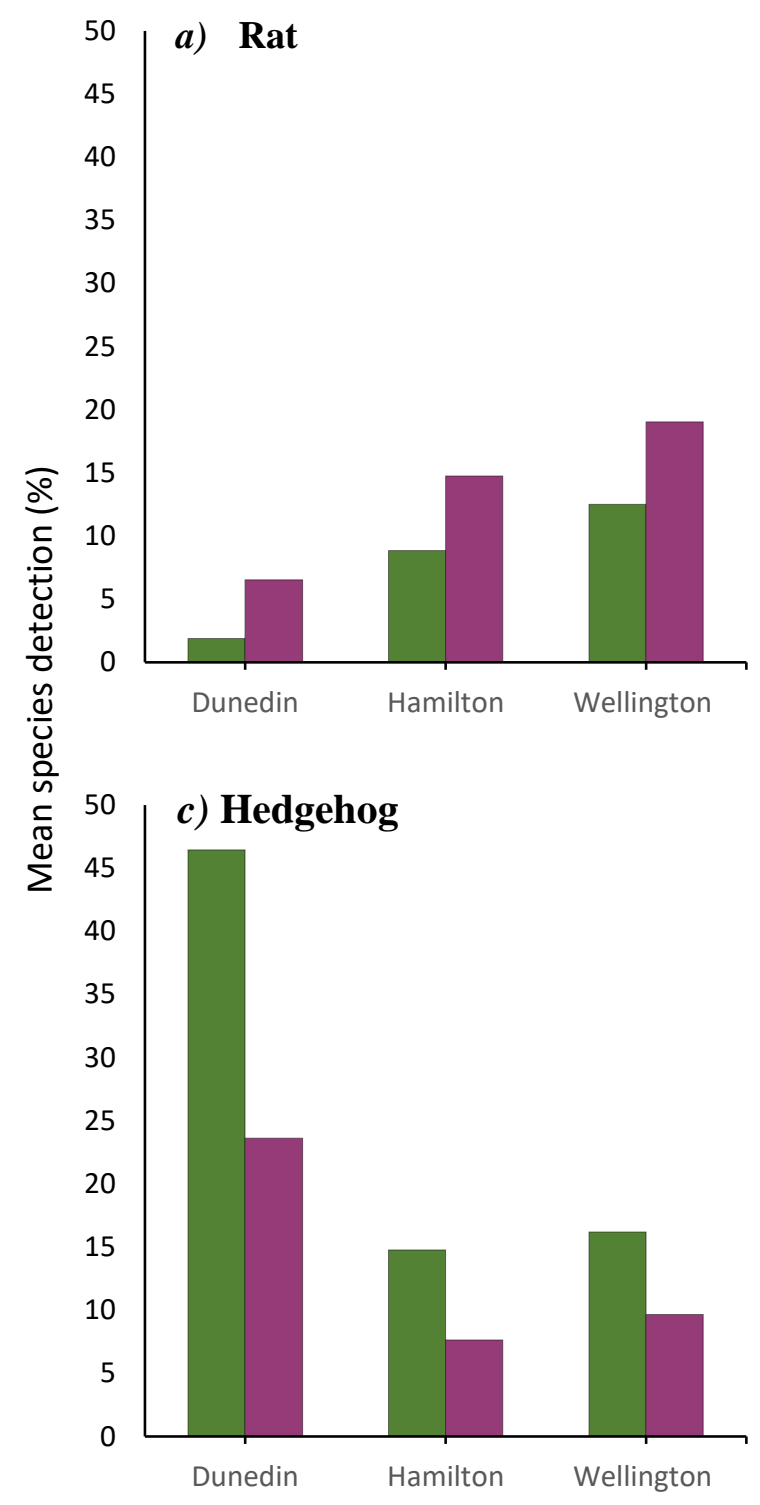

\section{b) Mouse}
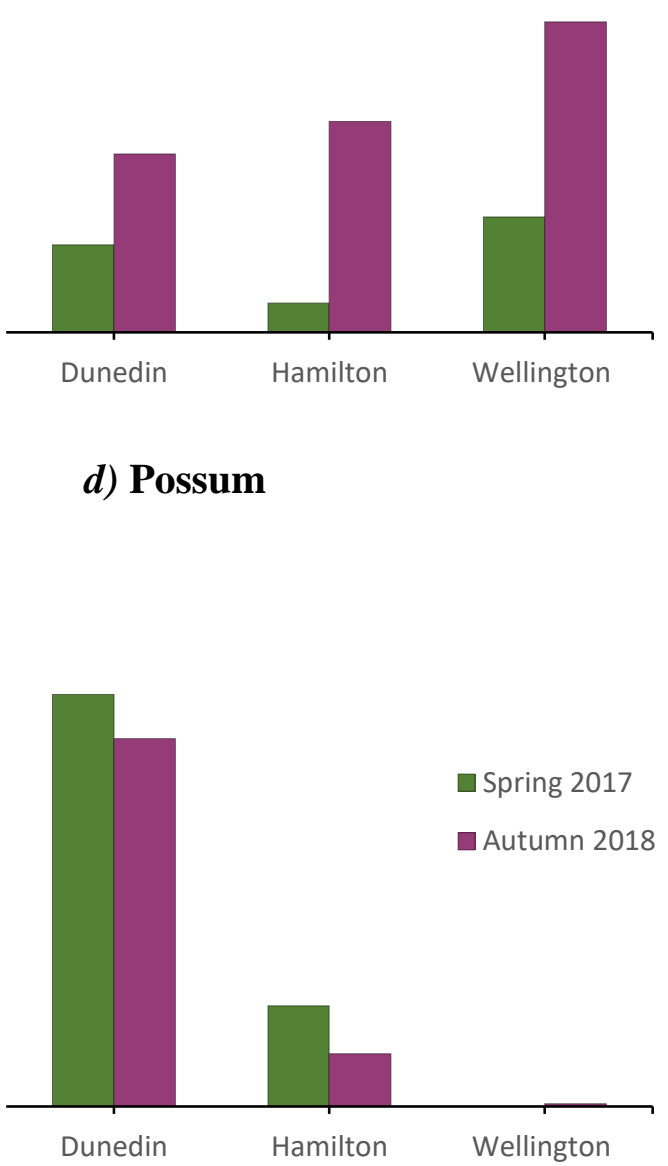

Figure 3.3: Mean presence of introduced mammalian species as a percentage of the total chew cards and tracking tunnels collected for $a$ ) rats, $b$ ) mice, the total tracking tunnels collected for $c$ ) hedgehogs, and the total chew cards collected for $d$ ) possums. The detection of rats, mice and hedgehogs demonstrated significant differences across seasons $(\mathrm{p}<0.002)$. 

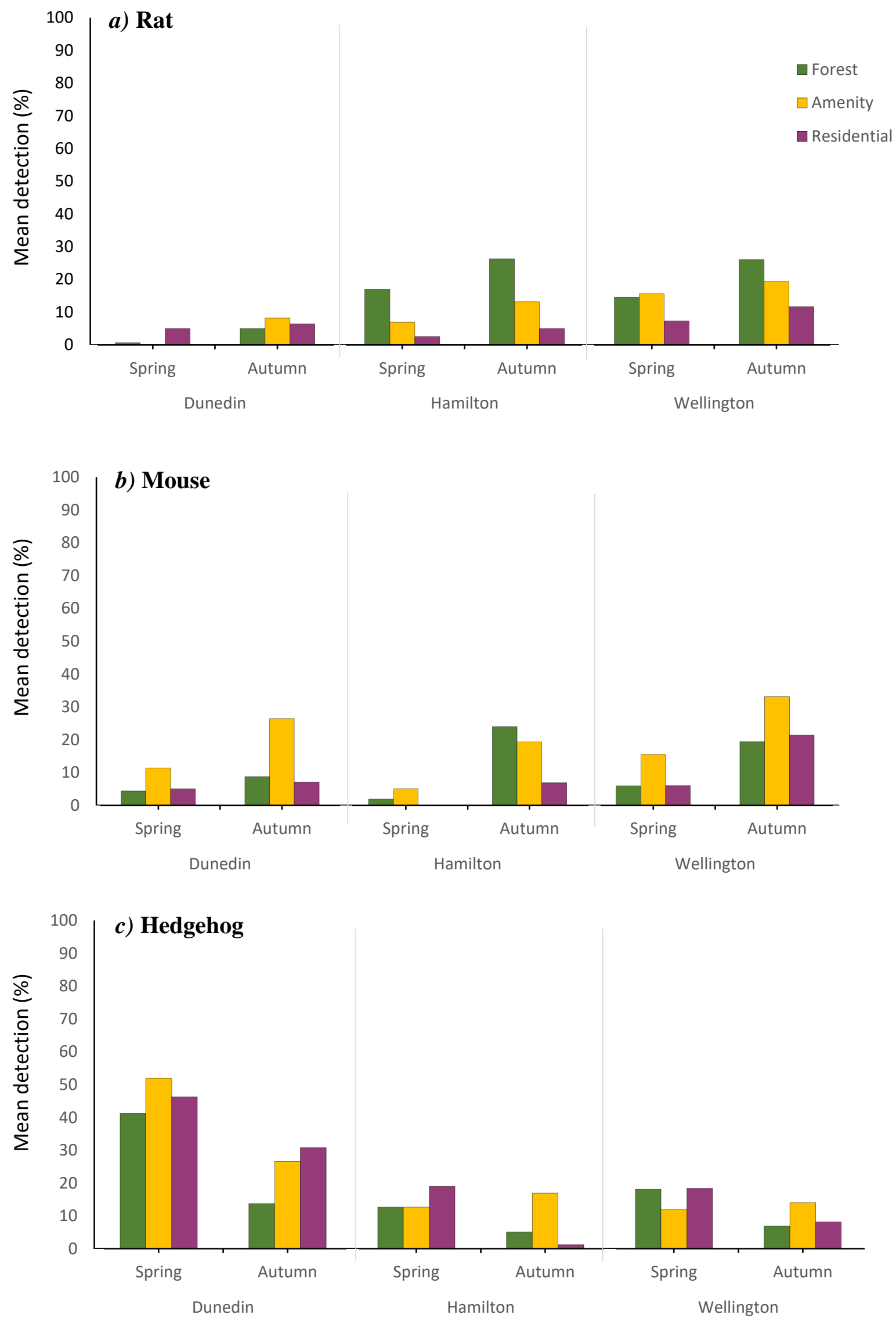


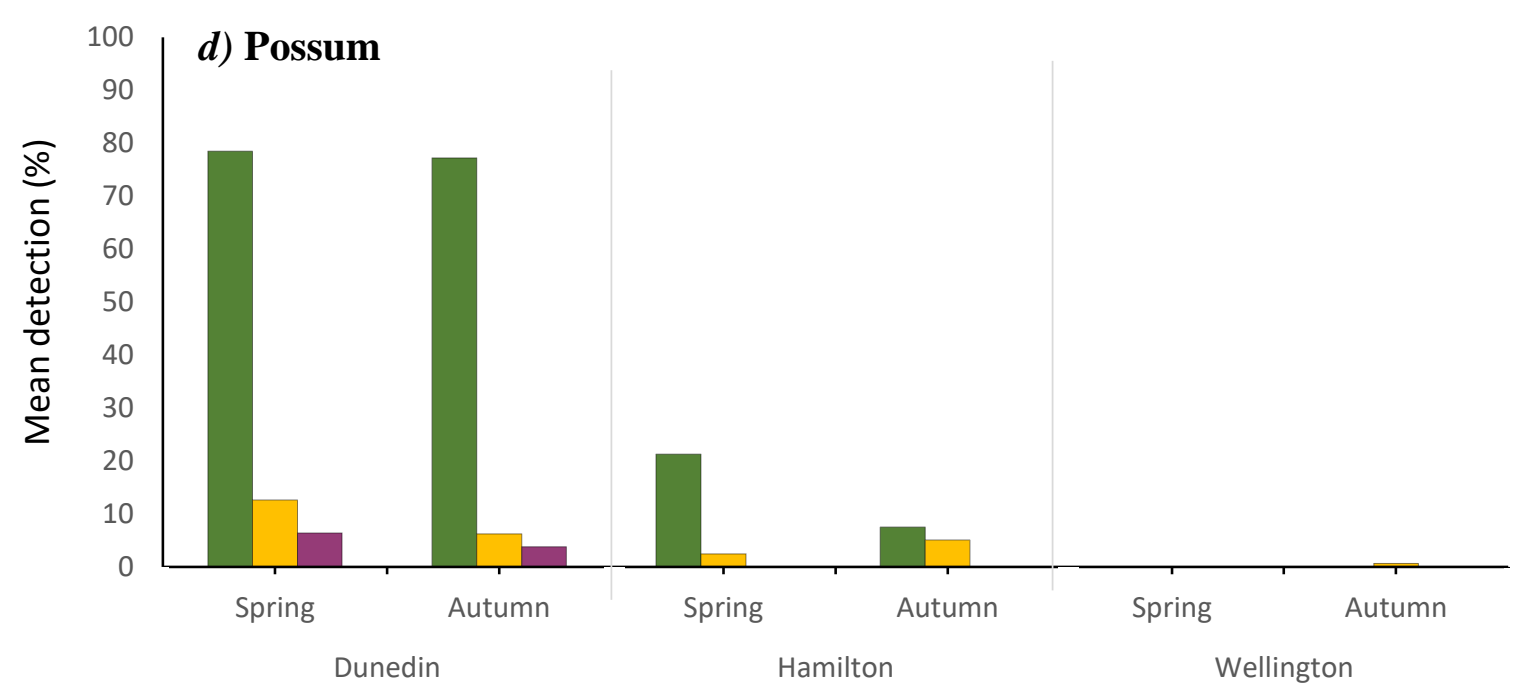

Figure 3.4: Mean detections of introduced mammalian species across habitat types as a percentage of the total chew cards and tracking tunnels collected for $a$ ) rats, $b$ ) mice, the total tracking tunnels collected for $c$ ) hedgehogs, and the total chew cards collected for $d$ ) possums. Detections of mice, hedgehogs and possums differed significantly across habitat types $(\mathrm{p}<0.02)$, however, only detections of hedgehogs significantly differed between habitats across seasons $(\mathrm{p}=0.012)$.

\section{Influence of landscape and microhabitat variables on mammal presence in Wellington}

The influence of season and habitat have been reported in previous analyses, however, they remain included in the full model to obtain the most reliable $R^{2}$ value of how the combination of multiple environmental variables explains the variation in species detections. Previously reported variables will not be discussed in this section if they were already reported as influential.

Habitat type was reported to show a correlation with vegetation cover in the two merged height tiers, with the percentage of vegetation cover at each height tier increasing from residential sites to forest sites (Table A2.1). However, habitat type is known from previous analyses to influence species distributions and therefore remained in the model. Models with habitat type removed did not significantly alter the results of the remaining variables. The 2$25 \mathrm{~m}$ height tier was correlated with several other variables in the models, including the distances from environmental variables (Table A2.2). Although it was not reported as having an influence on species detections, its removal from models commonly resulted in convergence errors, therefore it remained in the models. 
Of the ten variables tested, season, habitat and the distance to the coast had an influence on rat detections (Table 3.4, Figure 3.5). The model that included trap density and type within $50 \mathrm{~m}$ was the only model to show a significant effect of all three variables, however, across the other three models, these variables still reported evidence of an influence (Table A2.3). There is an increase in rat detections in forest sites, but a decrease in detections with the increasing distance from the coast (Table 3.4, Figure 3.8). When vegetation tiers 3-6 were removed, there was some evidence that the distance of sites to large vegetated areas influenced rat detections. Although it had low significance, there is an increase in the detections of rats with the increasing distance from areas of vegetation. Trap density within any of the specified radii did not have an influence on rat detections, however, the model containing $100 \mathrm{~m}$ trap density provided the highest overall explanation of the variation in rat detections $\left(R_{m}^{2}=0.191, R_{c}^{2}=0.337\right)$.

Mouse and hedgehog models would not converge with specified trap types in different radii; thus, the influence of trap type could only be assessed from the $200 \mathrm{~m}$ zone.

Only season and habitat had an influence on mouse detections across the four models, with no landscape variables reporting any evidence of an influence on the detections of mice (Table 3.4, Figure 3.6). Trap density within any of the specified radii did not have an influence on mouse detections, however, the model containing $25 \mathrm{~m}$ trap density provided the highest explanation of the variation in mouse detections $\left(R^{2}{ }_{m}=0.212, R_{c}^{2}=0.254\right.$, Table A2.4).

Of the ten variables tested, season and human population had an influence on hedgehog detections (Table 3.4, Figure 3.7). There was an increase in the detection of hedgehogs in sites where human population is higher (Figure 3.9), however, the interaction of habitat type and human population did not have an influence on hedgehog detections. Trap density within any of the specified radii did not have an influence on hedgehog detections, however, the model containing $200 \mathrm{~m}$ trap density provided the highest explanation of the variation in hedgehog detections $\left(R_{m}^{2}=0.1051, R^{2}{ }_{c}=0.3992\right.$, Table A2.5). 
Table 3.4: Type III ANOVA table reporting the most significant results obtained from GLMM models on the influence of microhabitat, landscape and management variables for $a$ ) rats, $b$ ) mice and $c$ ) hedgehogs.

\begin{tabular}{lccc}
\hline \hline a) Rat & Chisq & df & $\operatorname{Pr}(>$ Chisq $)$ \\
\hline (Tier1 + Tier2) & 0.77 & 1 & 0.38 \\
(Tier3 + Tier4 + Tier5+ Tier6) & 0.37 & 1 & 0.55 \\
I(log10(dist2veg + 1)) & 2.18 & 1 & 0.14 \\
I(log10(dist2stream)) & 0.03 & 1 & 0.87 \\
I(log10(dist2coast)) & 5.23 & 1 & 0.02 \\
Habitat & 8.09 & 2 & 0.02 \\
I(sqrt(hpopulation)) & 0.14 & 1 & 0.71 \\
Season & 18.11 & 1 & $<0.001$ \\
Traps_50m & 1.73 & 1 & 0.19 \\
Trap_type50 & 3.49 & 6 & 0.74 \\
\hline \hline
\end{tabular}

\begin{tabular}{lccc}
\hline \hline b) Mouse & Chisq & df & $\operatorname{Pr}(>$ Chisq) \\
\hline (Tier1 + Tier2) & 1.18 & 1 & 0.28 \\
(Tier3 + Tier4 + Tier5+ Tier6) & 2.09 & 1 & 0.15 \\
I(log10(dist2veg + 1)) & 0.67 & 1 & 0.41 \\
I(log10(dist2stream)) & 0.68 & 1 & 0.41 \\
I(log10(dist2coast)) & 1.48 & 1 & 0.22 \\
Habitat & 5.22 & 2 & 0.07 \\
I(sqrt(hpopulation)) & 0.21 & 1 & 0.65 \\
Season & 35.90 & 1 & $<0.001$ \\
Traps_25m & 1.20 & 1 & 0.27 \\
Trap_type & 4.17 & 6 & 0.65 \\
\hline \hline & & & \\
\hline \hline c) Hedgehog & Chisq & df & $\operatorname{Pr}(>$ Chisq) \\
\hline (Tier1+ Tier2) & 0.18 & 1 & 0.67 \\
(Tier3 + Tier4 + Tier5+ Tier6) & 0.02 & 1 & 0.90 \\
I(log10(dist2veg + 1)) & 0.05 & 1 & 0.83 \\
I(log10(dist2stream)) & 0.20 & 1 & 0.66 \\
I(log10(dist2coast)) & 0.80 & 1 & 0.37 \\
Habitat & 0.18 & 2 & 0.91 \\
I(sqrt(hpopulation)) & 5.01 & 1 & 0.03 \\
Season & 7.04 & 1 & 0.01 \\
Traps_200m & 1.43 & 1 & 0.23 \\
Trap_type & 4.72 & 6 & 0.58 \\
\hline \hline
\end{tabular}




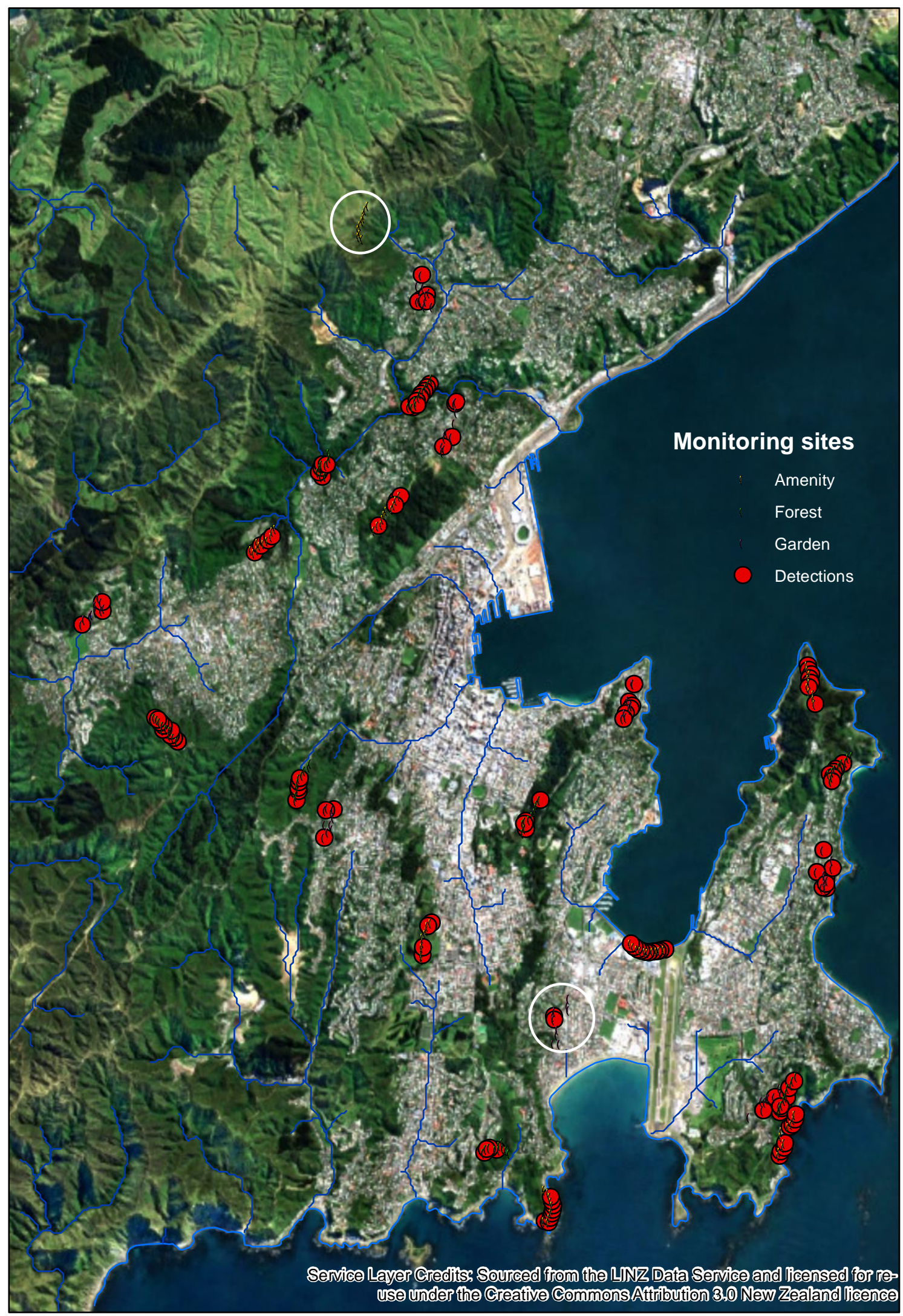

Figure 3.5: Map depicting the detections of rats at monitoring sites across Wellington, for the spring 2017 and autumn 2018 monitoring seasons. The two highlighted lines represent the sites that had the fewest detections. Background image was sourced from LINZ and used in ArcMap 10.5.1. 


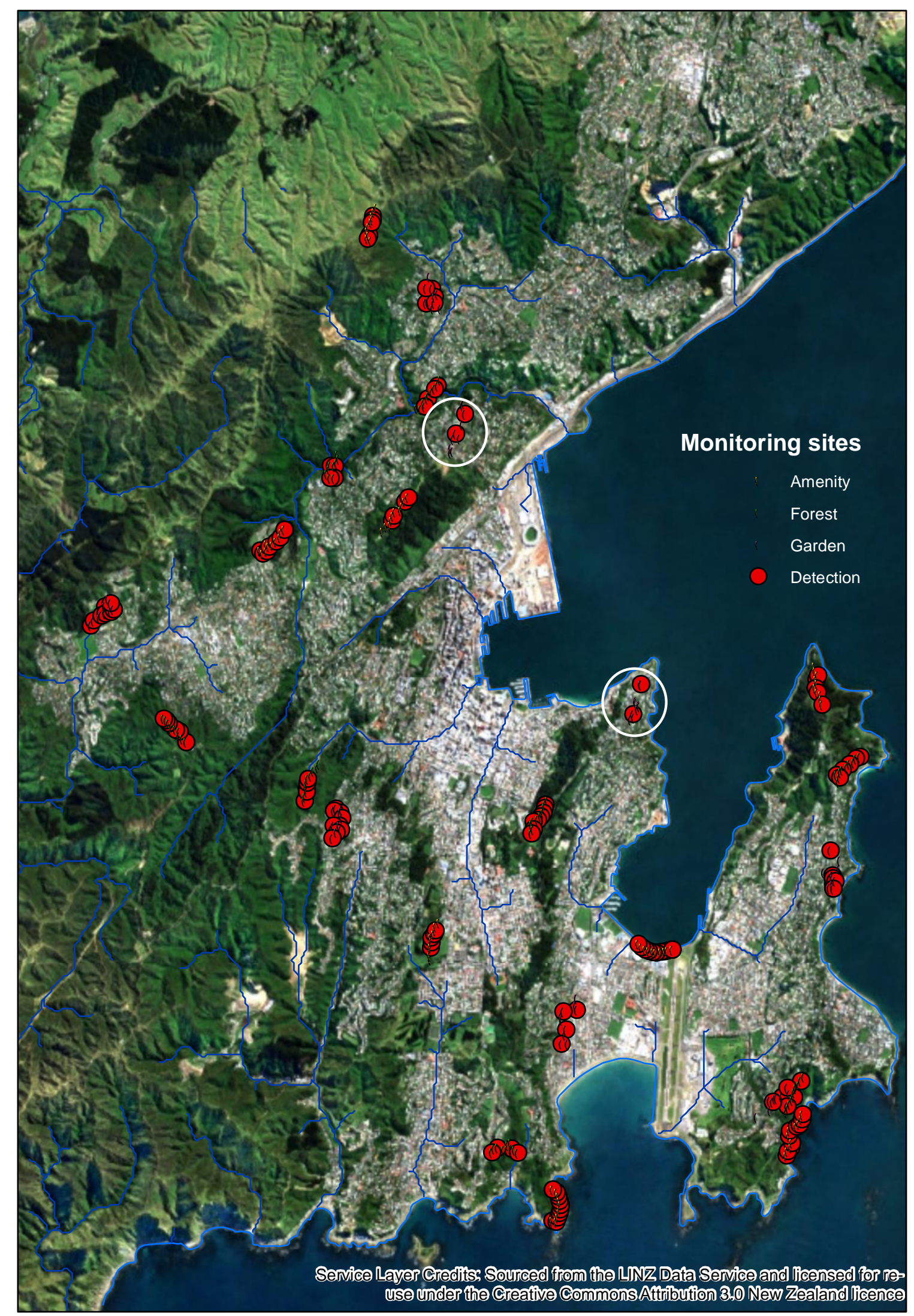

Figure 3.6: Map depicting the detections of mice at monitoring sites across Wellington, for the spring 2017 and autumn 2018 monitoring seasons. The two highlighted lines represent the sites that had the fewest detections. Background image was sourced from LINZ and used in ArcMap 10.5.1. 


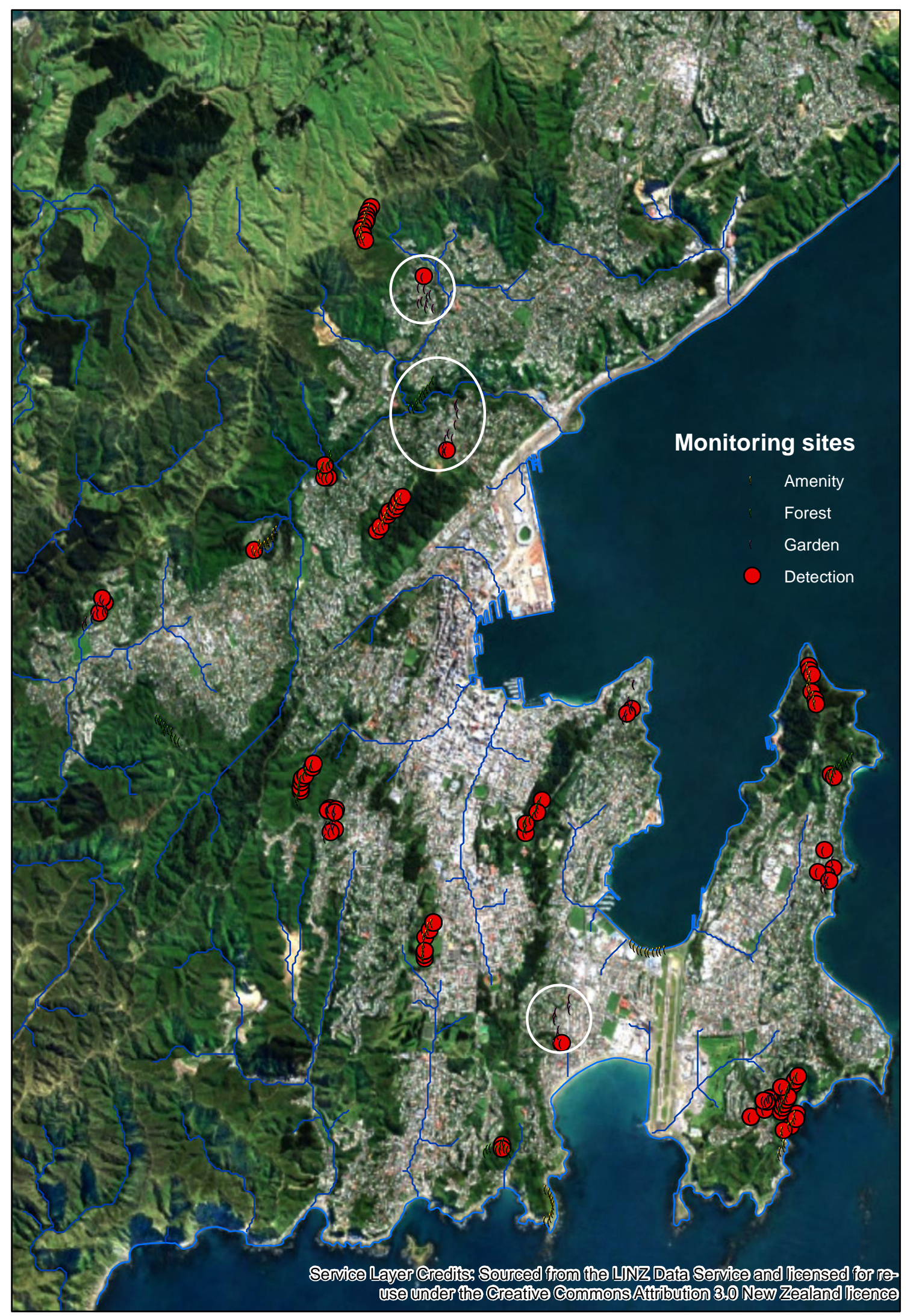

Figure 3.7: Map depicting the detections of hedgehogs at monitoring sites across Wellington, for the spring 2017 and autumn 2018 monitoring seasons. The highlighted lines represent the sites that had the fewest detections. Background image was sourced from LINZ and used in ArcMap 10.5.1. 


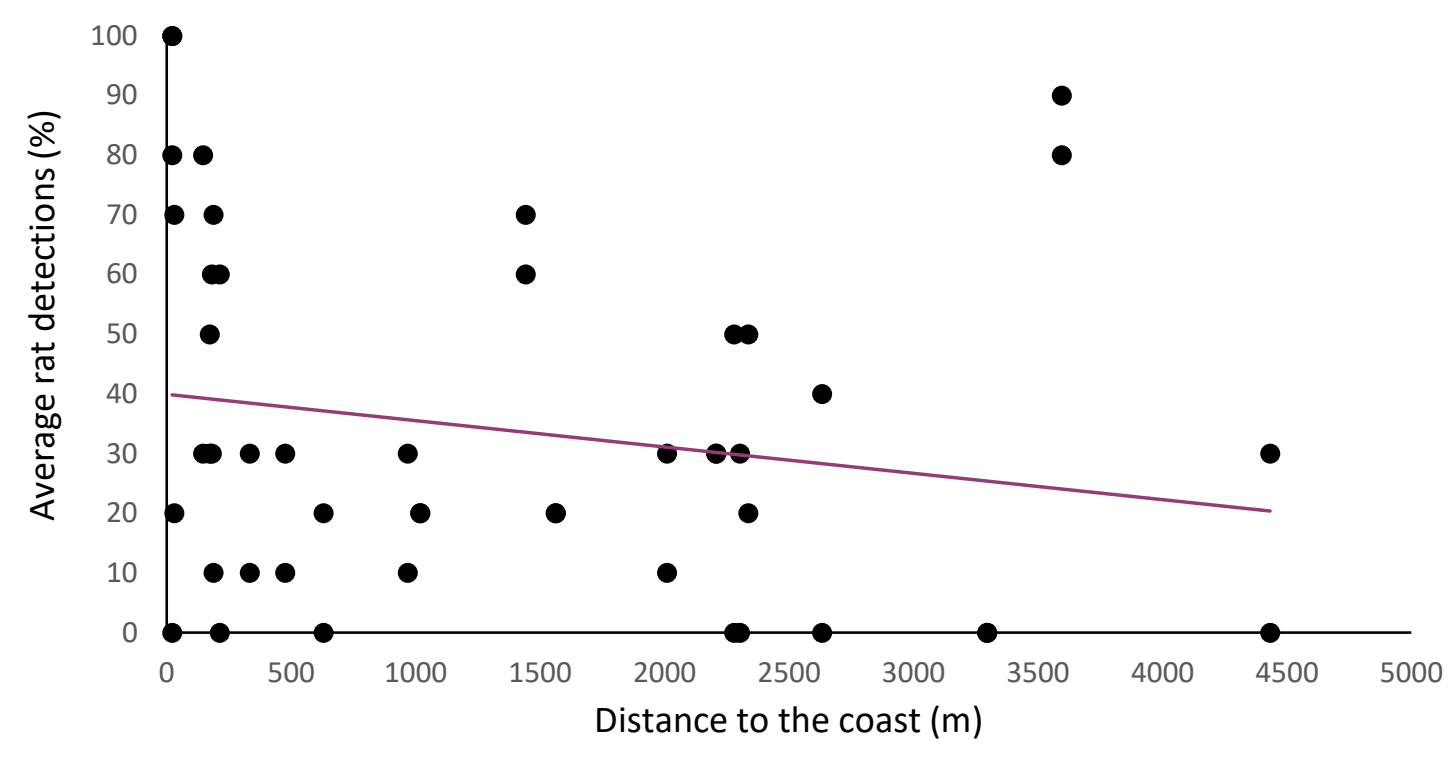

Figure 3.8: The influence of the distance to the coast on detections of rats. Values have been averaged per line for graphical representation.

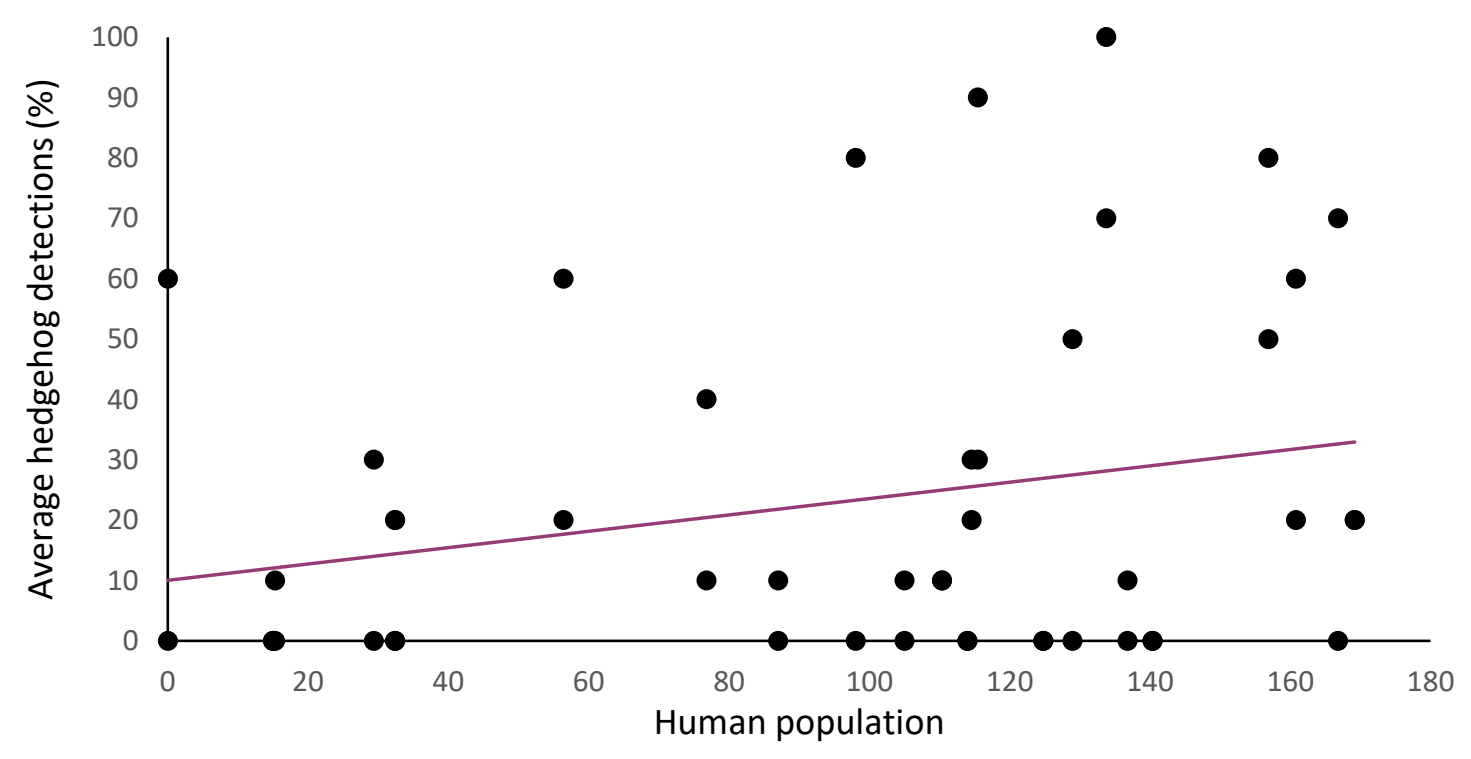

Figure 3.9: The influence of human population size in specified mesh blocks on the detections of hedgehogs.

Values have been averaged per line for graphical representation. 
Separate models were run to assess the interactive effects of habitat type and trap density, and season and trap density, on the detection of species. Hedgehog detections were influenced by the density of traps across the three broad habitat types. The increase in trap numbers within 100 and 200m zones resulted in a decrease in detections in forest and residential sites, comparative to amenity sites (Table 3.5). However, these differences likely arose due to the seasonal interaction with trap density. Hedgehog detections increased in spring with the increase in trap density at these radii, but decreased with density in a 50m radius. The interactive effect of trap density and season had an influence on the detections of rats at differing radii. There is a decrease in the detection of rats in spring when trap densities at 25 and $50 \mathrm{~m}$ increase.

Table 3.5: Type III ANOVA table for the influence of trap density and specified radii, trap type, and the interaction between trap density and season for rats and hedgehogs.

\begin{tabular}{lccc}
\hline \hline a) Rats, 25m traps & Chisq & df & $\operatorname{Pr}(>$ Chisq $)$ \\
\hline Traps 25m & 0.11 & 1 & 0.73 \\
Trap type & 4.70 & 6 & 0.58 \\
Season*Traps_25m & 5.13 & 1 & 0.02 \\
\hline \hline
\end{tabular}

\begin{tabular}{lccc}
\hline \hline b) Rats, 50m traps & Chisq & df & $\operatorname{Pr}(>$ Chisq $)$ \\
\hline Traps 50m & 0.03 & 1 & 0.86 \\
Trap type & 4.41 & 6 & 0.62 \\
Season*Traps_50m & 10.99 & 1 & $<0.001$ \\
\hline \hline
\end{tabular}

\begin{tabular}{lccc}
\hline \hline c) Hedgehogs, 50m traps & Chisq & df & $\operatorname{Pr}(>$ Chisq $)$ \\
\hline Traps 50m & 0.03 & 1 & 0.86 \\
Trap type & 4.41 & 6 & 0.62 \\
Season*Traps_50m & 10.99 & 1 & $<0.001$ \\
\hline \hline
\end{tabular}

\begin{tabular}{lccc}
\hline \hline c) Hedgehogs, 100m traps & Chisq & df & $\operatorname{Pr}(>$ Chisq $)$ \\
\hline Traps 100m & 3.51 & 1 & 0.06 \\
Trap type & 2.42 & 6 & 0.88 \\
Season*Traps_100m & 8.30 & 1 & $<0.001$ \\
\hline \hline
\end{tabular}




\begin{tabular}{lccc}
\hline \hline c) Hedgehogs, 200m traps & Chisq & df & $\operatorname{Pr}(>$ Chisq $)$ \\
\hline Traps 200m & 3.07 & 1 & 0.08 \\
Trap type & 2.81 & 6 & 0.83 \\
Season*Traps_200m & 6.22 & 1 & 0.01 \\
\hline \hline
\end{tabular}

\section{Species interactions}

There is some evidence to suggest that presence of certain species had an influence on the detection of other species within the same location. Within season, three interactions were identified, however, only one was significant. The detection of rats in autumn increased when detections of hedgehogs were lower, accounting for $18.32 \%$ of the variability in rat detections $\left(R_{m}^{2}=0.183, R_{c}^{2}=0.190\right)$ (Figure 3.10). There was some evidence to suggest that the same pattern occurs in spring. There is also some evidence that an increase in mice detections in autumn occurs when detections of hedgehogs are low, however, neither of these interactions were significant.

The interaction of monitoring duration and season had an influence on species interactions and three interactions were identified, however, only two were significant. The detection of rats on one-night exposures in autumn increases with the increase in mouse detections, accounting for $14.18 \%$ of the variability in rat detections (Figure 3.11$)\left(R^{2}{ }_{m}=0.142\right.$, $\left.R^{2}{ }_{c}=0.317\right)$. There was some evidence to suggest that rat detections decreased on one-night exposures in spring with the increase in mouse detections, however, the interaction was not quite significant at the threshold of 0.05 , and only explained $4.9 \%$ of the variability $\left(R_{m}^{2}=0.0491, R_{c}^{2}=0.2777\right)$. Across six-night exposures, the detection of rats increased in autumn when hedgehog detections decreased, accounting for $12.2 \%$ of the variation in rat detections (Figure 3.12) $\left(R^{2}{ }_{m}=0.1218, R_{c}^{2}=0.1218\right)$. Species were more likely to be present together on six-night card exposures compared to one-night exposures (Figure 3.13). This was the case across both seasons, however, there were a greater percentage of occurrences with hedgehogs in spring.

The interaction of habitat type and season did not report any significant species interactions. There was some evidence to suggest that detections of mice increased with lower hedgehog detections, however, this interaction was not significant. 


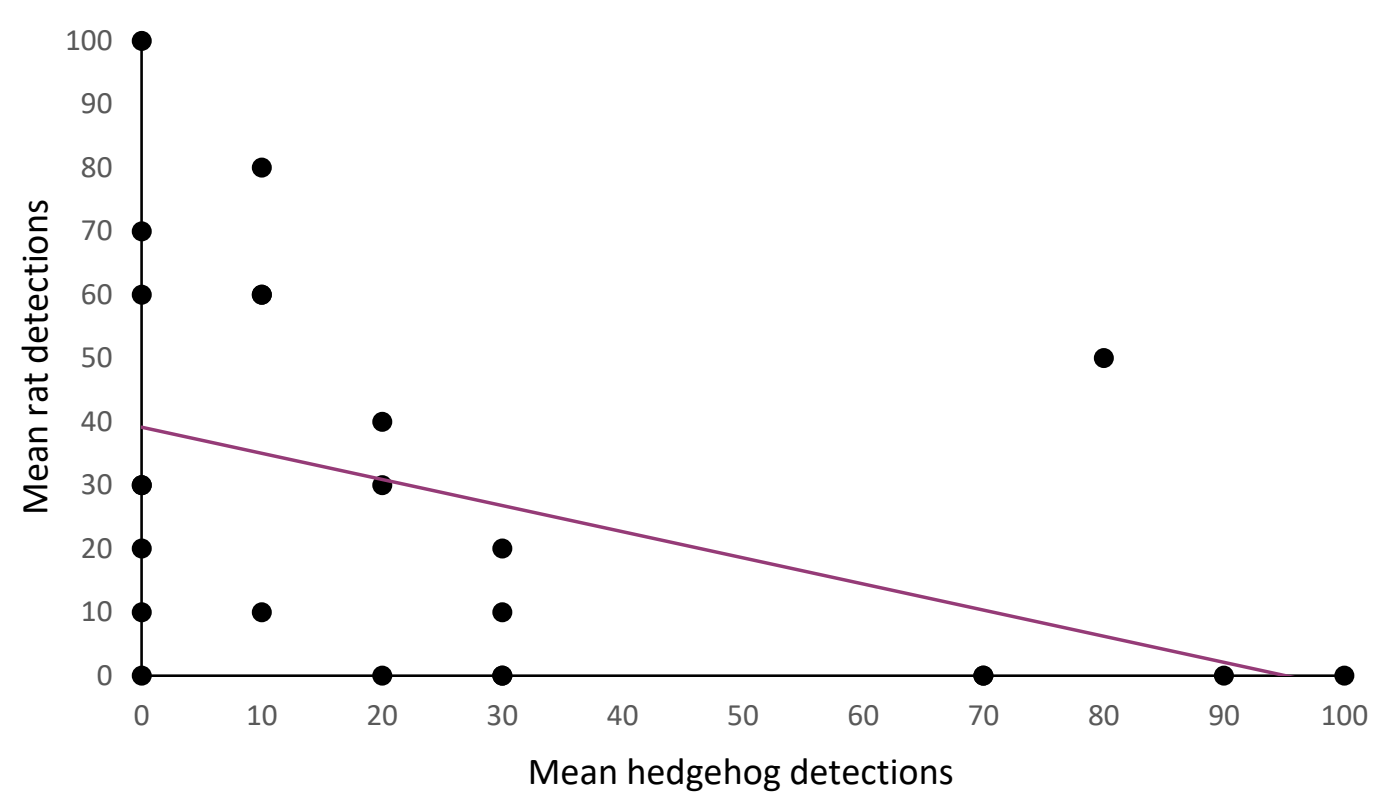

Figure 3.10: The relationship between the mean hedgehog detections and the mean rat detections across monitoring lines in autumn 2018.

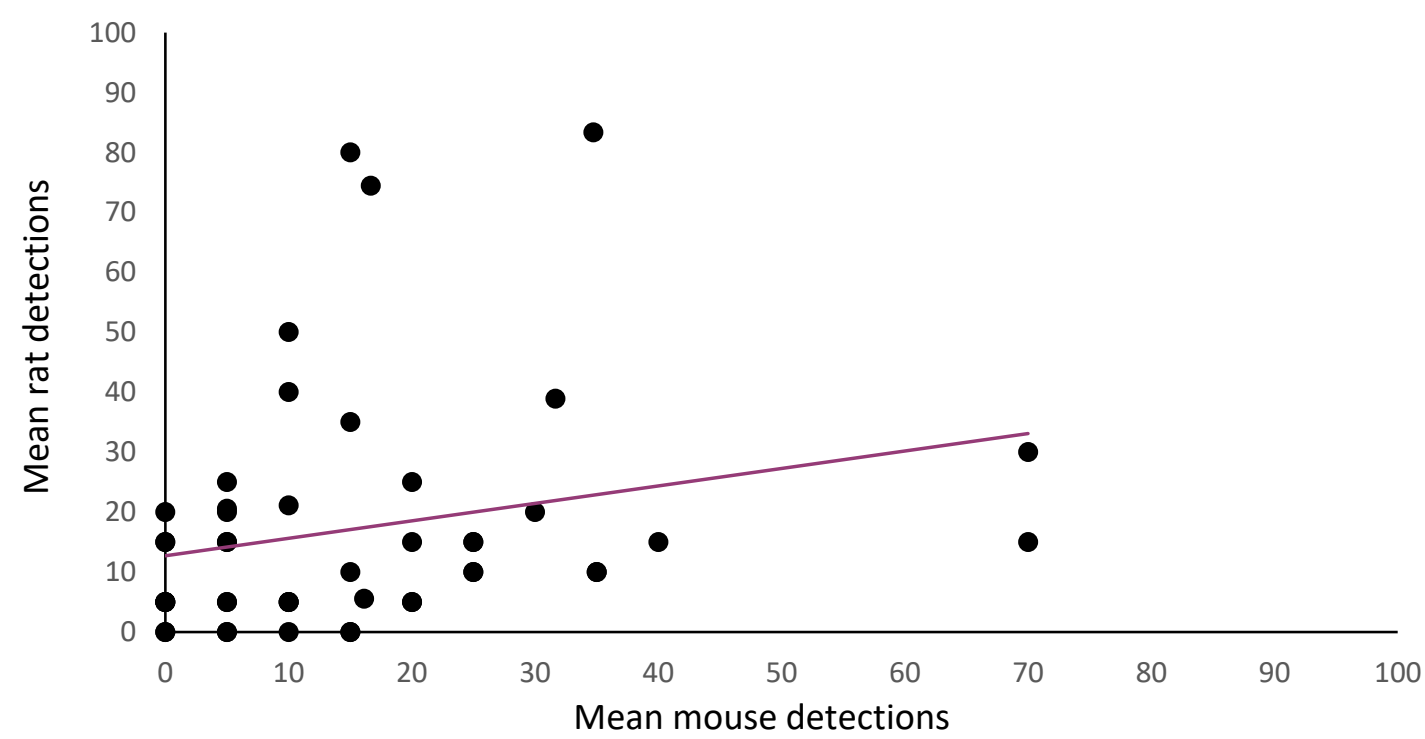

Figure 3.11: The relationship between the mean mouse detections and the mean rat detections across monitoring lines with one-night exposures of cards in spring 2017. 


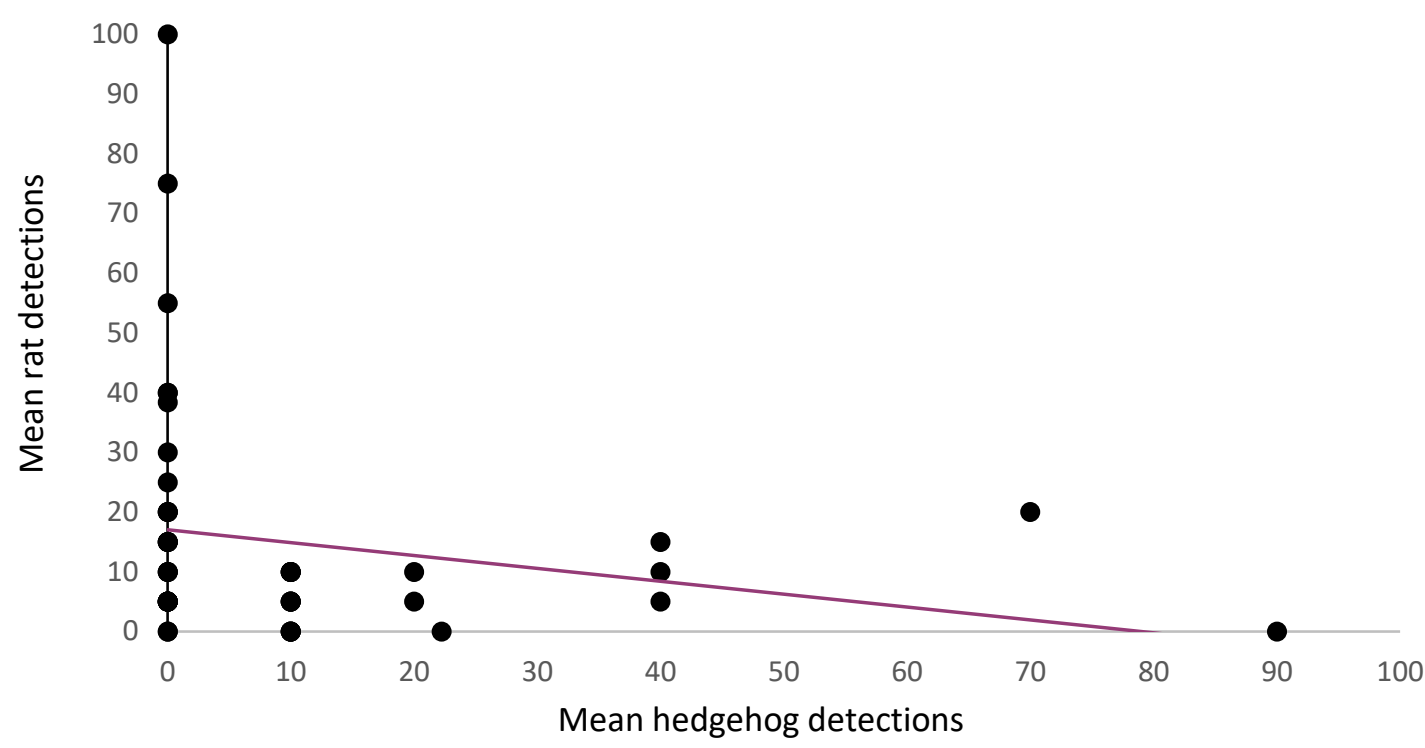

Figure 3.12: The relationship between the mean hedgehog detections and the mean rat detections across monitoring lines with six-night exposures of cards in autumn 2018.

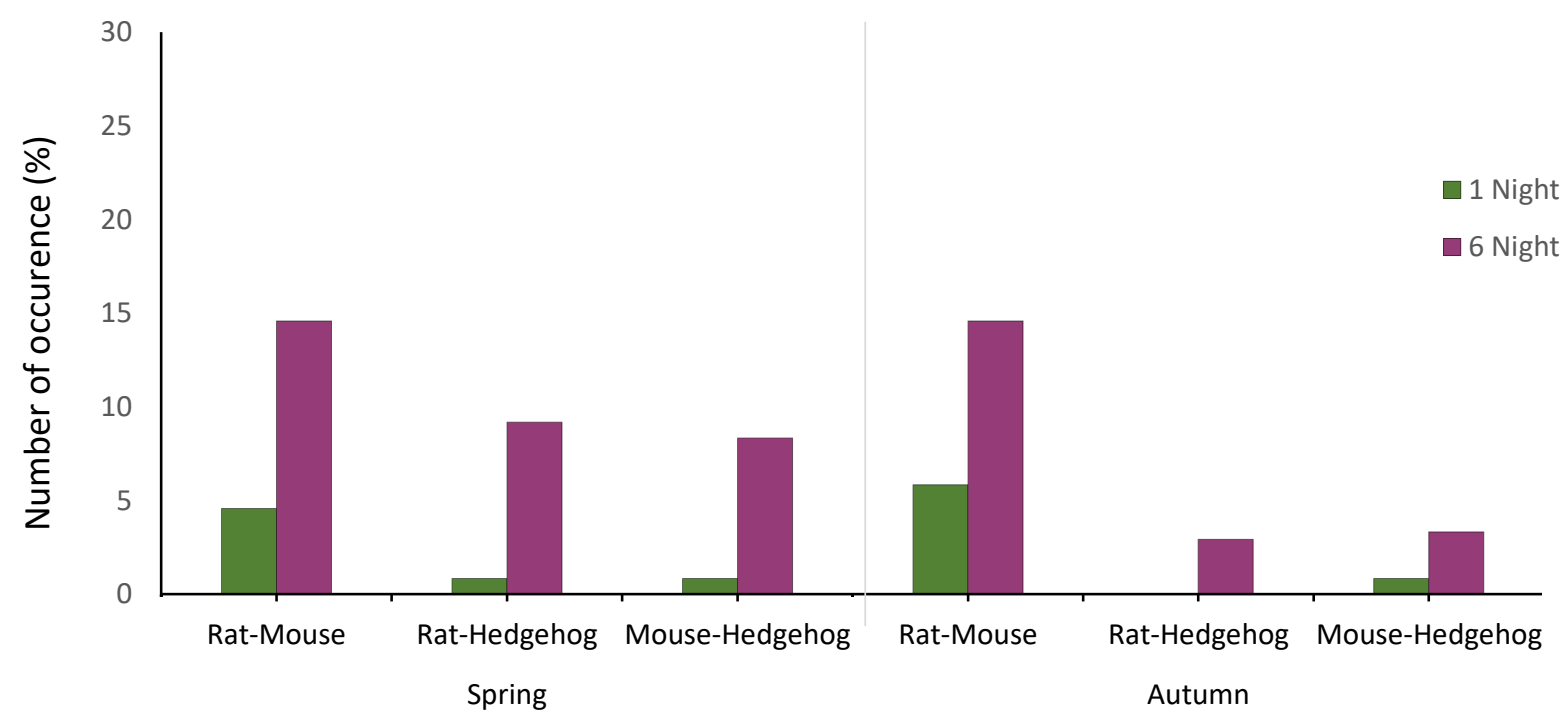

Figure 3.13: Mean percentage of species-species occurrences at the same site over a one-night and six-night monitoring period in the seasons of spring and autumn. 


\section{Discussion}

There are general city-wide differences in the detection rates of the monitored species. Dunedin was categorised by high detections of hedgehogs and possums, Wellington was categorised by the highest detections of rats and mice, and Hamilton was categorised as having moderate detections of all species. The observed differences could be explained by the differences in pest management. Wellington has invested a great deal of effort in the management of possums, whilst also having trapping programmes operating on council land for the control of rats and mice (Greater Wellington Regional Council, 2007). In 2003, the Greater Wellington Regional Council and the Wellington City Council successfully implemented the possum eradication programme on the Miramar Peninsula (Greater Wellington Regional Council, 2004). It is likely that the efforts occurring in Wellington have been a result of the minimal number of possum detections occurring. The Waikato Regional Council and Hamilton City Council have also reported several accounts of intensive pest control operations extending over three month periods, mostly in parks and areas of forest. Dunedin City council only controls possums up to four times a year via trapping lines which are only set over a four-night period (Dunedin City Council, 2018). However, without direct sources of information from the Dunedin City Council and the Hamilton City Council, reliable comparisons are unable to be made.

Only a small subset of the suite of variables tested were demonstrated to have an influence on species detections. Both broad scale and microhabitat variables were tested, however, it was the broad scale variables that had the most significant influences on species distribution. There was a strong seasonal variation in species detections between spring and autumn. The detection rates of rats and mice demonstrated an increase in autumn, whereas detections of hedgehogs and possums demonstrated a decrease. Without accompanying estimates of abundance it is difficult to suggest that population densities alter between seasons, however, the seasonal variation in detection of these species could be explained by seasonal changes in breeding, food sources or behaviour, such as home range size and hibernation.

Rats and mice have the potential to breed all year round, however, there is a higher proportion of females breeding in spring (Efford et al., 2006; Innes et al., 2001). As a result, rat and mice populations are at the highest densities over autumn and winter, when resources such as seed and fruit are also high (Choquenot \& Ruscoe, 2000; Efford et al., 2006; Innes et al., 2001). Increase in population densities are expected to translate to a greater chance that 
individuals will interact with tunnels. Furthermore, high population densities can result in the decline of natural food sources, thus encouraging individuals to visit baited devices as they provide a readily available source of food (Choquenot \& Ruscoe, 2000; Russell et al., 2008).

In autumn, there is an abundance of seasonally available fruits which contribute a large portion of the nutritional value in possum diets and may be eaten in large quantities during these months (Cowan, 2001; Glen et al., 2012; Nugent et al., 2000), potentially resulting in the reduced contact with baited monitoring devices. Alternatively, the seasonal behaviour of possums may alter detectability. The possum breeding season occurs in autumn (Ramsey et al., 2002), therefore, the increase in population sizes likely coincides with the monitoring occurring in late spring. Male possums are also more active in summer and early autumn (Cowan \& Clout, 2000), which somewhat coincides with the spring monitoring. The increased activity of males likely increases their chances of coming into contact with monitoring devices.

Broad scale habitat type did not have a strong influence on the entire assemblage of mammalian predators. Overall, mice had higher detections in amenity sites and possums had higher detections in forest sites across seasons. Rats and mice are known competitors of resources and space (Caut et al., 2007; Ruscoe et al., 2011; Yom-Tov et al., 1999). Rat detections were frequently higher in forest habitat than mouse detections, so the competitive interactions between the two species could have resulted in the displacement of mice to amenity areas. Alternatively, mice are commonly distributed in habitats that have a dense, low vegetation cover, particularly in the presence of other rodent species (Brown et al., 1996; Ruscoe, 2001). The amenity sites in the study were often dominated by small shrubs and bushes, or stands of dense, long grasses which would be suitable habitat for mice. However, the density of canopy cover was not reported to influence the distribution of mice in this study.

Possums were rarely present, if not absent, in amenity and residential habitats. The high detection in forest habitat could be explained by their diet and behavioural preference for moving through trees. The diet of possums consists of a diverse range of native and exotic foliage with the addition of fruits and flowers when available (Glen et al., 2012; Nugent et al., 2000). Several of the consumed species are woody trees which typically dominate forested areas (Nugent et al., 2000), therefore, the occupation of forest habitat might be largely a result of resource availability. 
A suite of microhabitat and landscape variables have the potential to influence species distributions, however, the variables that were examined in the study in Wellington did not provide many explanations for the distribution of rats, mice or hedgehogs in an urban environment. Rat detections were highest in areas of forest, and closer to the coast. The higher detection of rats in forests is likely similar to that of possums, and is largely based around the opportunity of resources. As Wellington lacks established populations of possums, the forest niche became available and rats were likely able to fill it due to the lack of competition from possums (Ruscoe et al., 2011; Sweetapple \& Nugent, 2007). The opportunity of resources is also postulated as a reason to why rats are located close to coastal areas. Due to their opportunistic nature, rats have been reported to prey on seabirds and their offspring, as well as other unexploited coastal resources (Caut et al., 2008; Dowding \& Murphy, 2001; Jones et al., 2008). However, the extent to which they utilise these environments has not been well documented.

Hedgehogs were not strongly influenced by factors of habitat, but instead were influenced by the presence of humans. In areas of high human populations, a higher number of hedgehogs were detected. Hedgehogs are opportunistic foragers and consume a diet largely of invertebrates over the spring and summer months (Jones et al., 2005). Spring and summer are the seasons in which rats consume the highest proportion of invertebrates (Daniel, 1973; McQueen \& Lawrence, 2008; Sweetapple \& Nugent, 2007), but, there is little documentation to suggest a competitive influence between the two species (Brockie, 1975). The postulated species interactions in Wellington instead suggest the contrary, with the declines in hedgehog detections during hibernation resulting in a higher detection of rats. Areas of high human population density are often linked with a high density of domestic animals, such as cats and dogs. Hedgehogs may utilise their adaptive defences to exploit highly populated areas, where predation by cats poses a greater risk to rats and mice (Gillies, 2001; Gillies \& Clout, 2003). Alternatively, urban areas are reported to provide additional resources, such as food and winter nest sites, which have been investigated as some of the drivers in previous studies (Brockie, 1975; Hubert et al., 2011; Morris \& Morris, 1988). Specifically, in spring, hedgehog detections declined with the increased distance of monitoring sites to waterways. Waterways are characteristic of damp and dense vegetation, which have the potential to provide hedgehogs with more suitable nest sites, and well as support their key invertebrate prey (Cameron et al., 2005; Shanahan et al., 2007). 
Predator control via trapping is one of the main forms of pest control in urban New Zealand. However, the high degree of trapping occurring across Wellington had a limited influence on species distributions when considered as a single variable. Information on the maintenance of traps, such as how frequent traps are checked and rebaited, was not often recorded by groups and was therefore not accounted for, but, it is highly likely that this factor influences species detections. When traps are sprung, they are inefficient at catching individuals, thus reducing the time for which the traps are actively trapping (Nelson \& Clark, 1973). Therefore, traps that are checked more frequently have a greater opportunity to catch individuals and as a result, are likely to influence species abundance and detection. Accounting for the effect of season and habitat did provide some insights into the influence of trapping. An increase in localised trap density (within a $25-50 \mathrm{~m}$ radius) was particularly influential in the decreased detections of rats in spring. The average home range of rats in a rural environment is approximately $0.86 \mathrm{ha}$, slightly greater than a radius of $50 \mathrm{~m}$. However, home ranges of rats living in urban areas tend to be much smaller as a result of physical barriers such as roads and other infrastructure (Byers et al., 2019; Desvars-Larrive et al., 2018) Thus, the increased number of traps within a $25 \mathrm{~m}$ and $50 \mathrm{~m}$ radius would likely provide a higher probability of interaction with smaller ranging individuals. The home range of urban hedgehogs could also have influenced the decrease of hedgehog detections within a $50 \mathrm{~m}$ radius. Nocturnal patterns of movement in urban hedgehogs have been studied in one context, and reported average home ranges of 2.87ha for males, and 0.77ha for females (Dowding et al., 2010), but, more information is required before an informative hypothesis can be made.

The microhabitat variables of canopy cover, and the distances of stations to waterways and forest fragments, were selected on the basis that they were proven to be influential variables in the distribution of mammalian predators within forests (Ruffell et al., 2015a). However, in urban sites, these same variables might not be as important. It is possible that there are other microhabitat and landscape variables that are influential, but were either not considered in the scope of this study, or were too difficult to measure. Factors such as vegetation composition, backyard structure and the degree of artificial landscape features are some possibilities that could have a greater contribution to distribution. Alternatively, mammalian predators may be more generalist species within urban environments, and categorised as a type of urban adapter (Hubert et al., 2011). Urban adapters are species that have been able to adapt to the urban environment and make use of the new resources. Urban adapters are behaviourally flexible, and are capable of changing their behaviour to utilise and thrive off of urban 
resources, such as food and shelters (Hubert et al., 2011; Kark et al., 2007; Shochat et al., 2006). However, cities in New Zealand are quite different from those categorised in other countries. New Zealand cities often consist of the combination of urban development and greenspaces. Across six cities, urban development was between $66.3 \%$ and $87.3 \%$ of the land cover, with the remaining $13-30 \%$ of non-urban land cover largely dominated by a variety of green spaces (e.g. grasslands, forest, scrub) (Woolley et al., 2018, unpublished). The percentage of greenspaces within cities also varies with distance from the urban core (Clarkson et al., 2007). The percentage of greenspaces that persist in the urban core ranges from $0-8.9 \%$, and often increases with distance from the core (Clarkson et al., 2007). However, there is great variability in the percentage of green spaces between cities. For example, Wellington is collectively made up of $24.1 \%$ indigenous vegetation, $35.4 \%$ nonindigenous vegetation and 39.5\% is urbanised area (Rastandeh et al., 2018). The presence of vast areas of vegetation, as well as the introduced opportunities and resources present within urban areas, makes urban environments a highly favourable habitat for introduced mammalian predators. With the diversity of factors to consider, and few identified patterns of distribution, it is yet unknown how influential the trapping of mammalian predators will be within urban ecosystems. Coordinated possum control, often using bat stations, does have the potential to significantly reduce and locally eradicate possums, as demonstrated by Miramar peninsular in Wellington (Greater Wellington Regional Council, 2004), however, it is currently unknown how these methods will influence other mammalian predators. 


\section{Chapter 4}

\section{A summary of council-led and community-led urban trapping in Wellington, and the influence of environmental variables on trap catches}

\section{Introduction}

Government enforced control efforts on rats, mice, possums and mustelids are well established in New Zealand and achieved via several methods, with the goal of minimising their impacts on native flora and fauna (Gillies et al., 2003; Russell et al., 2015; Towns et al., 2013) as well as their impacts on agricultural productivity (Forsyth et al., 2005; Sweetapple $\&$ Nugent, 2011). The two main methods of pest control in New Zealand are the use of toxins in the form of poison baits, and several varieties of traps, each targeted at a select range of species. Poison baits, such as brodifacoum and sodium fluoroacetate (1080), are deployable baits that act effectively to target possums and rodents (Innes et al., 1995). This method of control requires less of an energetic investment than the likes of trapping. In several operations, the two methods are often used in conjunction for the most effective control. Trapping can be expensive and difficult to maintain over a large scale, as traps require strategic placement and frequent checks to be most effective (Brown et al., 2015). Areas that have only used traps in the past have often utilised toxins as the use of traps was ineffective at controlling reinvasions (Brown et al., 2015). However, in urban ecosystems, the use of poisons is more constrained due to the increased risk of contact with people and domestic mammals (Carter et al., 2016). Poison baits are still deployed in areas of urban forest, however, traps are the most widely used form of control in residential parks and suburbs.

Council-led predator control programmes have been established in Wellington since the early 2000's, alongside some community-led initiatives that have adopted public reserves and riparian zones. However, only since 2013 has widespread community-led trapping in residential areas (so-called "backyard" trapping) been implemented. Through the Enhancing the Halo project led by the Morgan Foundation, the initiative aimed to introduce backyard trapping to Wellington. This led to the formation of Predator Free Crofton Downs, the first coordinated backyard trapping group organised by Kelvin Hastie. With the introduction of the Predator Free Wellington initiative in 2016 (pfw.org.nz), approximately 43 community groups are now established and involved in trapping. Two types of community groups have been identified: residential trapping groups which consist of householders maintaining one or 
two of their own backyard traps, and reserve trapping groups, which consist of a small group of people who service several trap lines within a forested or coastal reserve area.

Council-led predator control has largely targeted species of rats and possums, as these species are believed to pose the biggest threats to native flora and fauna (Ruffell et al., 2015a; Wellington City Council, 2004). However, the introduction of community trapping has led to the control of a wider array of species, with hedgehogs, rats and mice as common captures. These groups trap a large number of small mammals and collect highly valuable data on the relative presence of introduced mammals that can be combined with monitoring data to gain a more comprehensive understanding of management outcomes. Even when control is considered to be intensive, the populations of mammalian predators may still be too high to protect the more sensitive species (Gillies, 2002a; Ruffell et al., 2015a). Therefore, analysing catch data is essential.

Trap catch data from community groups is commonly stored on platforms such as Trap.NZ and without permission, this data is inaccessible for public purposes. To date, community group data has not been analysed in public journals, nor provided publically in a form for which data can be viewed without compromising the privacy of the many volunteers involved in the groups. Therefore, the aim of this chapter was to compile trapping information from various community groups in Wellington City and summarise their trapping efforts and trap catches over a fifteen-month period, quantifying the density of traps and the number of catches per season. This information will then be analysed against various microhabitat variables to assess where trapping efforts are most successful.

\section{Methods}

\section{Data collection}

A letter was sent out to the coordinators of various residential and reserve trap groups across Wellington City, formally requesting access to their data via Trap.NZ or other platforms of collection. Data on trap location and catches were extracted from the period of November 2017 to January 2019. This time period was specified as it coincides with the first monitoring that occurred for the People, Cities and Nature project, and spans over a year to include seasonal variation. Earlier data was not included to limit the size of the data to be compiled. All trap groups were contacted regardless of their areas not being included in the monitoring 
sites, to gain a city-wide view of mammal presence via trap catches in the past year. Some data was unobtainable due to permissions and the nature of the databases in which they were stored, however, trap data were compiled for 26 groups. Only 22 groups provided data on trap type and thus four groups were removed from summaries. Data reporting trap catches were reduced further, and compiled for 18 groups (Table 4.2). Additional data on councilowned traps in public reserve were provided by Wellington City Council. Data were imported into ArcMap version 10.5.1 and a map of the wider Wellington City was created. Trap information collected from trap groups was consolidated into a density map for display where individual households could not be determined, thus, maintaining individual privacy (Figure 4.1). A density map of traps was created for residential areas via the density tool in ArcMap. The number of traps within a 200x200m square grid, which equates to an area of 4 hectares, was displayed as specified by the privacy guidelines of Trap.NZ (trap.nz). Utilising the near tool, the distance of the nearest coast, stream and bush fragment to traps with recorded catches were measured. Although it is not a complete dataset of trapping across Wellington, it can still provide some useful knowledge on the activity that is occurring across a large area of the city.

\section{Statistical analyses}

All analyses were performed in $\mathrm{R}$ version 3.5 .2. Summaries were conducted to identify the common trap types and mammal catches across Wellington city, whilst individually assessing these variables between residential areas and reserves. Pearson correlations were performed to assess if the total number of traps within a trap group had an influence on the total number of catches at that site. The influence of trap density on the total catches at specified traps was assessed by calculating the number of traps that fall within a 100m radius of known catches. Trap density was calculated in ArcMap utilising the spatial join tool. Total catches at an individual trap between November 2017 and January 2019 were calculated for rats, mice, hedgehogs, stoats and weasels, to assess whether the increased number of traps within an area influenced the number of catches. Linear models $(\mathrm{lm})$ were fitted to assess the direction of potential relationships. Trap density and season, and trap density and area, were combined to assess if there was any interactive influence that might assist in explanation.

Generalised linear mixed effects models (GLMM's) were individually performed on trap catch data for rats, mice, hedgehogs, stoats and weasels, to assess if various environmental 
factors had an influence on the species caught in traps, accounting for trap ID and suburb as random variables where models would allow (Table 4.1). Trap ID was included as a random variable as several recorded catches were often from the same trap. All models were fitted to the dataset which contained catch data for both residential and reserve traps. Brooklyn, Island Bay and Wild Aro data were removed from the dataset as they did not consist of all the variables being tested against. Karori data were removed from the dataset as distances could not be obtained without specific coordinate information on ArcMap thus, trap catch data were only assessed for 14 of the trap groups. For two species, full models containing the total six variables did not converge, hence a reduced model testing which combination of variables would converge for stoats and weasels was performed. Trap type was the only variable removed in stoat and weasel models, however the influence of trap type on these species was still tested in separate models. Type III ANOVA's and post-hoc Tukey tests were run on significant variables to compare the relationships between all possible variations. Separate models were performed on the combination of season and area to assess whether there was an interactive effect. Season was included in the model to discern if there is seasonal variation in the number of individuals being caught.

Utilising the estimates obtained from GLMM models, trap catch prediction maps were created in ArcMap using the raster calculator tool. Intercept and estimate values of habitat type, and the distance to the nearest coast, stream and bush fragment, were input into ArcMap and heat maps predicting the probability that a given location would result in catches of rats, mice, hedgehogs, stoats or weasels were generated. 
Table 4.1: Fixed effects for the GLMM models assessing the influence of environmental variables on trap catches across Wellington City.

\begin{tabular}{lccc}
\hline \hline Fixed effects & Median & Min & Max \\
\hline Distance to bush fragment (m) & 62.41 & 0 & 624.97 \\
Distance to coast (m) & 668.88 & 0.72 & 3070.18 \\
Distance to stream (m) & 281.39 & 0.04 & 1953.21 \\
\hline & Categories & $\mathbf{N}$ \\
\hline Land ownership & Residential, reserve & 2 \\
Season & Spring, summer, autumn, & 4 \\
& winter & \\
& Victor, DOC 200, A24, & \\
Trap type & Snap E Rat, mouse trap, & \\
& Cage trap, DOC250, & 11 \\
& DOC150, Ka mate, T-Rex, & \\
& unspecified & \\
\hline \hline
\end{tabular}


Table 4.2: A list of the 43 recorded trap groups within Wellington City. The right column details what data I have obtained from each trapping group to discern which groups were included in which analyses.

\begin{tabular}{|c|c|c|c|}
\hline Residential & Trap locations & Trap types & Trap catches \\
\hline \multicolumn{4}{|l|}{ Conservation Highbury } \\
\hline \multicolumn{4}{|l|}{ Crofton Downs Predator Free Community } \\
\hline Otari Predator Free & $\checkmark$ & & \\
\hline \multicolumn{4}{|l|}{ Pest Free South Makara } \\
\hline \multicolumn{4}{|l|}{ Pest Free Tawa } \\
\hline \multicolumn{4}{|l|}{ Predator Free Broadmeadows } \\
\hline Predator Free Brooklyn & $\checkmark$ & $\checkmark$ & $\checkmark$ \\
\hline Predator Free Churton Park & $\checkmark$ & & \\
\hline \multicolumn{4}{|l|}{ Predator Free Glenside } \\
\hline \multicolumn{4}{|l|}{ Predator Free Grenada Village } \\
\hline Predator Free Houghton Valley & $\checkmark$ & $\checkmark$ & $\checkmark$ \\
\hline Predator Free Island Bay & $\checkmark$ & $\checkmark$ & $\checkmark$ \\
\hline \multicolumn{4}{|l|}{ Predator Free Johnsonville } \\
\hline Predator Free Karori & $\checkmark$ & $\checkmark$ & $\checkmark$ \\
\hline Predator Free Khandallah & $\checkmark$ & & \\
\hline \multicolumn{4}{|l|}{ Predator Free Kilbirnie } \\
\hline \multicolumn{4}{|l|}{ Predator Free Lyall Bay, Rongotai and Melrose } \\
\hline Predator Free Miramar & $\checkmark$ & $\checkmark$ & $\checkmark$ \\
\hline Predator Free Mt Cook, Newtown and Berhampore & $\checkmark$ & $\checkmark$ & $\checkmark$ \\
\hline Predator Free Mt Victora, Oriental Bay, Roseneath and Haitaitai & $\checkmark$ & $\checkmark$ & $\checkmark$ \\
\hline \multicolumn{4}{|l|}{ Predator Free Newlands, Paparangi and Woodridge } \\
\hline Predator Free Ngaio & $\checkmark$ & $\checkmark$ & $\checkmark$ \\
\hline Predator Free Northland & $\checkmark$ & $\checkmark$ & $\checkmark$ \\
\hline Predator Free Seatoun & $\checkmark$ & $\checkmark$ & $\checkmark$ \\
\hline \multicolumn{4}{|l|}{ Predator Free Thorndon } \\
\hline Rodent Free Wadestown & $\checkmark$ & & \\
\hline Wild Aro & $\checkmark$ & $\checkmark$ & \\
\hline \multicolumn{4}{|l|}{ Reserves } \\
\hline Birdwood Rat Trapping & $\checkmark$ & $\checkmark$ & $\checkmark$ \\
\hline \multicolumn{4}{|l|}{ Brooklyn Trail Builders } \\
\hline Places for Penguins & $\checkmark$ & $\checkmark$ & $\checkmark$ \\
\hline \multicolumn{4}{|l|}{ Friends of Tawa Bush Reserves } \\
\hline Katch 22 (Makara Peak) & $\checkmark$ & $\checkmark$ & \\
\hline Kumutoto & $\checkmark$ & $\checkmark$ & \\
\hline Mt Victoria Vermin Trappers & $\checkmark$ & $\checkmark$ & $\checkmark$ \\
\hline Polhill Protectors & $\checkmark$ & $\checkmark$ & $\checkmark$ \\
\hline Predator Free Ngaio Reserves & $\checkmark$ & $\checkmark$ & $\checkmark$ \\
\hline RAMBO (Rats and Mustelid Blitzing Otari) & $\checkmark$ & $\checkmark$ & $\checkmark$ \\
\hline Scorching Bay/Mahanga Bay Trap Network & $\checkmark$ & $\checkmark$ & $\checkmark$ \\
\hline Tanera Gully Restoration Project & $\checkmark$ & $\checkmark$ & $\checkmark$ \\
\hline \multicolumn{4}{|l|}{ Tapu Te Ranga Rat Busters } \\
\hline Te Motu Kairangi & $\checkmark$ & $\checkmark$ & $\checkmark$ \\
\hline \multicolumn{4}{|l|}{ Trelissick Park Group } \\
\hline Upstream (Friends of Central Park) & & & \\
\hline
\end{tabular}




\section{Results}

Trap types

Over 7000 traps were recorded across residential areas and reserves in Wellington, and a total of ten different trap types were recorded in varying quantities across these sites (Figure 4.1). Residential areas consisted of the trapping that is occurring specifically in residential backyards. Reserves consist of the trapping networks that are maintained by both community groups and Wellington City Council. Victor, DOC 200 and Snap E Rat traps were the most common trap types to occur across Wellington, totalling over $80 \%$ of all recorded traps (Figure 4.2).

Residential areas recorded over three times the number of traps that were recorded in reserves. The types of traps deployed in backyards ranged from small mouse traps to larger DOC 200 traps, and vary in the number deployed around households. From the eight residential trap groups that provided data on trap types, 5733 traps were recorded. Several households had recorded at least two separate traps on a single property, often of a different type. Approximately $21 \%$ of trap owners possessed more than one trap, with approximately 99\% of those being of a different type (Figure 4.3). Victor traps and Snap E Rat traps were the two most common traps occurring in residential areas. Of all the traps recorded, these two types totalled to over $75 \%$. A further $15 \%$ of traps consisted of standard rat traps and supplementary Snap E Mouse traps. All the remaining trap types occurred in less than $10 \%$ of backyards (Figure 4.2).

In most reserve areas, only a single trap was deployed at each location. Only $4 \%$ of all trap sites contained more than one trap, often a supplementary mouse trap placed within the larger trap box (Figure 4.3). Two trap types make up a large portion of the total traps deployed. Like residential areas, Victor traps were a common trap type occurring in reserves. The Victor traps were largely reported as rat traps, although 8 of the total traps consisted of Victor stoat traps. DOC 200 traps were the most common type of trap to occur in reserves, making up over 50\% of all reported traps. The self-resetting A24 traps only made up 7\% of the total reserve traps recorded, however, they are almost twice as common when compared to residential groups (Figure 4.2). 


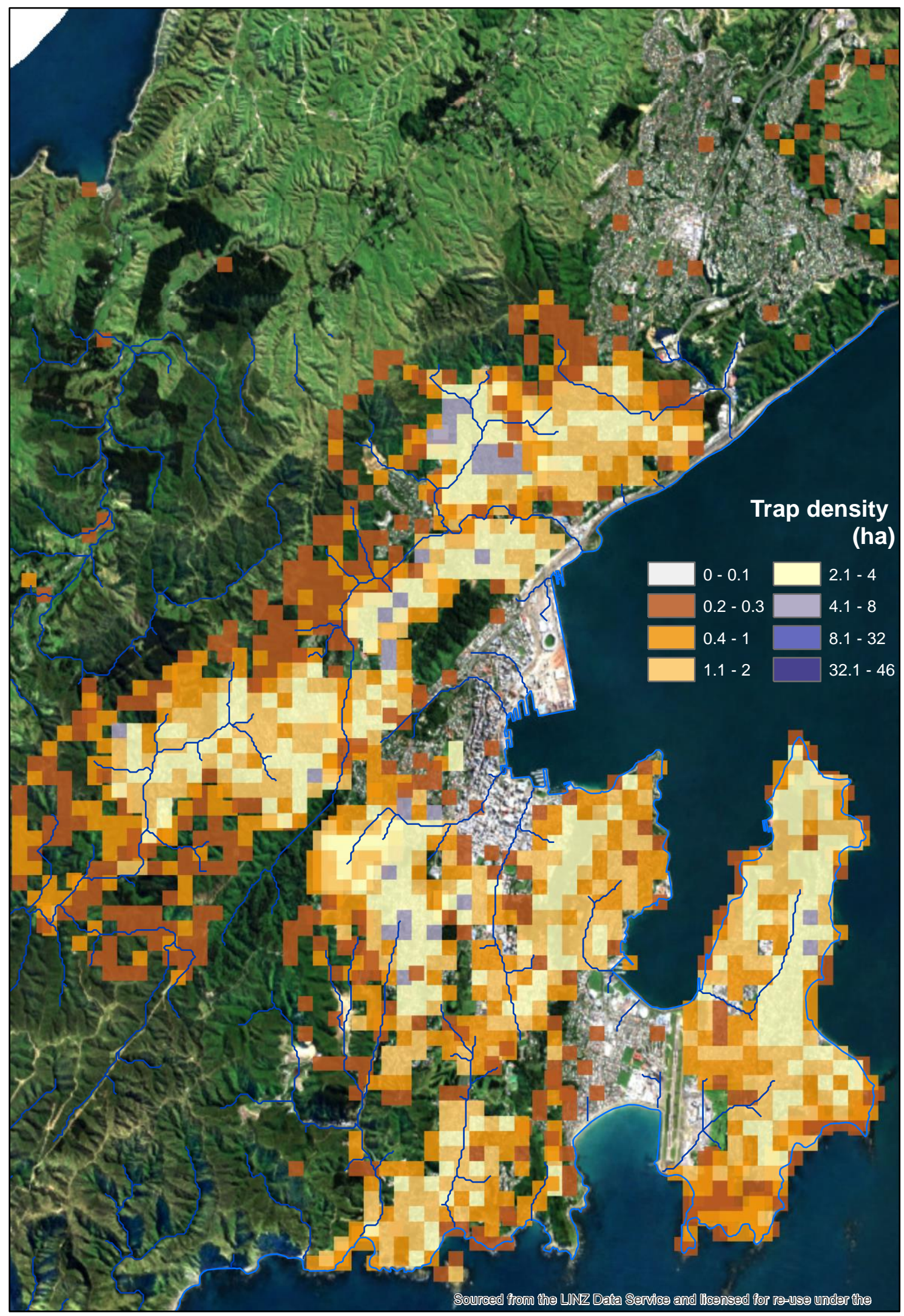

Figure 4.1: Map of the Wellington City area, depicting the recorded trapping across various residential and reserve sites. Trap density is displayed as a heat map, representing density per hectare over 4 hectare $(200 \mathrm{mx} 200 \mathrm{~m})$ grid cells. Sites that only provided trap location data are included on the map to visualise the extent of traps across Wellington. Background image was sourced from LINZ and used in ArcMap 10.5.1 


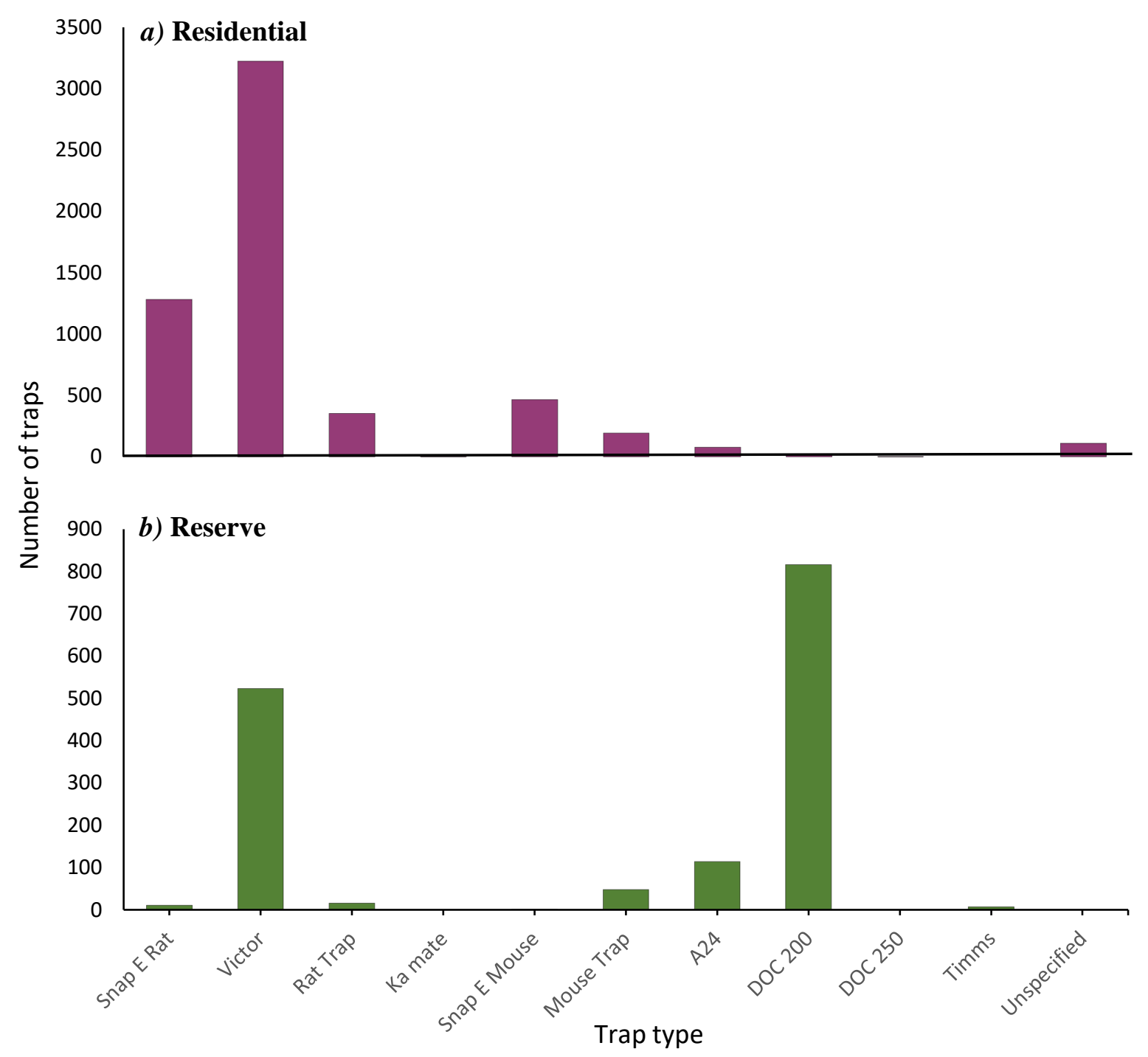

Figure 4.2: The number of each specified trap type occurring across $a$ ) residential sites ( $\mathrm{n}=11$ trap groups) and b) reserve sites ( $\mathrm{n}=11$ trap groups) within Wellington City. Note the change in scale on the y axis.

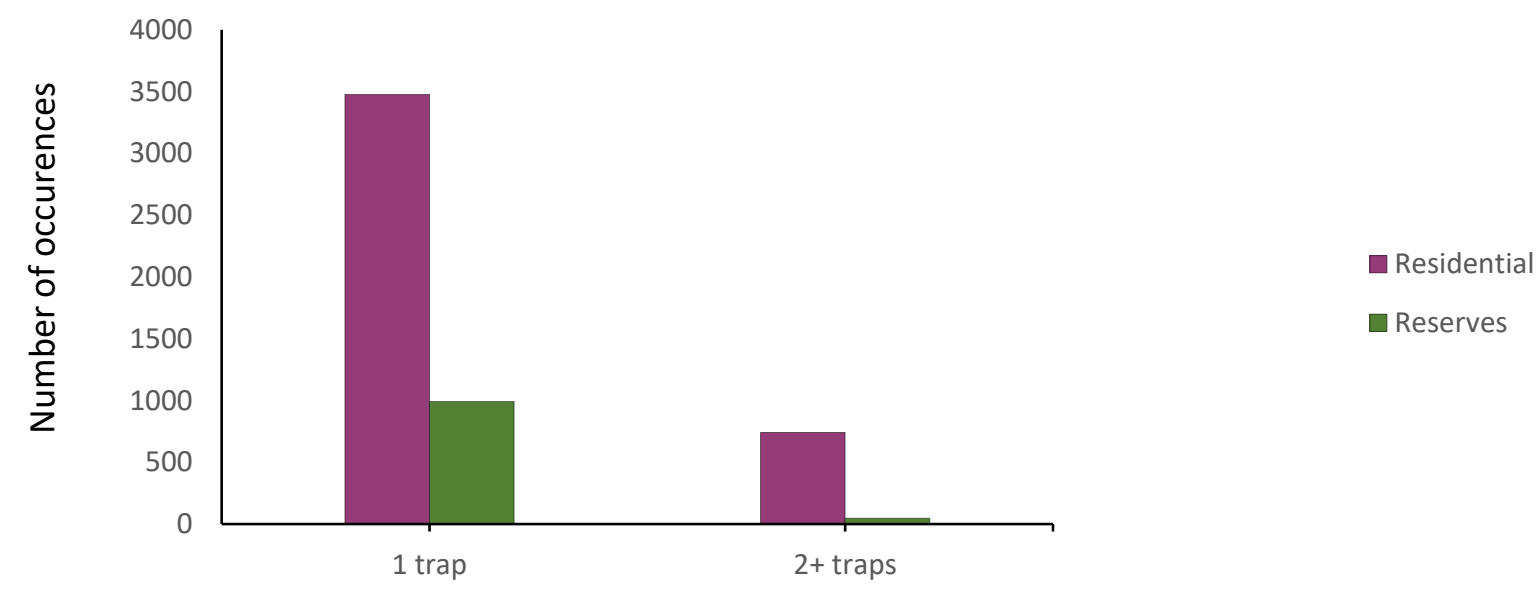

Figure 4.3: The total number of occurrences at which just one trap, or more than one trap, was located in a single backyard or reserve site. 
Relationship between trap number and trap catches

There is a strong correlation between the number of traps within a trap group and the number of trap catches made (Table A3.1). With the increase in the number of traps within a trap group, there is an associated increase in the total number of reported catches. In particular, the number of traps is positively associated with the number of reported rat, mouse and hedgehog catches across groups (Figure 4.4). Mustelids, such as stoats and weasels, were rarely caught in traps regardless of the number of traps within a group.

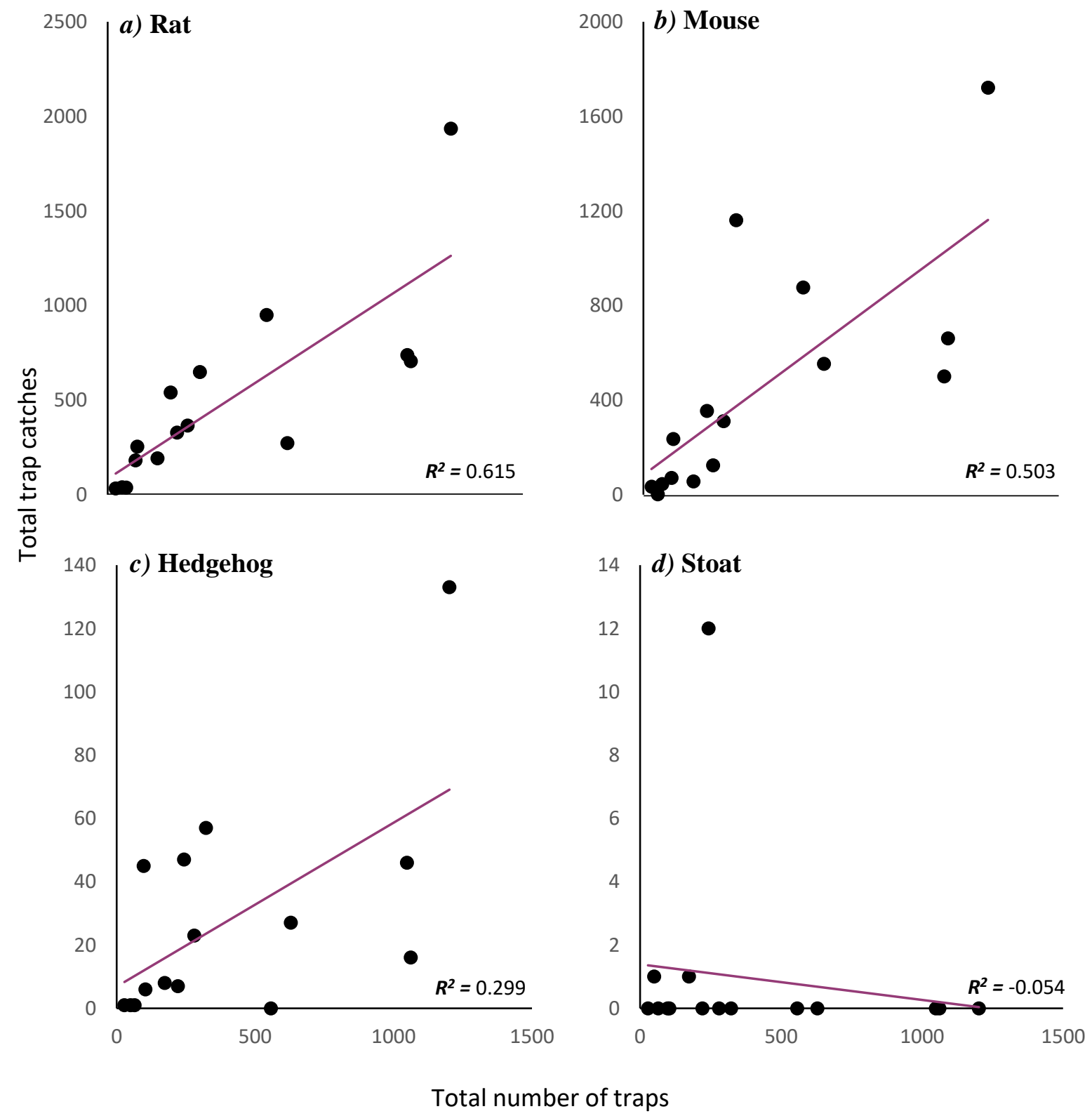




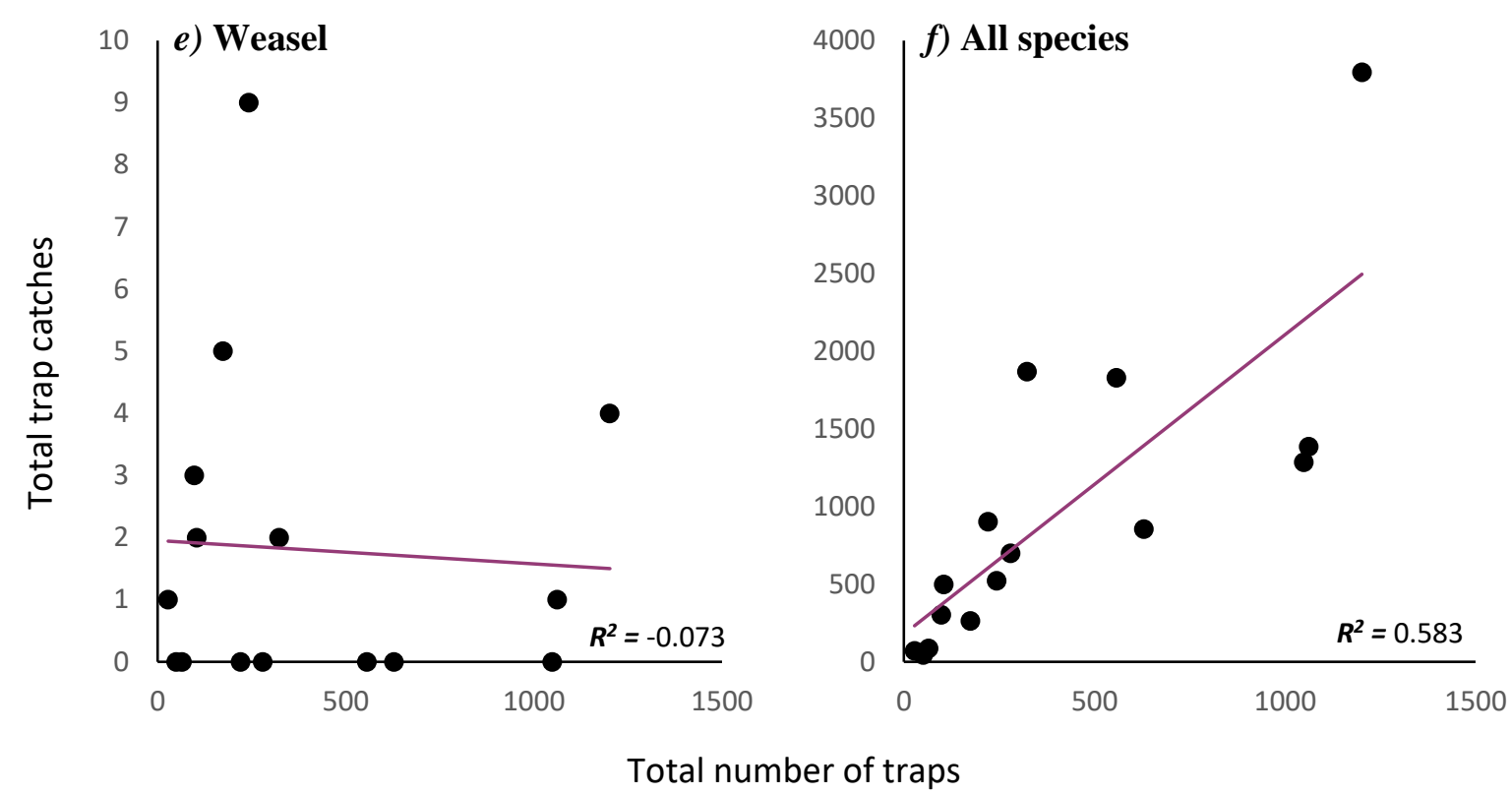

Figure 4.4: The influence of the number of traps on the total number of recorded trap catches. Associated $R^{2}$ values are reported at the bottom of each plot.

The density of traps within a 100m radius of reported catches only influenced catches of mice, hedgehogs, stoats and weasels. In all cases, the increased number of traps within a trap group resulted in a decrease in catches of mice, hedgehogs, stoats and weasels (Table 4.3). The variability in trap catches explained by trap density accounted for less than $1 \%$ for the three species.

When seasonal patterns of catches were considered, trap density influenced catches of mice, hedgehogs and weasels (Table 4.3). A greater number of mice and weasels were caught in autumn than in spring or summer, with the increase in trap density. The opposite trend was apparent for hedgehogs. A greater number of hedgehogs were caught in summer than autumn, with the increase in trap density. Results imply that the importance of trap density is seasonal in selected species.

When land ownership was considered, trap density influenced catches for four of the five total species assessed (Table 4.3). The increase in trap density in reserves resulted in a greater number of mouse catches when compared with residential sites. However, the increase in trap density in residential sites resulted in a greater number of hedgehog, stoat and weasel catches when compared with reserves. 
Overall, less than $3 \%$ of the variability in all trap catches were attributed to trap density and its interaction with season and site type, indicating that other variables may be more influential.

Table 4.3: GLMM table reporting the influences of trap density, and its interaction with land ownership and season, on the catches of mammalian predators

\begin{tabular}{lcccc}
\hline \hline a) Rat & Estimate & Std. Error & $\mathrm{t}$ value & $\operatorname{Pr}(>|\mathrm{t}|)$ \\
\hline Trap density & -0.004 & 0.01 & -0.33 & 0.74 \\
Area*Trap density & 0.000 & 0.01 & -0.04 & 0.97 \\
Spring*Trap density & -0.003 & 0.02 & -0.21 & 0.83 \\
Summer*Trap density & 0.002 & 0.02 & 0.10 & 0.92 \\
Winter*Trap density & -0.017 & 0.02 & -1.04 & 0.30 \\
\hline \hline
\end{tabular}

\begin{tabular}{lcccc}
\hline \hline b) Mouse & Estimate & Std. Error & $\mathrm{t}$ value & $\operatorname{Pr}(>|\mathrm{t}|)$ \\
\hline Trap density & 0.033 & 0.013 & 2.512 & 0.01 \\
Area*Trap density & -0.052 & 0.015 & -3.410 & $<0.001$ \\
Spring*Trap density & -0.040 & 0.019 & -2.121 & 0.03 \\
Summer*Trap density & -0.001 & 0.019 & -0.050 & 0.96 \\
Winter*Trap density & -0.011 & 0.019 & -0.597 & 0.55 \\
\hline \hline
\end{tabular}

\begin{tabular}{lcccc}
\hline \hline c) Hedgehog & Estimate & Std. Error & t value & $\operatorname{Pr}(>|\mathrm{t}|)$ \\
\hline Trap density & -0.008 & 0.002 & -3.769 & 0.00 \\
Area*Trap density & 0.007 & 0.002 & 2.654 & 0.01 \\
Spring*Trap density & 0.005 & 0.003 & 1.732 & 0.08 \\
Summer*Trap density & 0.006 & 0.003 & 1.965 & 0.05 \\
Winter*Trap density & 0.003 & 0.003 & 1.011 & 0.31 \\
\hline \hline
\end{tabular}

\begin{tabular}{lcccc}
\hline \hline d) Stoat & Estimate & Std. Error & $\mathrm{t}$ value & $\operatorname{Pr}(>|\mathrm{t}|)$ \\
\hline Trap density & -0.002 & 0.000 & -5.551 & $<0.001$ \\
Area*Trap density & 0.002 & 0.000 & 4.705 & $<0.001$ \\
Spring*Trap density & 0.000 & 0.001 & 0.593 & 0.55 \\
Summer*Trap density & 0.000 & 0.001 & 0.218 & 0.83 \\
Winter*Trap density & 0.000 & 0.001 & 0.604 & 0.55 \\
\hline \hline
\end{tabular}




\begin{tabular}{lcccc}
\hline \hline e) Weasel & Estimate & Std. Error & $\mathrm{t}$ value & $\operatorname{Pr}(>|\mathrm{t}|)$ \\
\hline Trap density & -0.003 & 0.001 & -5.024 & $<0.001$ \\
Area*Trap density & 0.003 & 0.001 & 4.262 & $<0.001$ \\
Spring*Trap density & -0.001 & 0.001 & -0.843 & 0.40 \\
Summer*Trap density & -0.002 & 0.001 & -2.890 & $<0.001$ \\
Winter*Trap density & -0.001 & 0.001 & -1.963 & 0.05 \\
\hline \hline
\end{tabular}

\section{Influence of microhabitat variables and trap type on catches}

Over 15,000 trap catches were recorded across Wellington between November 2016 and January 2019. Of the total catches, over $95 \%$ were of rats and mice alone (Figure 4.5). Rats and mice were the highest caught predators, making up $47 \%$ and $49 \%$ respectively, of all reported catches across residential and reserve sites (Figure 4.5). Hedgehogs were caught more infrequently than rats and mice and only made up $2.6 \%$ of the total catches. However, 402 hedgehogs were caught in total across 14 of the groups included in the dataset which remains a substantial number. Mustelids were rarely caught in traps and made up less than $1 \%$ of all catches. Overall, stoats were only caught 14 times, and weasels only 26 times over a year long period. Traps in residential sites caught almost three times as many individuals as reserve traps, with a total of 11,725 reported individuals caught. A total of 3569 individuals were recorded for all reserves assessed, however, the percentages of species captured is highly consistent between the two site types (Figure 4.5).

Rats accounted for $45-47 \%$ of catches in residential and reserve sites, with a strong seasonal variation in catches. There was an increase in the number of rats caught in autumn in comparison to the other three seasons, with catches demonstrating a general decline after their peak in May (Figure 4.6 and 4.7). Season, trap type, and the distance of traps to the nearest stream were all influential variables in the captures of rats (Table 4.5). Victor, rat traps (unspecified and Snap E), and mouse traps were all highly influential types in the captures of rats compared to A24 and DOC 200 traps. There was an increase in the number of rats caught with the use of Victor and rat traps, which caught comparatively more rats than mouse traps. Traps that were deployed with increased distance from streams also recorded more catches of rats. There is a $26-34 \%$ probability that rats will be caught within a close proximity to streams, but a 66-79\% probability around coasts (Figure 4.8). The combination 
of these variables explained $45 \%$ of the variation in rat catches when suburb and trap ID were considered $\left(R_{m}^{2}=0.1309, R_{c}^{2}=0.4512\right)$.

Mice accounted for $48-50 \%$ of catches in residential and reserve sites, with approximately three times more mice captured in residential traps. Seasonal differences were also present in the captures of mice. There was an increase in the number of mice caught in autumn in comparison to the other three seasons, with catches demonstrating a general decline after their peak in April (Figure 4.6 and 4.7). Site type, season, trap type, and the distance of traps to the nearest stream were all influential variables in the captures of mice (Table 4.5). Victor, rat traps (unspecified and Snap E), and mouse traps were all highly influential trap types in the captures of mice compared to A24 and DOC 200 traps. However, mouse traps catch comparatively more mice than Victor and rat traps. The proximity of traps to streams reported the opposite pattern from rats, with traps in a closer proximity to streams instead reporting more catches of mice (Table 4.5). There is a 58-63\% probability that mice will be caught with proximity to streams, and reduces to $36-43 \%$ near the coast (Figure 4.9). The combination of these variables explained only $18.2 \%$ of the variation in mouse catches when suburb was considered $\left(R^{2}{ }_{m}=0.1653, R_{c}^{2}=0.1817\right)$.

There were a greater number of hedgehogs caught in residential sites than reserves, however, hedgehogs accounted for $2 \%$ more of the proportion of total catches in reserves (Figure 4.5). The influence of land ownership on hedgehog catches was insignificant if trap ID was included, suggesting that several of the hedgehog catches are coming from specific traps. Catches of hedgehogs were high in both summer and autumn, with the most catches occurring in summer (Figure 4.6 and 4.7). The magnitude of these seasonal changes in catch numbers differs considerably between residential and reserve sites and, in all cases, the number of hedgehog catches is higher in reserves (Table A3.3). Season, trap type, and the distances to the nearest coast and stream were all influential variables in the captures of hedgehogs (Table 4.5). A24 and DOC 200 traps were highly influential trap types in the captures of hedgehog's compared to all other trap types. A24 and DOC 200 traps were the only two types to catch significantly higher numbers of hedgehogs (Table 4.5). With an increasing distance from the coast and a closer proximity to streams, a greater number of hedgehog catches were reported, with a 7-21\% probability of catching hedgehogs at these sites (Figure 4.10). The combination of these variables explained $76.6 \%$ of the variability in hedgehog catches when suburb was considered $\left(R^{2}{ }_{m}=0.5320, R_{c}^{2}=0.7659\right)$. It is highly uncommon for models in ecology to report such large $R^{2}$ values. It can be noted that these 
combination of variables do influence hedgehog catches, however, caution should be taken when interpreting the weight that the variables influence hedgehog catches.

Although only 26 individual weasels were captured over the fifteen-month period, the type of site in which they were caught was highly influential. Weasel catches were higher in reserves, where 24 of the 26 total catches occurred (Figure 4.5). The influence of trap type could not be assessed for weasels due to the limited amount of data on catches. However, all of the recorded weasel catches were from a combination of DOC 200, Victor and unspecified rat traps. The distance of traps to the nearest bush fragment and coast was an important variable in the catches of weasel. Weasel catches demonstrated a decline with the increasing distance from the coast and bush fragment (Table 4.5). Overall, the probability of catching weasels in Wellington is predicted at less than $3 \%$, however, the highest probabilities occur close to the coast (Figure 4.11)

Only 14 stoats were captured in traps over the year long period. The influence of trap type could not be assessed for stoats due to the limited amount of data on catches. However, all of the recorded stoat catches were reported from DOC 200 traps. Overall, no microhabitat variables significantly influenced stoat catches.

Table 4.4: GLMM table reporting the influence of area and season on the trap catches of rats, mice, hedgehogs, stoats and weasels. Area results are reporting the influence of residential sites in comparison to reserves, and season results are reporting the influence of spring in comparison to autumn catches.

\begin{tabular}{lcccc}
\hline \hline Rat & Estimate & Std. Error & $\mathrm{z}$ value & $\operatorname{Pr}(>|\mathrm{z}|)$ \\
\hline Area & -0.28713 & 0.09238 & -3.108 & 0.6990 \\
Season & 0.16395 & 0.04252 & 3.856 & $<0.001$ \\
\hline \hline
\end{tabular}

\begin{tabular}{lcccc}
\hline \hline Mouse & Estimate & Std. Error & z value & $\operatorname{Pr}(>|\mathrm{z}|)$ \\
\hline Area & -0.54224 & 0.09845 & 5.508 & $<0.001$ \\
Season & -0.21547 & 0.04323 & -4.985 & $<0.001$ \\
\hline \hline
\end{tabular}

\begin{tabular}{lcccc}
\hline \hline Hedgehog & Estimate & Std. Error & $\mathrm{z}$ value & $\operatorname{Pr}(>|\mathrm{z}|)$ \\
\hline Area & -0.9654 & 0.1236 & -7.812 & $<0.001$ \\
Season & 0.3838 & 0.11 & 3.488 & $<0.001$ \\
\hline \hline
\end{tabular}




\begin{tabular}{lcccc}
\hline \hline Stoat & Estimate & Std. Error & $\mathrm{z}$ value & $\operatorname{Pr}(>|\mathrm{z}|)$ \\
\hline Area & -3.581 & 3.6096 & -0.992 & 0.3210 \\
Season & -0.7574 & 0.99 & -0.765 & 0.4440 \\
\hline \hline
\end{tabular}

\begin{tabular}{lcccc}
\hline \hline Weasel & Estimate & Std. Error & $\mathrm{z}$ value & $\operatorname{Pr}(>|\mathrm{z}|)$ \\
\hline Area & -2.9429 & 0.5622 & -5.234 & $<0.001$ \\
Season & 0.3852 & 0.3865 & 0.996 & 0.3190 \\
\hline \hline
\end{tabular}

Table 4.5: Type III ANOVA table reporting the influence of microhabitat variables of trap catches of $a$ ) rats, $b$ ) mice, $c$ ) hedgehogs and $d$ ) weasels.

\begin{tabular}{lccc}
\hline \hline a) Rat & Chisq & df & $\operatorname{Pr}(>$ Chisq $)$ \\
\hline Distance to stream & 44.24 & 1 & $<0.001$ \\
Distance to bush & 0.18 & 1 & 0.67 \\
Distance to coast & 3.20 & 1 & 0.07 \\
Trap type & 268.13 & 11 & $<0.001$ \\
\hline \hline
\end{tabular}

\begin{tabular}{lccc}
\hline \hline b) Mouse & Chisq & df & $\operatorname{Pr}(>$ Chisq $)$ \\
\hline Distance to stream & 28.93 & 1 & $<0.001$ \\
Distance to bush & 0.18 & 1 & 0.67 \\
Distance to coast & 0.01 & 1 & 0.92 \\
Trap type & 485.04 & 11 & $<0.001$ \\
\hline \hline
\end{tabular}

\begin{tabular}{lccc}
\hline \hline c) Hedge hog & Chisq & df & $\operatorname{Pr}(>$ Chisq) \\
\hline Distance to stream & 41.39 & 1 & 0.00 \\
Distance to bush & 0.00 & 1 & 0.95 \\
Distance to coast & 47.15 & 1 & 0.00 \\
Trap type & 182.65 & 11 & $<0.001$ \\
\hline \hline
\end{tabular}

\begin{tabular}{lccc}
\hline \hline d) Weasel & Chisq & df & $\operatorname{Pr}(>$ Chisq) \\
\hline Distance to stream & 1.33 & 1 & 0.25 \\
Distance to bush & 6.22 & 1 & 0.01 \\
Distance to coast & 3.27 & 1 & 0.07 \\
\hline \hline
\end{tabular}




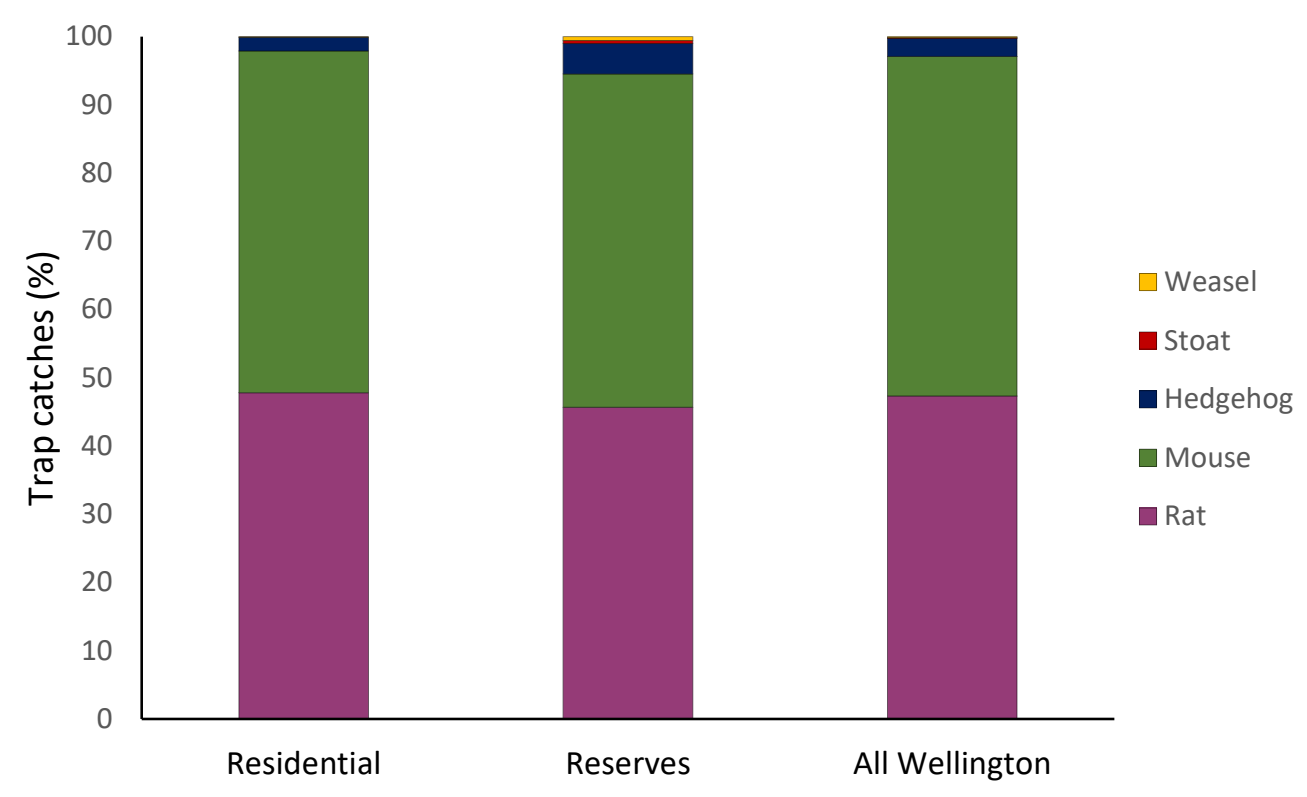

Figure 4.5: The percentage of species catches in residential sites, reserve sites, and the total percentage of all catches across Wellington City for the five listed species.

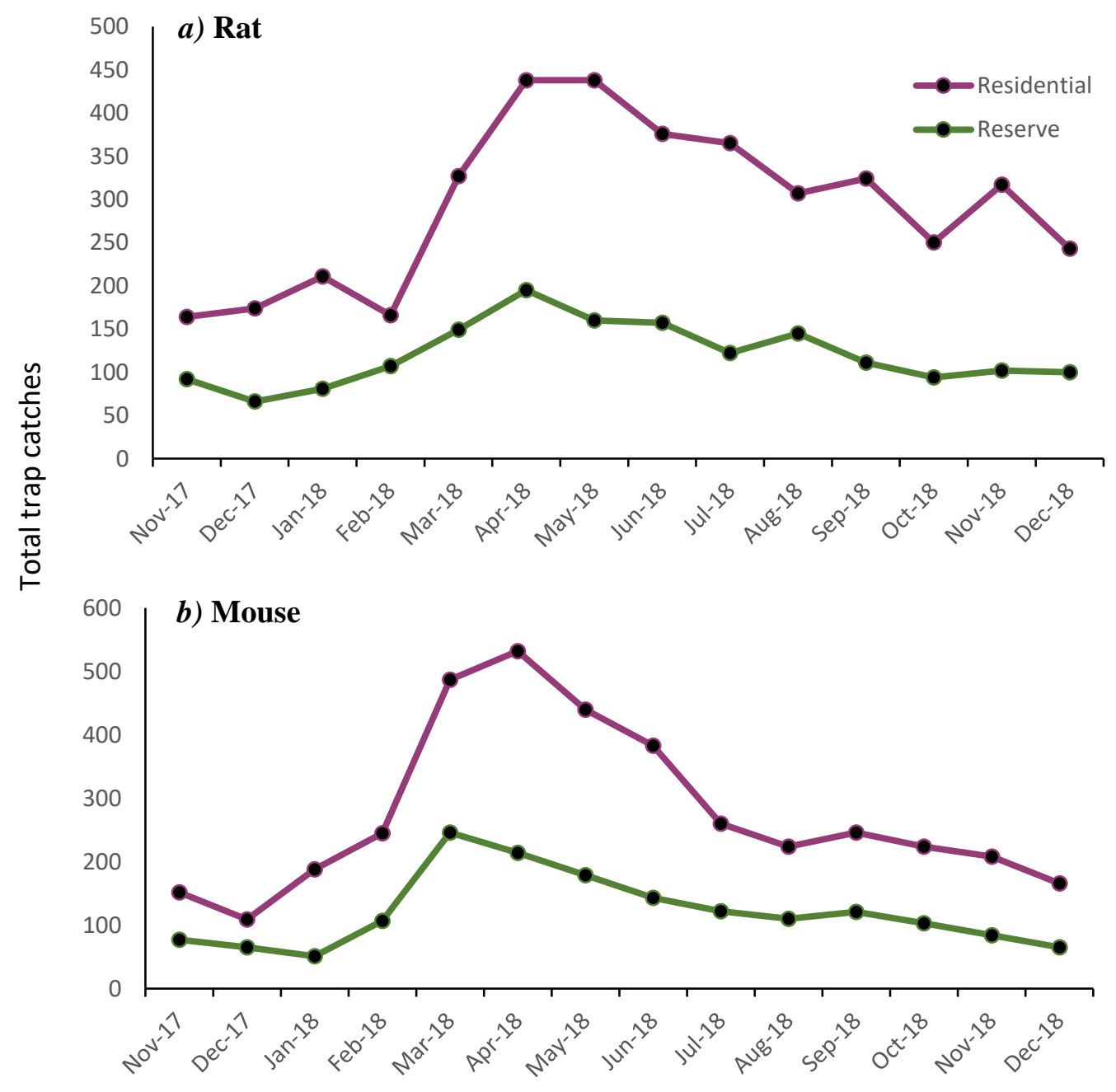




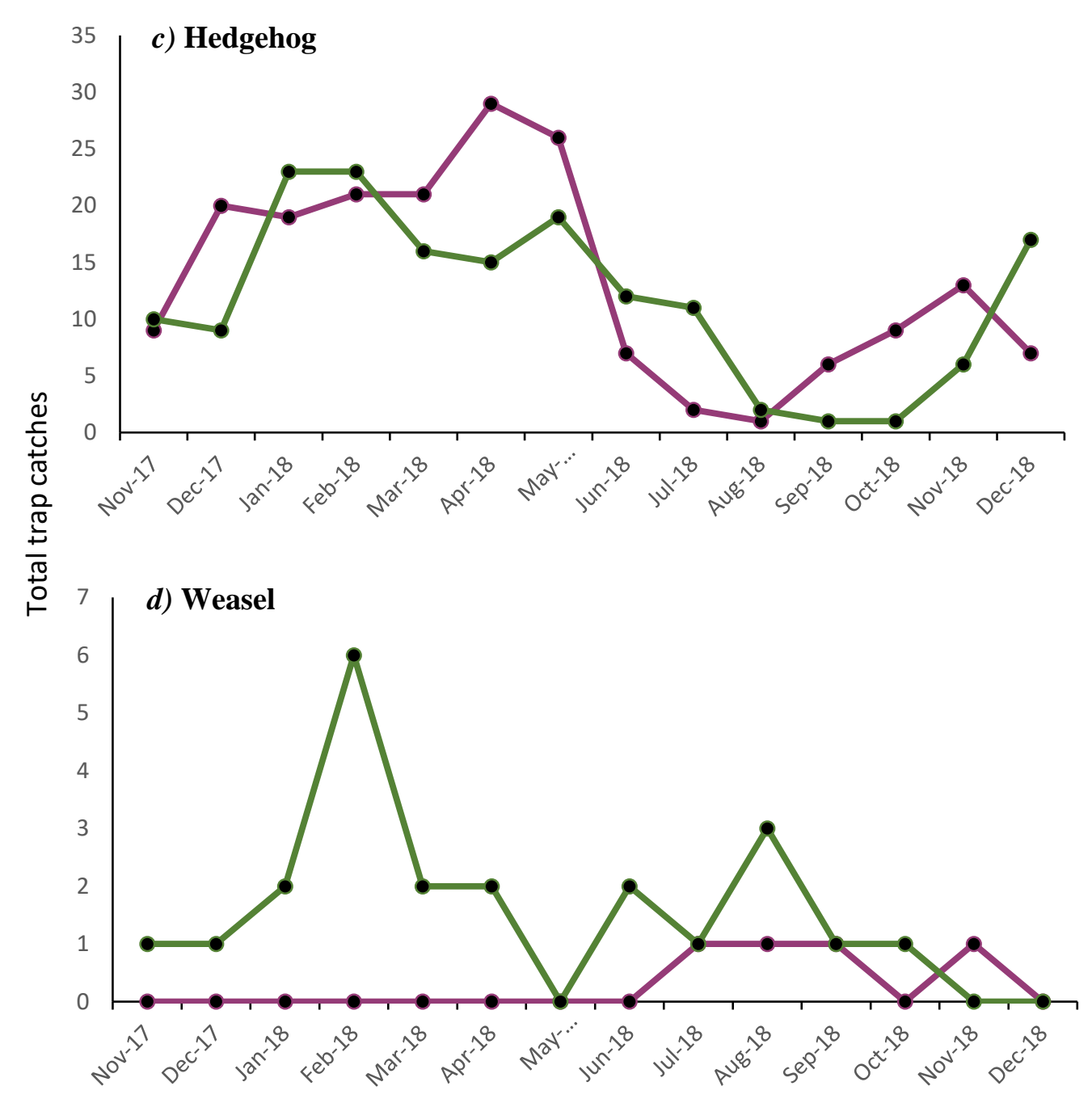

Figure 4.6: Total monthly catches across 14 trapping groups in Wellington for $a$ ) rats, $b$ ) mice, $c$ ) hedgehogs and $d$ ) weasels. 
a) Rat

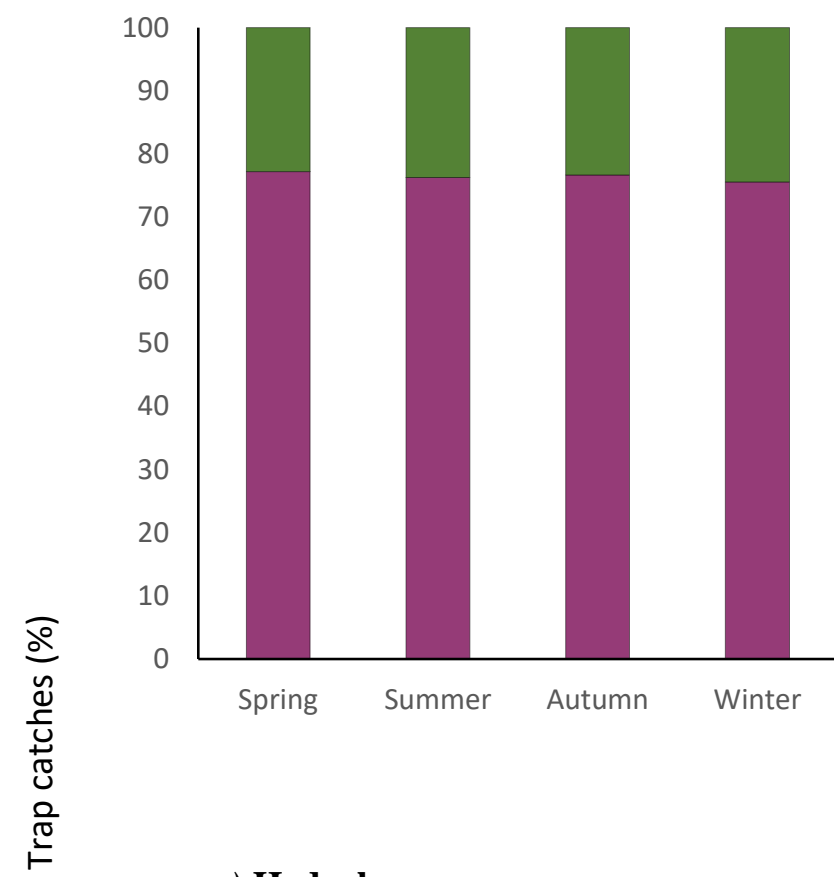

c) Hedgehog

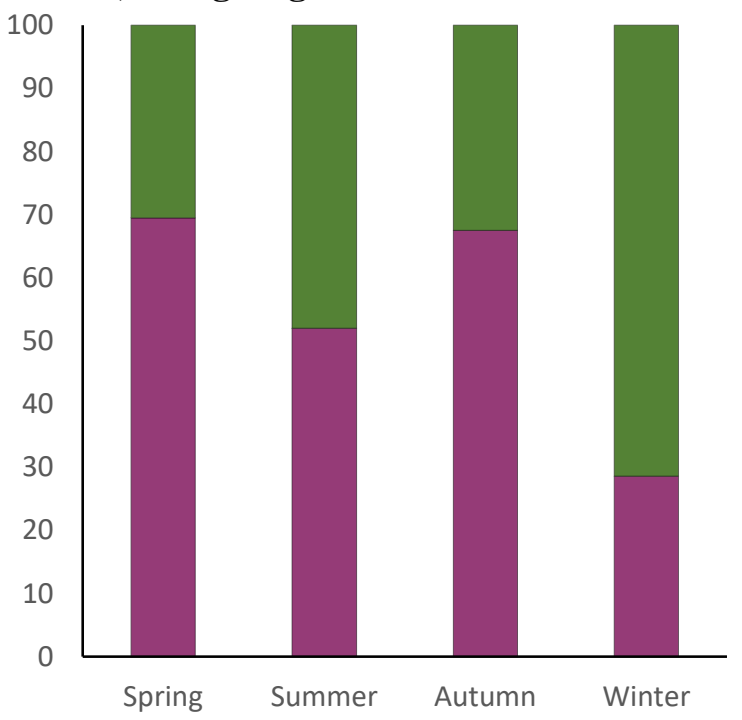

b) Mouse

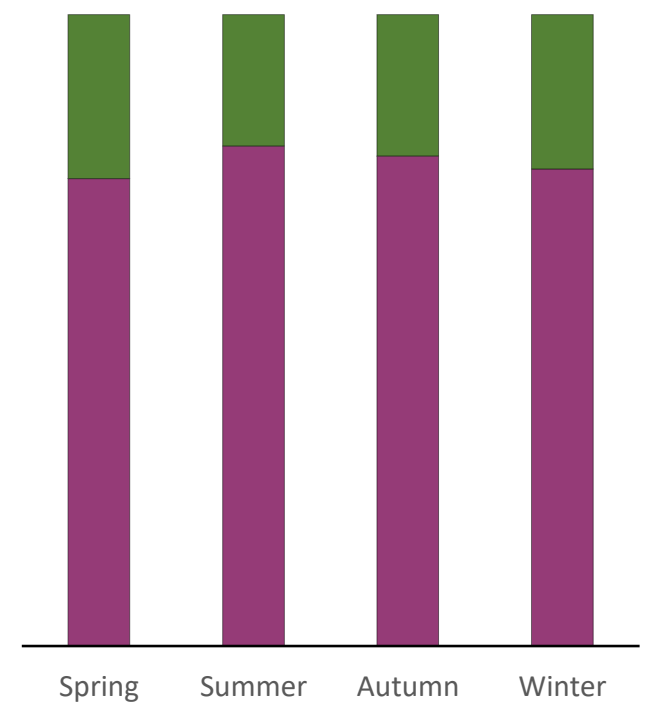

d) Weasel

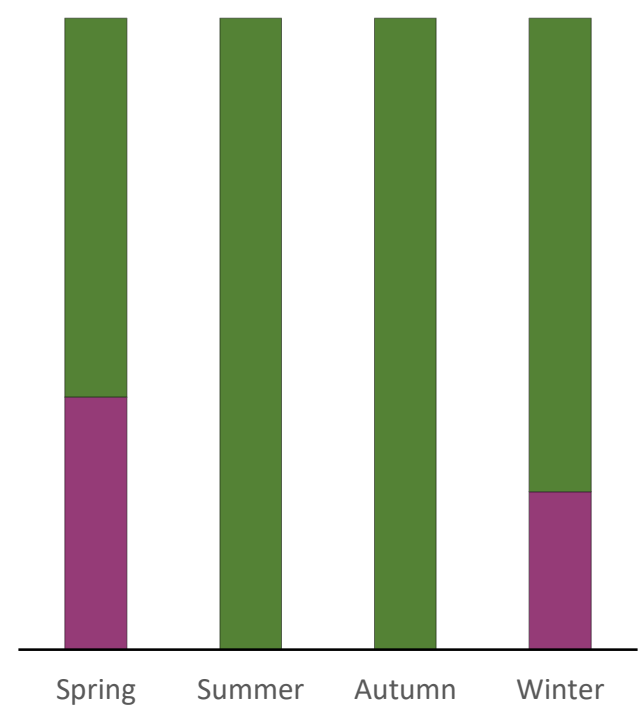

$\square$ Residential $\square$ Reserve

Figure 4.7: The percentage of species catches in residential and reserve traps across the four seasons. Both rats and mice consistently have a higher catch rate in residential traps irrespective of season. 


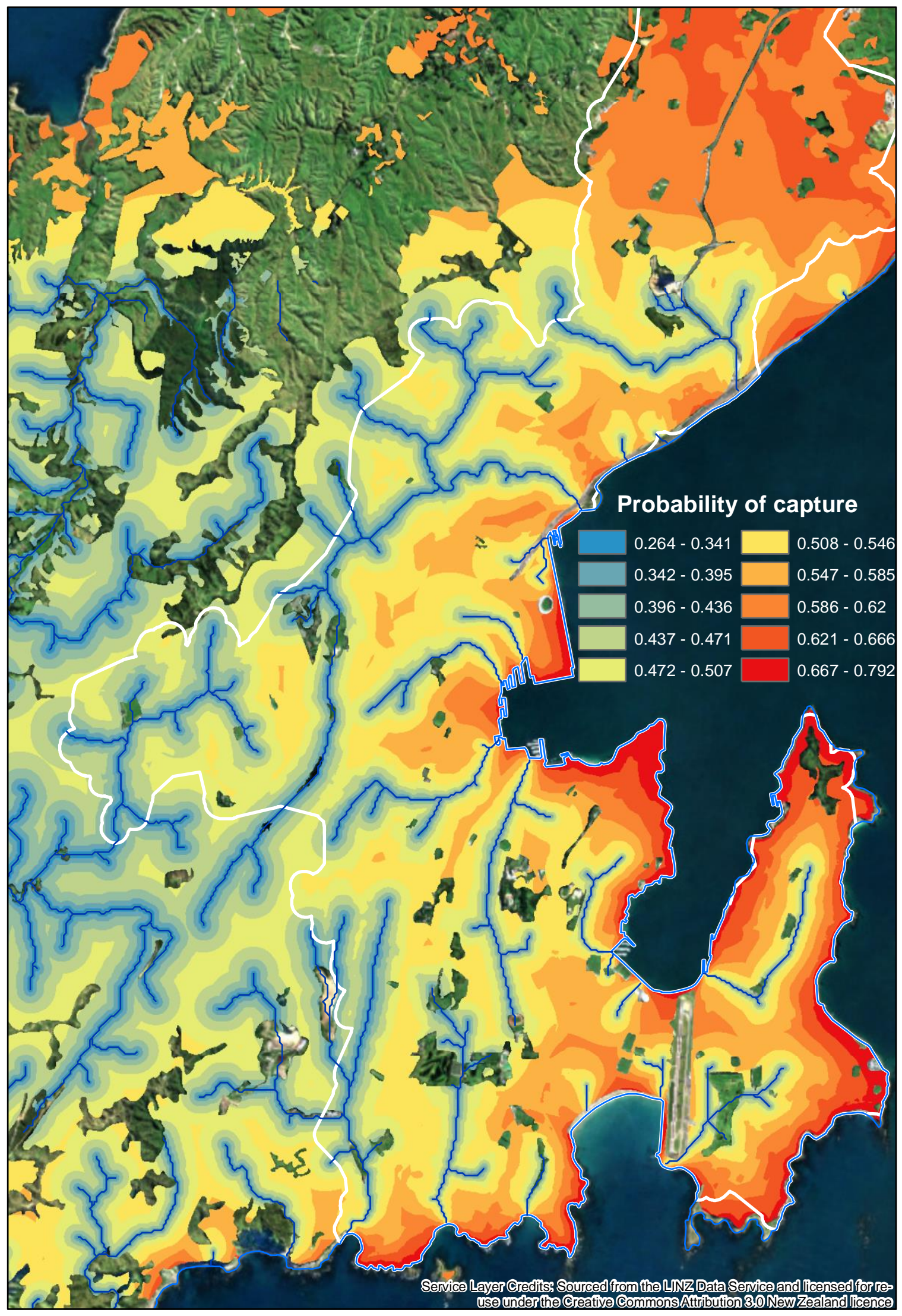

Figure 4.8: Rat catch predictions for Wellington City. Map depicts the probability of rat capture within a given location. White line outlines the main boundary between the Wellington core and surrounding forest.

Background image was sourced from LINZ. Map created using ArcMap 10.5.1. 


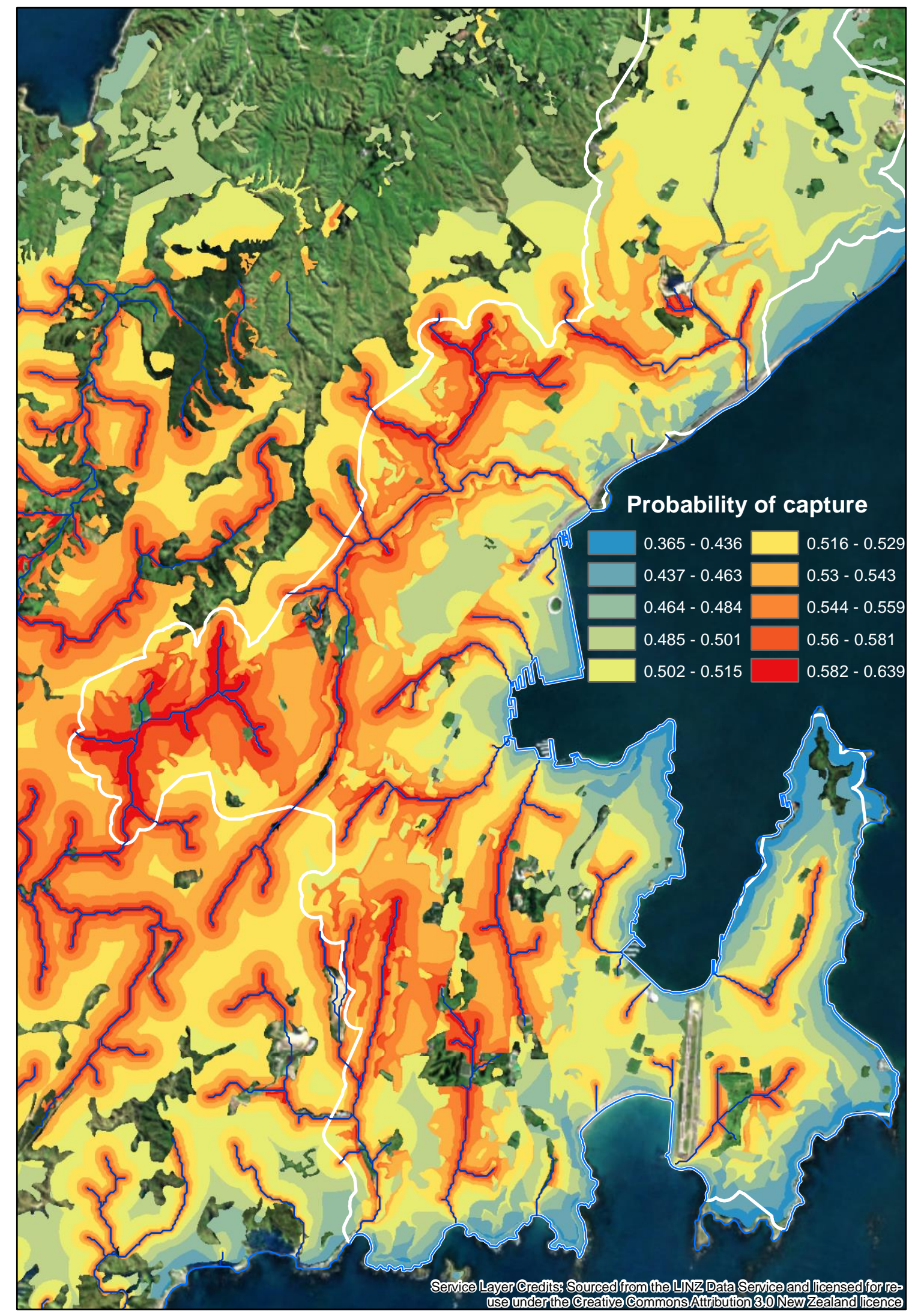

Figure 4.9: Mouse catch predictions for Wellington City. Map depicts the probability of mouse capture within a given location. White line outlines the main boundary between the Wellington core and surrounding forest. Background image was sourced from LINZ. Map created using ArcMap 10.5.1. 


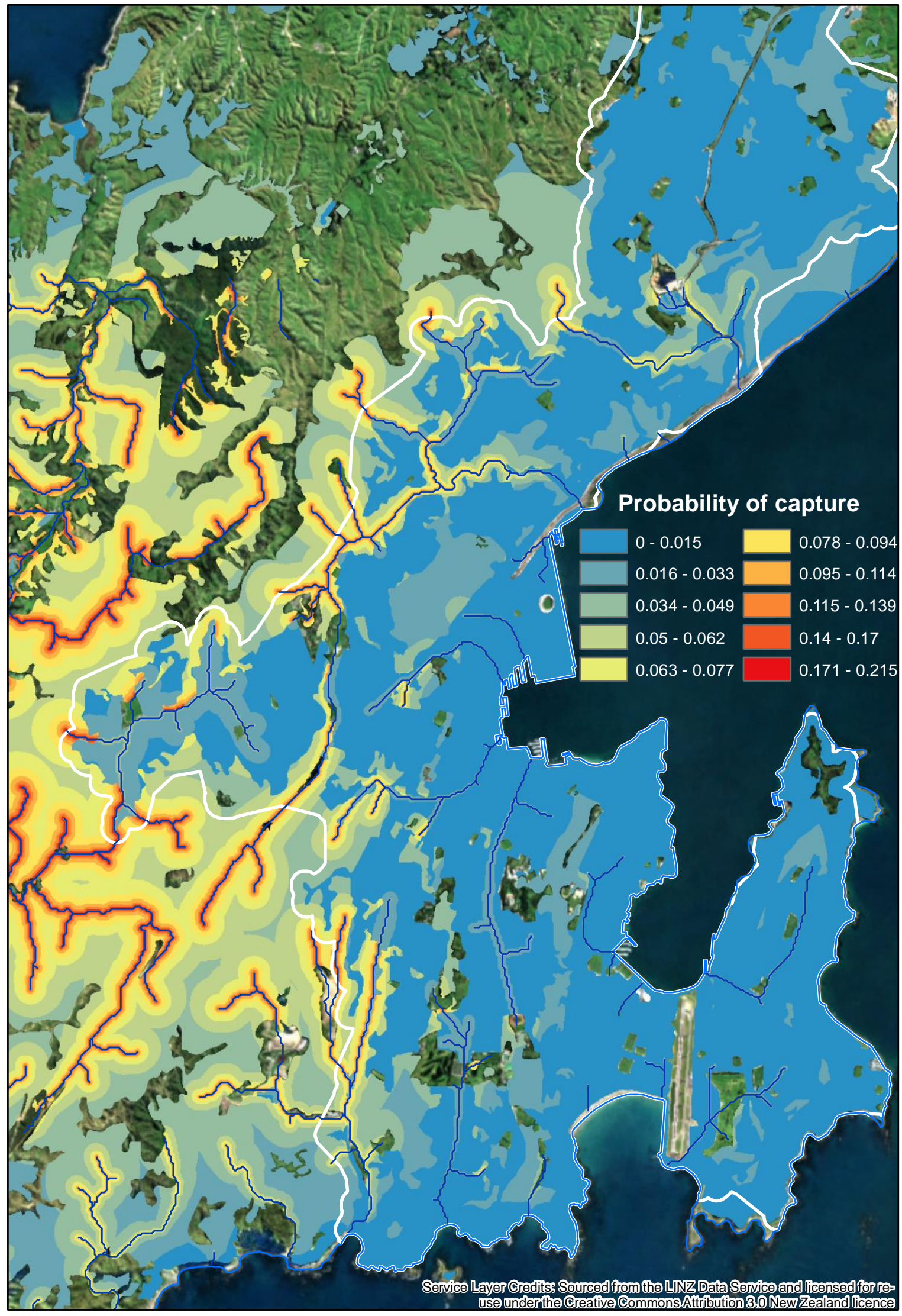

Figure 4.10: Hedgehog catch predictions for Wellington City. Map depicts the probability of hedgehog capture within a given location. White line outlines the main boundary between the Wellington core and surrounding forest. Background image was sourced from LINZ. Map created using ArcMap 10.5.1. 


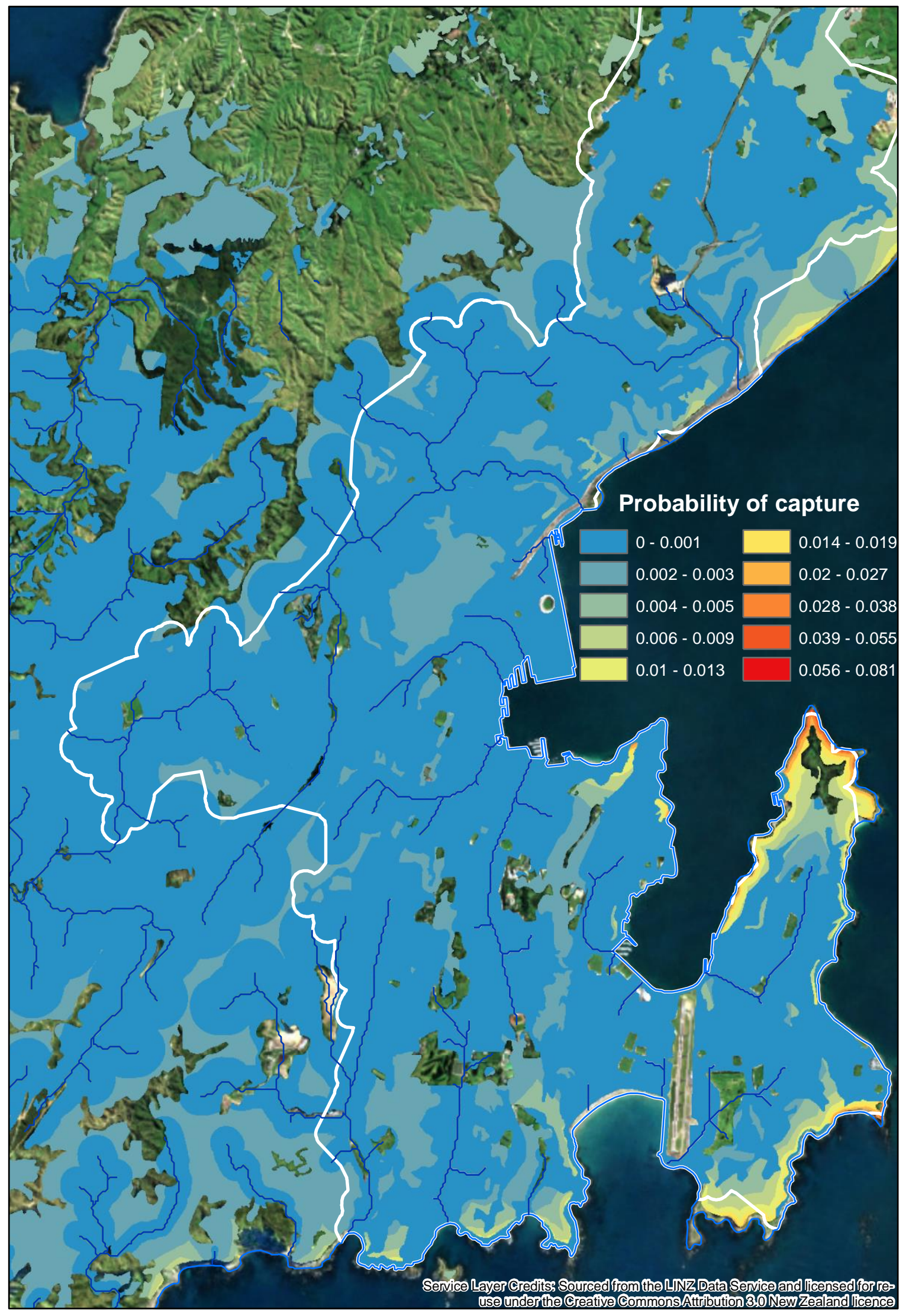

Figure 4.11: Stoat catch predictions for Wellington City. Map depicts the probability of stoat capture within a given location. White line outlines the main boundary between the Wellington core and surrounding forest. Background image was sourced from LINZ. Map created using ArcMap 10.5.1. 


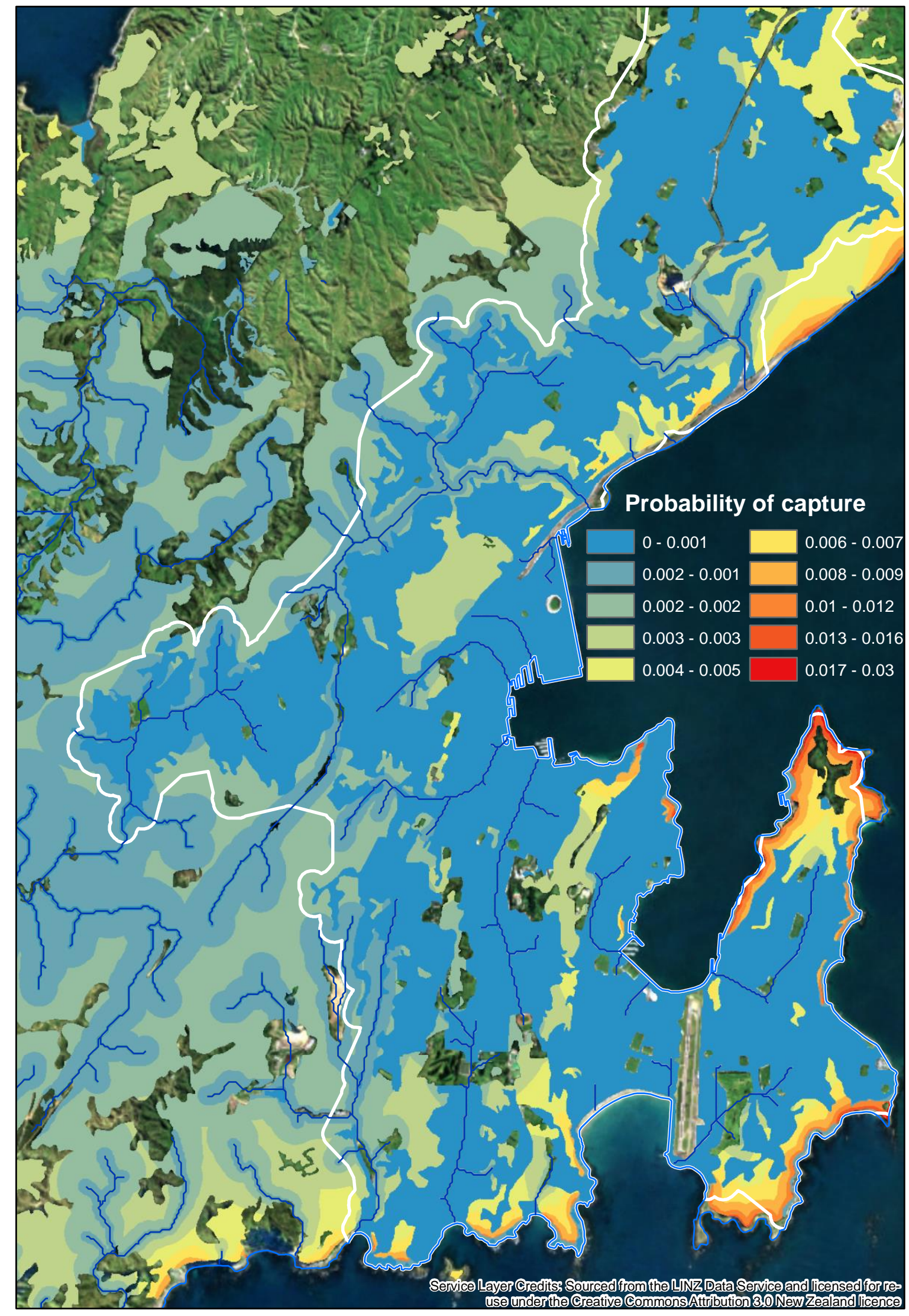

Figure 4.12: Weasel catch predictions for Wellington City. Map depicts the probability of weasel capture within a given location. White line outlines the main boundary between the Wellington core and surrounding forest. Background image was sourced from LINZ. Map created using ArcMap 10.5.1 


\section{Discussion}

The degree of trapping occurring within residential and reserve sites in Wellington City is shown to be relatively extensive, with over 7,500 recorded traps deployed within 22 groups. There are currently 43 trapping groups across the city with a large portion of these occurring in residential suburbs. The 22 trapping groups included in this study were those that responded to my requests for data who had data easily available for analysis, thus, the results that I have obtained from my analyses only demonstrates an approximate third of the residential trapping efforts occurring across Wellington.

Although there were relatively equal numbers of residential and reserve groups in the dataset, residential sites had a substantially greater number of traps. More traps are likely deployed in residential sites due to their ease of deployment and maintenance, as well as the recent social aspects of trapping within suburbs (Brown et al., 2015). Residential trap groups largely consist of household owners that have been recruited by the local suburb trap group and provided with a trap to deploy in their backyards. These traps are easily accessible and can be checked on a more regular basis than reserve traps due to the low effort required to maintain, although it is unknown how often the average trap owner is checking their traps. Backyard trapping is also coordinated by local residents of the suburbs, creating a strong social aspect to trapping. Studies conducted on the social behaviour of individuals find that decisions can be influenced by what is perceived as the social "norm" (MacDonald et al., 2015). Trap coordinators often share information through flyers and social media, and on the occasion attend public events. In addition, numerous articles and websites publicising Predator Free Wellington and what is being achieved by communities likely drives the normative idea, and thus potentially encourages more individuals to get involved (MacDonald et al., 2015). However, studies on the public motivations of community trapping have yet to be assessed. The deployment of traps to reserves has quite an energetic cost as these sites are often not accessible via vehicles, so traps and trap boxes have to be transported to each site individually (Brown et al., 2015; Wright, 2011). Depending on the method of transport, only a few traps can be deployed by an individual in a single visit due to their size and weight. Once they are deployed, traps are able to be serviced more regularly, however this remains a potential reason as to why fewer traps may occur in reserves. Another potential reason is the area of the reserve. Several of the reserves that are located in the centre of suburbs are often much smaller than the surrounding residential sites, and it has been shown that the cost of 
trapping significantly increases with decreasing area size (Norbury et al., 2014), therefore fewer traps are capable of being deployed. There is no definitive conclusion as to why there is such a substantial difference between the number of traps within residential and reserve sites, however, these are just some of the potential factors that could influence decisions about trapping.

The identification of the most common traps utilised by residential and reserve groups is beneficial as traps are often species specific, only targeting a narrow range of species (Morriss \& Warburton, 2014; Poutu \& Warburton, 2005). Across Wellington, Victor traps were the most common type of trap, accounting for 56\% of residential traps and $29 \%$ of reserve traps. Victor traps are largely targeted at rats and mustelids but, modified versions are available for mice (Morriss \& Warburton, 2014). Snap E Rat traps are also a common type occurring in residential sites, accounting for $22 \%$ of residential traps. The ease and minimised risk of injury when setting these traps makes them a suitable option for residential groups and is likely why they are a common choice (Morriss \& Warburton, 2014). Although Victor rat traps are capable of catching mice, due to their light weight, mice are capable of setting the trap off or taking the bait without getting caught (Drickamer \& Mikesic, 1993; Mengak \& Guynn Jr, 1987). However, Snap E Rat traps have a greater clamping force compared with Victors, and used in conjunction, are more likely to capture mice (Baker et al., 2012). Mouse catches were shown to increase with simple mouse traps yet, mouse traps only accounted for $11 \%$ of residential traps, and only $4.5 \%$ of reserve traps. Although this is the case, catches of rats and mice were approximately equal in both reserves and residential sites. A24's are an easy-set trap that requires less maintenance than standard predator traps (Peters et al., 2014), but only 78 were recorded in backyards, compared to 114 in reserves. Although they reduce maintenance efforts, they are considerably more expensive than standard traps, costing approximately $\$ 189.00$ NZD. Although they have been reported to kill hedgehogs and mice (Gillies et al., 2014), A24 traps are only targeted at rats and stoats, making them likely as effective as a Victor trap (Peters et al., 2014).

In reserves, the DOC 200 traps are the most common type of trap, accounting for $58 \%$ of all reserve traps. DOC 200's are capable of targeting rats, hedgehogs and mustelids, and used in conjunction with Victor traps and the self-resetting A24's, target a broad array of species (Carter et al., 2016; Poutu \& Warburton, 2005). Mice are often too light to trigger the trapping mechanism of DOC200's and as a result, mouse traps are frequently placed inside the trap box alongside the DOC200's. A24's were more common in reserves than in 
residential sites, likely due to their effectiveness at targeting multiple species and their ability to reset after kills, reducing the costs of labour and the maintenance efforts required to successfully control an area (Carter et al., 2016; Gillies et al., 2013; Peters et al., 2014). Overall, the differences in trap types between residential sites and reserves could potentially be a result of the species assemblages identified, as well as the ability of trappers to confidently set traps.

There is some evidence to suggest that the number of rats, mice and hedgehogs caught is in fact related to the number of traps within a site. The relationship held for both residential and reserves sites, however, the results are only as reliable as the data that I obtained from community trapping groups. The reliability of this data is strongly based on the individual trappers checking their traps regularly and reporting their catches. It is unknown how often individuals in residential sites are checking their traps, however, with a greater number of traps in a group, there is likely a higher probability that a greater number of individuals are checking their traps regularly. Suburbs such as Ngaio are reporting over three times more catches than there are traps. Although this could be due to their location, as many households are close to bush fragments which was considered an important factor in some species catches, it could also be due to the vigilance of the trap group. I am unable to disentangle which factors are most influential without first quantifying the trapping efforts of each group, however, both of these factors likely play an influential role in trap catches. This is not necessarily the case in reserves. Although trap number remains related to catch number in reserves, it is unlikely that they are being checked as regularly as residential traps. However, several reserves are catching between two to four times more individuals than there are traps. Again, without certainty on the trapping efforts of each group and without a proper assessment, it is difficult to attribute these results to a particular set of factors, but, these sites are likely in a closer proximity to the influential environmental variables that were reported and thus could have an influence on the number of catches.

The number of traps within a 100m radius was less influential than the total number of traps within a group, however, it provided a more in depth view of the influence of trapping at a small scale. The most notable results are when trap densities were considered between areas. In reserves, mouse catches increased when trap density increased. A $100 \mathrm{~m}$ radius equates to an area of 3.14ha. Mice have notoriously small home ranges that averages at $0.60 \mathrm{ha}$ (Fitzgerald et al., 1981), therefore increasing the number of traps within the area increases the chances that mice will come into contact with a trap. The same pattern held true for 
hedgehogs, stoats and weasels in residential sites. The increase in hedgehog catches with increasing trap density could be a result of the traps that are present within residential sites. As previously mentioned, the number of traps capable of catching hedgehogs is reduced in residential sites, therefore, the increasing density of traps is likely to increase the chances that a hedgehog will come across a trap that is capable of its capture. This is unlikely the case for stoats and weasels, as the most common trap type was the Victor, which is capable of catching both species. Stoats and weasels are characteristically neophobic and therefore are not easily caught in traps (King et al., 2009), however, the increase in potential food sources, as well as the increased occurrence of making contact with a trap, may have potentially resulted in the higher catches recorded.

Overall, rats and mice accounted for $95 \%$ of the total reported catches in Wellington between November 2017 and January 2019. With an understanding of the number and proportion of deployed traps, it is unsurprising that more individuals were caught in residential sites and that trap type was one of the influential factors in the catches of these species. Several factors influenced the catches of rats and mice, including the time of year. The same reasoning for rat and mice detections hypothesised in the discussion in Chapter 3, can also be applied as an explanation for the increase in catches in autumn. The increase in population size in autumn as a result of the summer breeding season (Efford et al., 2006; Innes et al., 2001), as well as the reduction of resources due to the increased population size (Choquenot \& Ruscoe, 2000; Russell et al., 2008), results in a higher probability that individuals will interact with traps. The distance of traps from streams was also a significant factor, with a higher proportion of mice caught within an increased proximity to streams, and a higher proportion of rats caught further from streams and in closer proximity to the coast. It was proposed in Chapter 3 that rats have been reported to prey on seabirds and their offspring, as well as other unexploited coastal resources (Caut et al., 2008; Dowding \& Murphy, 2001; Jones et al., 2008), which is one potential reason why they are commonly caught in coastal traps. However, this opportunistic behaviour may not be the driver to explain why mice are more commonly caught close to streams and instead could be a result of exclusion. Rats have been shown to demonstrate aggression and predatory behaviours towards mice (Bridgman et al., 2013), therefore, mice might be occupying habitats where rats are less abundant, resulting in more mice catches in these sites.

Hedgehog catches were influenced by several of the variables reported for rats and mice, however, often in differing ways. Hedgehog catches were higher in reserves, and A24 and 
DOC200 traps caught considerably more individuals than others. The results above on the proportions of trap types in each site strongly corroborates this finding. Hedgehog catches were highest over the summer months, which can be explained with the coincidence of their hibernation which occurs between mid-April and early September (Moss \& Sanders, 2001). More hedgehogs were also caught with an increased distance from coastal areas, but with reduced distance from streams. Since the main component of a hedgehog's diet is invertebrates, it has been stated that hedgehogs are often located around damp areas of river braids and wetlands where there is a high presence of invertebrates in dense vegetated areas (Jones et al., 2005; Jones \& Norbury, 2006; Morris \& Morris, 1988; Shanahan et al., 2007), which is mostly consistent with the findings here.

There were few reported catches of weasels over the fifteen-month long dataset. However, catches were attributed with the proximity to coast and bush fragments. The diet of weasels mainly consists of birds, lizards and rodents (King et al., 2001; Murphy et al., 1998). Their proximity to both of these locations may allow for the maximisation of resources that are associated with these two habitat types.

Understanding what community trapping groups are targeting and catching, accompanied with monitoring data, can provide information on the effectiveness of current trapping programmes on introduced mammalian predators. Although the work in this chapter was only conducted on a third of the efforts occurring across Wellington, predictions have been suggested for the entire city based on the obtained results, and provides a basis which has the potential to be utilised when planning future trapping. A more extensive collection of data should be acquired to enhance these models, however, the findings in this chapter highlight the importance of trap data and how it can be utilised.

Trap.NZ provided a very useful platform for storing data on trap locations and catches. Several of the datasets that were used in this chapter were obtained from gaining access to various group pages. The storage of data was easily accessible, and for research purposes, easily obtainable and in a format for direct use in both ArcMap and Excel. I recommend the use of this platform for future recording if the goal is to utilise this data in future research. However, other platforms, such as GIS in Conservation (GIC), provide an equally acceptable database, with more figures and visual data, if the goal is just to inform the interested residents. 


\section{Chapter 5}

\section{General discussion}

The studies conducted within this research provide an assessment on the efficacy and use of monitoring equipment to conduct research on the distribution of introduced mammalian predators within urban ecosystems. These techniques were used to investigate the influence of landscape, habitat, and microhabitat features on the distribution of predators. Furthermore, I have been able to compile trapping data from local community groups and assess how their efforts are reflected in their catches. Six-night monitoring devices are the more sensitive method for detecting mammalian predators in an urban environment. The use of these devices have shown that habitat type, season, and some degree of trapping has an influence on the distribution of these species. Furthermore, microhabitat variables, such as the distance of traps to streams and the coast, have a significant influence on the probability of catching a particular species. Overall, the results from these studies can be compiled to provide an account on the use of studying mammalian predators in an urban environment.

\section{The use of monitoring devices in an urban context}

The use of non-invasive devices to monitor the introduced mammalian predators of New Zealand has proven to be an applicable technique to monitor the presence of rats, mice and possums in rural systems (Brown et al., 1996; Ruffell et al., 2015b). Chapter 2 demonstrates the efficacy of their use to monitor mammalian predators in an urban environment, which prior to this study had not been formally tested. Furthermore, there is limited documentation on the use of these devices to monitor hedgehogs (Berry, 1999), thus, this study provides an insight into their use for detection. It has been shown that chew cards and tracking tunnels are both useful devices at detecting urban mammals, and work most effectively when used in conjunction to assess the distribution of the wide array of target species. The accuracy of card identifications was relatively consistent between chew cards and tracking tunnels (85-95\%), informing their use in urban monitoring, as well as their reliability for the estimates of presence and distribution. The detections of mice on chew cards demonstrated the most inaccuracies, suggesting that tracking tunnels are the favoured technique for monitoring mice (Sweetapple \& Nugent, 2011).

The standard operating procedure for tracking tunnels follows a one-night exposure for rats and a three-night exposure for mustelids (Gillies \& Williams, 2013). The one-night procedure 
has been proven as an effective and convenient time frame for assessing the relative abundance of rats and possums in forests (Blackwell et al., 2002; Brown et al., 1996; Ruffell et al., 2015b), however, it has not been proven as effective in estimating mice abundance (Brown et al., 1996; Ruscoe et al., 2001). The sensitivity of monitoring devices is largely influenced by the monitoring duration and the density of predator populations (Burge et al., 2017; Sweetapple \& Nugent, 2011). Saturation or interference can become an issue with the increase in duration for which monitoring devices are active, often making estimates of presence difficult to accurately obtain (Burge et al., 2017). In non-forest sites, devices deployed for at least three nights produced the high results of detections for several mammalian species (Burge et al., 2017; Pickerell et al., 2014), with minimal interference or saturation (Burge et al., 2017). In Chapter 2, six-night exposures of chew cards and tracking tunnels provided the highest rates of species detection. Six-night tracking tunnels were particularly more effective at detecting hedgehogs and mice within sites. The increase in hedgehog detections is consistent with the results obtained from a river braid system in South Canterbury, whereby hedgehog detections increased with the increase in exposure, and it was suggested that ten-night exposures were optimal in this system (Pickerell et al., 2014). Mouse detections were also reported to increase in tracking tunnels over monitoring periods, potentially as a result of their learned attraction to baits (Brown et al., 1996).

Chew cards are considered to be one of the most sensitive monitoring devices for rats and possums, but requires duration to be balanced with species abundance to limit the influence of interference and saturation (Burge et al., 2017). Burge et al. (2017) suggested that exposures of at least three nights were necessary to limit false negative results. In our study, six-night chew cards were more effective at detecting rats, and considerably more possums, which is consistent with the suggestions of Burge et al (2017), that exposures of approximately five nights will balance out the risks of saturation and the reporting of false absences. In urban areas where populations of mammalian predators are considered to be moderate to low, six-night cards are likely to be sufficient for monitoring. In areas of high mouse or rat detections, six-night tracking cards were reaching a level of saturation, therefore, six nights is likely the limit before card prints becomes unidentifiable. Further testing utilising one, three and six-night cards may be beneficial to more accurately estimate the appropriate duration, whilst reducing saturation, for different species across habitat types. With various durations tested by different authors it can be difficult to know which to use, 
and the development of a standard method for urban systems would be desirable so that different studies and councils can compare their results. Given that community groups may be doing much of the monitoring, I suggest that devices set for a minimum of three nights, however, a seven-night duration might be optimal because of the logistical ease of setting up and collecting on the same day of the week.

\section{The drivers of distribution in urban mammalian predators}

Previous studies assessing the distribution of mammalian predators in New Zealand have had a strong focus in forest environments, where results indicated that rats, mice and hedgehogs are largely distributed in areas of undisturbed native vegetation (Harper et al., 2005; King et al., 1996). However, urban environments are composed of several broad scale habitats, including coastal areas, forests and residential suburbs, and are comprised of differing microhabitats. The findings of Chapter 3 demonstrated a diverse distribution of mammalian predators, with forest sites only strongly favoured by possums. There were no significant differences in the detection rate of rats and hedgehogs across the three broad habitat types, however, mice had a significantly higher detection in amenity sites. I obtained few records of trapping in what was considered as an amenity site. It is unclear how much trapping is occurring in public parks and coastal areas, thus, trapping efforts could have been one potential reason why mice numbers were higher in these sites.

Microhabitat variables such as forest composition and structure (Harper et al., 2005; King et al., 1996), climate and topography (Christie et al., 2009; Ruffell et al., 2015a), and the proximity of sites to waterways and vegetated areas (Christie et al., 2009; Morgan et al., 2009; Ruffell et al., 2014) strongly influenced the distribution of rats and mice in rural locations. In chapter 3, several of these variables were tested for their influence on the distribution of urban mammalian predators, however, their influence was greatly reduced within an urban environment.

Rats have commonly been distributed in areas of steep, native forest (King et al., 1996) that are further from forest edges (Christie et al., 2009) and close to sources of water (Morgan et al., 2009). In Chapter 3, we identified that rats in Wellington had a high presence in forest sites, and that the distance of sites to the coast was one of the few influential drivers detected. A study on Pearl Island identified that rats do utilise coastal habitat and are capable of 
exploiting the available food sources (Harper et al., 2005). Their presence in coastal sites has also been identified as they are significant predators of seabirds (Caut et al., 2008; Dowding \& Murphy, 2001).

Dense, low vegetation cover has been associated with the distribution of rodents, particularly mice (King et al., 1996; Morgan et al., 2009), and is considered one of the influential driving factors of mouse presence (Ruscoe, 2001). In Chapter 3, the direct measurement of vegetation cover did not have an influence on the distribution of mice, however, the highest detections occurred in amenity sites which were dominated by a dense cover of low vegetation and shrubbery. Although there were no direct links made to vegetation cover, it is possible that the distribution of mice is still influenced by low ground cover in urban environments.

The distribution of hedgehogs in New Zealand has not received a great deal of investigation, but studies have identified that habitat, diet and their distance from predator populations are the likely driver of their distribution (Hubert et al., 2011; Morris \& Morris, 1988). Within a forest system, hedgehogs have been distributed in both native and exotic stands of forest (King et al., 1996). However, investigations into the presence of hedgehogs in forest and urban environments have identified that there is a higher proportion of hedgehogs in urban sites (Hubert et al., 2011; Morris \& Morris, 1988). Results from Chapter 3 are concordant with these findings, as the highest detections of hedgehogs occurred in residential and amenity sites. The association with higher human population density was one of the few variables that influenced the presence of hedgehogs in monitoring sites across Wellington, which fits with their higher detections in the more urbanised habitats.

\section{Urban trapping}

The detection of mammalian predators following the implementation of long term control programmes has shown to result in large reductions of rats, mice, possums and mustelids (Byrom et al., 2016; Dilks et al., 2003; Gillies et al., 2003; Ruscoe et al., 2013) and provides evidence for the benefits of pest control. However, these control programmes rarely utilised only traps in control, and often deployed poison baits in conjunction (Brown et al., 2015). Urban environments have a strong focus on trapping due to the constraints of using poison baits in close proximity to people and domestic mammals (Brown et al., 2015). In Wellington, 46 community groups are currently trapping residential and reserve areas, however, the impacts of residential trapping on pest populations are largely unknown. 
In Chapter 3, the intensity of trapping was calculated across increasing radii from monitoring stations $(25 \mathrm{~m}, 50 \mathrm{~m}, 100 \mathrm{~m}$ and $200 \mathrm{~m})$ to assess if trapping influenced the detections of urban mammals. It is recommended that traps spaced no more than $25-50 \mathrm{~m}$ apart is the best practice when controlling for rodents, due to the size of their home ranges (Brown et al., 2015; Weihong et al., 1999). There is currently no best practice for catching hedgehogs, however, previous studies have utilised distances of 100-200m spacing's in the capture of hedgehogs (Keedwell \& Brown, 2001; Reardon et al., 2012) Trapping intensity did not have a strong influence on the detections of any of the three species tested, least of all mice. However, the influence of trap density did differ with season. Rat detections significantly decreased in spring with the increase in trap density at $25-50 \mathrm{~m}$, which is consistent with the current understanding of rodent trapping. However, detections of hedgehogs in an urban environment declined with the increase in traps at $50 \mathrm{~m}$, less than the spacing of studies conducted in rural environments (Reardon et al., 2012). There is limited literature on the movements of hedgehogs within urban environments in New Zealand, but Dowding et al (2010) suggested that the home ranges of hedgehogs were somewhat smaller in urban environments and were averaged between 2.87 ha for males, and 0.77 ha for females, which could provide an explanation for these differences in the urban context.

Species detections and distribution should, in theory, somewhat correlate with those of trap catches, as methods have been used interchangeably to measure species density (Blackwell et al., 2002; Brown et al., 1996). In Chapter 4, I summarised the community trapping efforts that were occurring within Wellington City, from the period of November 2017 to January 2019, and related trap catches to various environmental factors that were also measured in Chapter 3. The type of trap utilised by community groups varied between residential sites and reserves, with small, easy to set, rat and mouse traps the common type to occur in residential backyards. Victor traps are specifically designed for the captures of rodents and mustelids (Morriss \& Warburton, 2014). This study reflected the use of these traps for rodents in residential sites, and is correlated with the higher catches of rats and mice. The results of the mammal monitoring in Chapter 3 appear consistent with the records of trap catches. Summer breeding in rats and mice has been associated with the increase in detections on tracking tunnels and chew cards in autumn, as a potential result of population size increases (Choquenot \& Ruscoe, 2000; Efford et al., 2006; Innes et al., 2001). In both instances, rats and mice had greater interactions with autumn devices. The high number of catches over 
autumn likely also relates to the declines in catches and detections that are apparent over spring.

The influence of environmental variables had a more significant influence on trap catches, however, in both cases, the distance to bodies of water had significant influences on rat detections and catches. In the monitoring study, the proximity to the coast resulted in increased detections of rats. Conversely, the increasing distance of traps from streams resulted in a decrease in rat catches. It suggests that coastlines are the more favoured source of water in urban systems, potentially due to resource opportunities. Several studies have reported that rats are a significant predator of seabirds and eggs (Caut et al., 2008; Jones et al., 2008), and in island systems, marine food sources have been identified in their systems (Harper et al., 2005).

Investigations into predator control have highlighted the outcomes of single targeted control. When a top predator is targeted, it can lead to the competitive release for lower species, often resulting in greater consequences (Ruscoe et al., 2011). Various types of rat traps make up a large proportion of the traps deployed to residential sites. Although they are capable of catching mice, mice are also capable of entering the traps without getting caught (Drickamer \& Mikesic, 1993; Mengak \& Guynn Jr, 1987). Rats and mice both had a high number of catches in autumn, however, mouse presence remains substantially higher in residential sites than for rats. It is unknown whether this represents a scenario of predator release, however, it is something to be considered in future trap planning.

DOC200 and Goodnature A24 traps are the most widely used traps in the captures of hedgehogs (Gillies et al., 2014), and were two of the most common traps deployed in reserve sites. The results from Chapter 4 are consistent with these findings, as hedgehog catches were strongly influenced by these trap types. The results of the mammal monitoring also appear to corroborate the records of trap catches. Hedgehogs enter hibernation between mid-April and September (Moss \& Sanders, 2001), therefore, both detections and catches are reportedly lower in autumn. The highest catches of hedgehogs occurred over summer in forest reserves, as did the highest detections. However, detections of hedgehogs were equally high in residential sites, but trap catches did not correlate with this. Hedgehog presence is known to be high in other urban contexts (Hubert et al., 2011; Morris \& Morris, 1988), but it is likely that the limited number of trap types capable of catching hedgehogs resulted in their higher detections in residential sites. Furthermore, the increased density of rodent traps in residential 
sites could have led to the competitive release from rodents. There is little evidence to suggest that competition occurs between rats and hedgehogs (Brockie, 1975), however, the diet of rats and hedgehogs both contains invertebrates. Although there may not be direct competition, the trapping of rodents may indirectly benefit hedgehogs through the acquisition of a greater portion of resources.

Prior to this study, the influence of trapping in an urban ecosystem had not been formally summarised. The results obtained from the mammal monitoring study can be linked with the results of trapping, and reflects some of the potential challenges associated with pest control in an urban context.

\section{Limitations and considerations}

An inherent limitation of mammal monitoring studies is the assumption that species detections are correlated with species presence, and that a high detection of species is directly related to abundance (Brown et al., 1996; Gillies, 2013). Although the results for Chapter 3 were not directly assessing species abundance, the results are based off of this underlying assumption. This assumption has been investigated with the use of tracking tunnels, and there is evidence that this is accurate in several species, including rats and mice (Brown et al., 1996). Although it has not been extensively tested for chew cards, detections on chew-track cards have shown significant relationships with abundance, highlighting the potential for standard chew cards (Ruffell et al., 2015b; Sweetapple \& Nugent, 2011). The reliability of estimates of species presence, particularly for hedgehogs, would greatly benefit from an investigation as to whether these assumptions hold within alternative environments, and which devices gain the best estimates.

Mammal monitoring studies are also limited in the species that they can detect. Although the devices are capable of detecting a broad array of introduced mammal species, observers of cards are unable to identify distinct species from the same genus. Two species of rats are commonly detected on monitoring devices; the ship rat and the Norway rat. As the two species are indistinguishable on the devices, all observations are categorised as rat. The limitations of combining observations is that the two species behave differently and are therefore likely to have different drivers of distribution (Innes, 2001; Innes et al., 2001). However, we are unable to disentangle those differences in the analyses and could thus possibly reduce the application of the results. 
An important factor to consider during monitoring is that of weather. The standard procedures for the monitoring equipment specify that devices should be deployed in fine weather with minimal rainfall to gain the most accurate estimates (Gillies, 2013; Gillies \& Williams, 2013). As I only had a limited time frame to conduct the monitoring, it was difficult to coincide the placement of devices with fine weather. Monitoring devices were deployed for the period of one and six nights, with trials occurring consecutively. Although the deployment of one-night card exposures could coincide with clear weather, it was unlikely that for the duration of the six-night exposure, weather would remain clear. This should be a consideration and something that is accounted for in future analyses as poor weather has the potential to lower activity, therefore influencing detection rates (Pickerell et al., 2014). It was observed that weather would often have a resulting impact on the rabbit based baits. In wet weather, bait would become increasingly moist, and in summer, baits would often become maggot-ridden. We do not know to what degree the weather influenced the attractiveness of baits, however, these factors should be considered as it could impact the interactions of target species with the monitoring. Furthermore, wet weather would commonly interfere with ink tracking tunnels, making markings difficult, if not impossible, to interpret.

\section{Recommendations}

Tracking tunnels and chew cards are effective at targeting different species, therefore depending on the goal of monitoring, both devices should be used in unison to detect a broad array of species. A six-night exposure of cards was the most sensitive technique at detecting mammalian predators, however, consistency of interpretations was lower in the case of rats and mice. Overall, chew cards would be the recommended device to monitor rats and possums, particularly in areas that experience high levels of disturbance. They are considerably cheap and easy to deploy (Sweetapple \& Nugent, 2011), and the inconsistency of interpretation is very minimal. Unlike tracking tunnels, chew cards are more robust in bad weather, and markings remain clearly visible, making chew cards a reliable device. However, tracking tunnels are necessary if the intention is to monitor hedgehogs. Hedgehogs were rarely present on chew cards, so tunnels are required for reliable estimates. Tracking tunnels are highly affected by weather and interference with animals, therefore a shorter duration (3-4 days) is recommended. 
Although cameras were not discussed in the context of this thesis, they have been shown to be a reliable, multi-species monitoring device (Anton et al., 2018; Glen et al., 2014). Cameras are capable of detecting a wider array of species than both chew cards and tracking tunnels, therefore there is a wide application for their use in dynamic urban environments (Anton et al., 2018). The combined use of cameras and monitoring devices also provides information on the utilisation of devices by these species.

Community trapping groups collect vast amounts of valuable catch data through the efforts of trapping, which can be used in research to answer questions about the behaviour of mammalian predators. The catch data utilised in this thesis were only a portion of what is available, and demonstrates its varied uses from a research perspective. I recommend that groups continue to actively record their catches, particularly when traps are sprung but no catches have been made, as this information can be utilised for more extensive future research. Trap.NZ (trap.nz) is one of the databases with which groups are storing their data. The data stored on this database were easily compiled for my research, therefore, is a recommendation for the benefits of future data utilisation.

Urban ecology is a relatively new field and there are still a lot of unknowns about the system. The present study is only a small investigation into one aspect of mammal ecology in an urban environment, therefore it is difficult to make strong recommendations on future trapping based on the present results.

\section{Conclusion}

The use of mammal monitoring devices to understand the presence and distribution of introduced mammalian predators remains an important step prior to the enforcement of predator control regimes (Ruffell et al., 2015a). The monitoring carried out in this thesis highlighted the use of chew cards and tracking tunnels to accurately identify and detect species of mammalian predators within an urban environment. The distribution of mammalian predators was highly diverse, highlighting the difference from prior studies conducted in rural ecosystems.

Overall, the results of the thesis suggest that there are important difference in the behaviours of mammalian predators between environments, and factors that currently influence species distribution within a rural ecosystem do not have the same influence in an urban context. However, the potential links between monitoring data and trap data provide some insights 
into the influence of residential trapping. There is limited certainty about the effectiveness of some control techniques, and given the recent goals of groups such as Predator Free Wellington, further investigation will likely be required to address predator populations and the efficacy of trapping. It is likely that a combination of techniques, such a trapping and poison application, will need to be utilised if we wish to achieve predator free goals. Continued mammal monitoring is likely to play a role in providing the information necessary to achieve conservation goals. Monitoring the effectiveness of trapping on predator species is only the first step. The next logical step is to understand how the biodiversity within these areas responds to the outcomes of monitoring. This step is equally as important, however, was outside of the scope of my thesis. 


\section{References}

Anton, V., Hartley, S., \& Wittmer, H. U. (2018). Evaluation of remote cameras for monitoring multiple invasive mammals in New Zealand. New Zealand Journal of Ecology, 42(1), 74-79.

Baker, P. J., Ansell, R. J., Dodds, P. A., Webber, C. E., \& Harris, S. (2003). Factors affecting the distribution of small mammals in an urban area. Mammal review, 33(1), 95-100.

Baker, S. E., Ellwood, S. A., Tagarielli, V. L., \& Macdonald, D. W. (2012). Mechanical performance of rat, mouse and mole spring traps, and possible implications for welfare performance. PloS one, 7(6), e39334.

Berry, C. J. (1999). Potential interactions of hedgehogs with North Island brown kiwi at Boundary Stream Mainland Island: Department of Conservation Wellington.

Blackie, H. M., MacKay, J. W., Allen, W. J., Smith, D. H. V., Barrett, B., Whyte, B. I., . . Ogilvie, S. (2014). Innovative developments for long-term mammalian pest control. Pest Management Science, 70(3), 345-351.

Blackwell, G. L., Potter, M. A., \& McLennan, J. A. (2002). Rodent density indices from tracking tunnels, snap-traps and Fenn traps: do they tell the same story? New Zealand Journal of Ecology, 43-51.

Bridgman, L. J., Innes, J., Gillies, C., Fitzgerald, N., Miller, S., \& King, C. M. (2013). Do ship rats display predatory behaviour towards house mice? Animal Behaviour, 86(2), 257-268.

Brockie, R. (1975). Distribution and abundance of the hedgehog (Erinaceus europaeus) L. in New Zealand, 1869-1973. New Zealand Journal of Zoology, 2(4), 445-462.

Brooke, M. d. L., Hilton, G., \& Martins, T. (2007). Prioritizing the world's islands for vertebrate-eradication programmes. Animal Conservation, 10(3), 380-390.

Brown, K., Elliott, G., Innes, J., \& Kemp, J. (2015). Ship rat, stoat and possum control on mainland New Zealand. Wellington: Department of Conservation.

Brown, K., Moller, H., Innes, J., \& Alterio, N. (1996). Calibration of tunnel tracking rates to estimate relative abundance of ship rats (Rattus rattus) and mice (Mus musculus) in a New Zealand forest. New Zealand Journal of Ecology, 271-275.

Burge, O. R., Kelly, D., \& Wilmshurst, J. M. (2017). Interspecies interference and monitoring duration affect detection rates in chew cards. Austral Ecology, 42(5), 522-532. 
Burns, B., Innes, J., \& Day, T. (2012). The use and potential of pest-proof fencing for ecosystem restoration and fauna conservation in New Zealand Fencing for conservation (pp. 65-90): Springer.

Byers, K. A., Lee, M. J., Patrick, D. M., \& Himsworth, C. G. (2019). Rats About Town: A Systematic Review of Rat Movement in Urban Ecosystems. Frontiers in Ecology and Evolution, 7, 13.

Byrom, A. E., Innes, J., \& Binny, R. N. (2016). A review of biodiversity outcomes from possum-focused pest control in New Zealand. Wildlife Research, 43(3), 228-253.

Cameron, B. G., van Heezik, Y., Maloney, R. F., Seddon, P. J., \& Harraway, J. A. (2005). Improving predator capture rates: analysis of river margin trap site data in the Waitaki Basin, New Zealand. New Zealand Journal of Ecology, 117-128.

Carter, A., Barr, S., Bond, C., Paske, G., Peters, D., \& van Dam, R. (2016). Controlling sympatric pest mammal populations in New Zealand with self-resetting, toxicant-free traps: a promising tool for invasive species management. Biological Invasions, 18(6), 1723-1736.

Caut, S., Angulo, E., \& Courchamp, F. (2008). Dietary shift of an invasive predator: rats, seabirds and sea turtles. Journal of Applied Ecology, 45(2), 428-437.

Caut, S., Casanovas, J. G., Virgos, E., Lozano, J., Witmer, G. W., \& Courchamp, F. (2007). Rats dying for mice: modelling the competitor release effect. Austral Ecology, 32(8), 858-868.

Choquenot, D., \& Ruscoe, W. A. (2000). Mouse population eruptions in New Zealand forests: the role of population density and seedfall. Journal of Animal Ecology, 69(6), 1058-1070.

Christie, J., Brown, D., Westbrooke, I., \& Murphy, E. (2009). Environmental predictors of stoat (Mustela erminea) and ship rat (Rattus rattus) capture success. DOC Research \& Development Series, 305.

Clapperton, B., McLennan, J., \& Woolhouse, A. (1999). Responses of stoats to scent lures in tracking tunnels. New Zealand Journal of Zoology, 26(3), 175-178.

Clarkson, B. D., Wehi, P. M., \& Brabyn, L. K. (2007). A spatial analysis of indigenous cover patterns and implications for ecological restoration in urban centres, New Zealand. Urban Ecosystems, 10(4), 441-457.

Clout, M. (2001). Where protection is not enough: active conservation in New Zealand. Trends in ecology \& evolution, 16(8), 415-416. 
Clout, M. (2002). Ecological and economics costs of alien vertebrates in New Zealand. Biological Invasions: Economic and Environmental Costs of Alien Plant, Animal and Microbe Species, 185-194.

Clout, M., \& Russell, J. (2006). The eradication of mammals from New Zealand islands. Assessment and Control of Biological Invasion Risks'.(Eds F. Koike, MN Clout, M. Kawamichi, M. De Poorter and K. Iwatsuki.) pp, 127-141.

Clout, M. N., \& Russell, J. C. (2008). The invasion ecology of mammals: a global perspective. Wildlife Research, 35(3), 180-184.

Coleman, J., \& Cooke, M. (2001). Mycobacterium bovis infection in wildlife in New Zealand. Tuberculosis, 81(3), 191-202.

Courchamp, F., Chapuis, J.-L., \& Pascal, M. (2003). Mammal invaders on islands: impact, control and control impact. Biological Reviews, 78(3), 347-383.

Cowan, P. (2001). Advances in New Zealand mammalogy 1990-2000: brushtail possum. Journal of the Royal Society of New Zealand, 31(1), 15-29.

Cowan, P., \& Clout, M. (2000). Possums on the move: activity patterns, home ranges, and dispersal. The brushtail possum: biology, impact and management of an introduced marsupial. Manaaki Whenua Press, Lincoln, New Zealand, 24-34.

Craig, J., Anderson, S., Clout, M., Creese, B., Mitchell, N., Ogden, J., . . Ussher, G. (2000). Conservation issues in New Zealand. Annual Review of ecology and Systematics, 31(1), 61-78.

Daniel, M. (1973). Seasonal diet of the ship rat (Rattus $r$. rattus) in lowland forest in New Zealand. Paper presented at the Proceedings (New Zealand Ecological Society).

Desvars-Larrive, A., Baldi, M., Walter, T., Zink, R., \& Walzer, C. (2018). Brown rats (Rattus norvegicus) in urban ecosystems: are the constraints related to fieldwork a limit to their study? Urban Ecosystems, 21(5), 951-964.

Dilks, P., Willans, M., Pryde, M., \& Fraser, I. (2003). Large scale stoat control to protect mohua (Mohoua ochrocephala) and kaka (Nestor meridionalis) in the Eglinton Valley, Fiordland, New Zealand. New Zealand Journal of Ecology, 1-9.

Dowding, C. V., Harris, S., Poulton, S., \& Baker, P. J. (2010). Nocturnal ranging behaviour of urban hedgehogs, Erinaceus europaeus, in relation to risk and reward. Animal Behaviour, 80(1), 13-21. 
Dowding, J. E., \& Murphy, E. C. (2001). The impact of predation by introduced mammals on endemic shorebirds in New Zealand: a conservation perspective. Biological Conservation, 99(1), 47-64.

Drickamer, L. C., \& Mikesic, D. G. (1993). Differences in trapping and killing efficiency of Sherman, Victor and Museum Special traps for house mice. American Midland Naturalist, 397-401.

Duncan, R. P., \& Blackburn, T. M. (2004). Extinction and endemism in the New Zealand avifauna. Global Ecology and Biogeography, 13(6), 509-517.

Dunedin City Council. (2018). Pest Control. Retrieved from

https://www.dunedin.govt.nz/archived2018/facilities/parks-and-reserves/pest-control

Efford, M., Fitzgerald, B., Karl, B., \& Berben, P. (2006). Population dynamics of the ship rat Rattus rattus L. in the Orongorongo Valley, New Zealand. New Zealand Journal of Zoology, 33(4), 273-297.

Fitzgerald, B., Karl, B., \& Moller, H. (1981). Spatial organization and ecology of a sparse population of house mice (Mus musculus) in a New Zealand forest. The Journal of Animal Ecology, 489-518.

Forsyth, D. M., Link, W. A., Webster, R., Nugent, G., \& Warburton, B. (2005). Nonlinearity and seasonal bias in an index of brushtail possum abundance. The Journal of wildlife management, 69(3), 976-984.

Forsyth, D. M., Perry, M., Moloney, P., McKay, M., Gormley, A. M., Warburton, B., .. . Dewhurst, R. (2018). Calibrating brushtail possum (Trichosurus vulpecula) occupancy and abundance index estimates from leg-hold traps, wax tags and chew cards in the Department of Conservation's Biodiversity and Monitoring Reporting System. New Zealand Journal of Ecology, 42(2), 179-191.

Gibbs, G. W. (2009). The end of an 80-million year experiment: a review of evidence describing the impact of introduced rodents on New Zealand's 'mammalfree'invertebrate fauna. Biological Invasions, 11(7), 1587-1593.

Gillies, C. (2001). Advances in New Zealand mammalogy 1990-2000: house cat. Journal of the Royal Society of New Zealand, 31(1), 205-218.

Gillies, C. (2002a). Managing Rodents on the New Zealand Mainland: What Options are Currently Available?: Summary of a Workshop Session at the Department of Conservation'mainland Island'Hui, Omapere, 20-23 August 2001 (0478222467). Retrieved from 
Gillies, C. (2002b). Managing Rodents on the New Zealand Mainland: What Options are Currently Available?: Summary of a Workshop Session at the Department of Conservation'mainland Island'Hui, Omapere, 20-23 August 2001: Department of Conservation.

Gillies, C. (2013). Animal pests: tracking tunnel indices

of small mammal abundance. Retrieved from

Gillies, C., \& Clout, M. (2003). The prey of domestic cats (Felis catus) in two suburbs of Auckland City, New Zealand. Journal of Zoology, 259(3), 309-315.

Gillies, C., Gorman, N., Crossan, I., Conn, S., Haines, M., \& Long, J. (2014). A third progress report on DOC S\&C Investigation 4276 'Operational scale trials of selfresetting traps for ground based pest control for conservation in NZ forests'. Unpublished internal report, DOCDM-1204312, p 50. Department of Conservation, Science \& Capability Group, Hamilton, New Zealand.

Gillies, C., Gorman, N., Crossan, I., Harawira, R., Hawaikirangi, R., Long, J., \& McCool, E. (2013). A second progress report on DOC S\&C Investigation 4276 'Operational scale trials of self-resetting traps for ground based pest control for conservation in NZ forests'. Report DOCDM-1204612, 4276, 24.

Gillies, C., Leach, M., Coad, N., Theobald, S., Campbell, J., Herbert, T., . . Pierce, R. (2003). Six years of intensive pest mammal control at Trounson Kauri Park, a Department of Conservation "mainland island", June 1996-July 2002. New Zealand Journal of Zoology, 30(4), 399-420.

Gillies, C., \& Williams, D. (2002). A short guide for identifying footprints on tracking tunnel papers. Retrieved from

Gillies, C., \& Williams, D. (2013). DOC tracking tunnel guide v2. 5.2: Using tracking tunnels to monitor rodents and mustelids. Retrieved from Hamilton:

Gleeson, D. M., Byrom, A. E., \& Howitt, R. L. (2010). Non-invasive methods for genotyping of stoats (Mustela erminea) in New Zealand: potential for field applications. New Zealand Journal of Ecology, 34(3), 356.

Glen, A., Warburton, B., Cruz, J., \& Coleman, M. (2014). Comparison of camera traps and kill traps for detecting mammalian predators: a field trial. New Zealand Journal of Zoology, 41(3), 155-160. 
Glen, A. S., Byrom, A. E., Pech, R. P., Cruz, J., Schwab, A., Sweetapple, P. J., . . Whitford, J. (2012). Ecology of brushtail possums in a New Zealand dryland ecosystem. New Zealand Journal of Ecology, 36(1), 29.

Goddard, M. A., Dougill, A. J., \& Benton, T. G. (2010). Scaling up from gardens: biodiversity conservation in urban environments. Trends in ecology \& evolution, 25(2), 90-98.

Goldson, S., Bourdôt, G., Brockerhoff, E., Byrom, A., Clout, M., McGlone, M., . . . Templeton, M. (2015). New Zealand pest management: current and future challenges. Journal of the Royal Society of New Zealand, 45(1), 31-58.

Greater Wellington Regional Council. (2004). Regional Pest Management Strategy 2002 2022 Retrieved from

Greater Wellington Regional Council. (2007). Regional Pest Management Strategy 2002 2022 Five Year Review. Retrieved from

Harper, G., Forder, S., Henderson, J., Joice, N., Carter, P., Chisnall, D., . . Rees, D. (2011). Rotoiti Nature Recovery Project Annual Report 2010-11. Retrieved from Nelson, New Zealand:

Harper, G. A., Dickinson, K. J., \& Seddon, P. J. (2005). Habitat use by three rat species (Rattus spp.) on Stewart Island/Rakiura, New Zealand. New Zealand Journal of Ecology, 251-260.

Harrison, X. A., Donaldson, L., Correa-Cano, M. E., Evans, J., Fisher, D. N., Goodwin, C. E., ... Inger, R. (2018). A brief introduction to mixed effects modelling and multi-model inference in ecology. PeerJ, 6, e4794.

Hasler, N., Klette, R., \& Agnew, W. (2004). Footprint recognition of rodents and insects. Retrieved from

Henry, P.-Y., Lengyel, S., Nowicki, P., Julliard, R., Clobert, J., Čelik, T., . . Henle, K. (2008). Integrating ongoing biodiversity monitoring: potential benefits and methods. Biodiversity and conservation, 17(14), 3357-3382.

Hice, C. L., \& Velazco, P. M. (2013). Relative effectiveness of several bait and trap types for assessing terrestrial small mammal communities in Neotropical rainforest: Museum of Texas Tech University.

Hopkins, K. (2008). Testing and improving baiting technologies for the management of mice (Mus musculus). Lincoln University. 
Hostetler, M., Allen, W., \& Meurk, C. (2011). Conserving urban biodiversity? Creating green infrastructure is only the first step. Landscape and Urban Planning, 100(4), 369-371.

Hubert, P., Julliard, R., Biagianti, S., \& Poulle, M.-L. (2011). Ecological factors driving the higher hedgehog (Erinaceus europeaus) density in an urban area compared to the adjacent rural area. Landscape and Urban Planning, 103(1), 34-43.

Hurst, J., \& Allen, R. (2007). The recce method for describing New Zealand vegetationexpanded manual: version 4. Lincoln, Landcare Research.

Innes, J. (2001). Advances in New Zealand mammalogy 1990-2000: European rats. Journal of the Royal Society of New Zealand, 31(1), 111-125.

Innes, J., Kelly, D., Overton, J. M., \& Gillies, C. (2010a). Predation and other factors currently limiting New Zealand forest birds. New Zealand Journal of Ecology, 34(1), 86.

Innes, J., King, C., Flux, M., \& Kimberley, M. (2001). Population biology of the ship rat and Norway rat in Pureora Forest Park, 1983-87. New Zealand Journal of Zoology, 28(1), 57-78.

Innes, J., King, C. M., Bridgman, L. J., Fitzgerald, N., Arnold, G., \& Cox, N. R. (2010b). Effect of grazing on ship rat density in forest fragments of lowland Waikato, New Zealand.

Innes, J., Warburton, B., Williams, D., Speed, H., \& Bradfield, P. (1995). Large-scale poisoning of ship rats (Rattus rattus) in indigenous forests of the North Island, New Zealand. New Zealand Journal of Ecology, 19(1), 5-17.

Jones, C., Moss, K., \& Sanders, M. (2005). Diet of hedgehogs (Erinaceus europaeus) in the upper Waitaki Basin, New Zealand: implications for conservation. New Zealand Journal of Ecology, 29-35.

Jones, C., \& Norbury, G. (2006). Habitat use as a predictor of nest raiding by individual hedgehogs Erinaceus europaeus in New Zealand. Pacific Conservation Biology, 12(3), 180-188.

Jones, C., Norbury, G., \& Bell, T. (2013). Impacts of introduced European hedgehogs on endemic skinks and weta in tussock grassland. Wildlife Research, 40(1), 36-44.

Jones, H. P., Tershy, B. R., Zavaleta, E. S., Croll, D. A., Keitt, B. S., Finkelstein, M. E., \& Howald, G. R. (2008). Severity of the effects of invasive rats on seabirds: a global review. Conservation Biology, 22(1), 16-26. 
Kark, S., Iwaniuk, A., Schalimtzek, A., \& Banker, E. (2007). Living in the city: can anyone become an 'urban exploiter'? Journal of Biogeography, 34(4), 638-651.

Keedwell, R. J., \& Brown, K. P. (2001). Relative abundance of mammalian predators in the upper Waitaki Basin, South Island, New Zealand. New Zealand Journal of Zoology, 28(1), 31-38.

King, C., Griffiths, K., \& Murphy, E. (2001). Advances in New Zealand mammalogy 19902000: Stoat and weasel. Journal of the Royal Society of New Zealand, 31(1), 165-183.

King, C., Innes, J., Flux, M., Kimberley, M., Leathwick, J., \& Williams, D. (1996).

Distribution and abundance of small mammals in relation to habitat in Pureora Forest Park. New Zealand Journal of Ecology, 215-240.

King, C. M., \& Barrett, P. (2005). The handbook of New Zealand mammals / edited by Carolyn M. King

with artwork by Priscilla Barrett (2nd ed.. ed.). Auckland, N.Z.: Auckland, N.Z. : Oxford University Press.

King, C. M., Innes, J. G., Gleeson, D., Fitzgerald, N., Winstanley, T., O’Brien, B., . . Cox, N. (2011). Reinvasion by ship rats (Rattus rattus) of forest fragments after eradication. Biological Invasions, 13(10), 2391.

King, C. M., McDonald, R. M., Martin, R. D., \& Dennis, T. (2009). Why is eradication of invasive mustelids so difficult? Biological Conservation, 142(4), 806-816.

Klimant, P., Klimantová, A., Baláž, I., Jakab, I., Tulis, F., Rybanský, L., . . Krumpálová, Z. (2017). Small mammals in an urban area: habitat preferences and urban-rural gradient in Nitra city, Slovakia. Polish Journal of Ecology, 65(1), 144-158.

Kuhn, M. (2008). Building predictive models in R using the caret package. Journal of statistical software, 28(5), 1-26.

Lal, A. (2008). A preliminary evaluation of mammalian predator trapping efficacy at Macraes Flat, Otago. Unpublished Diploma in Wildlife Management thesis, University of Otago, Dunedin, New Zealand.

Lee, A. C., \& Maheswaran, R. (2011). The health benefits of urban green spaces: a review of the evidence. Journal of public health, 33(2), 212-222.

MacDonald, E., Milfont, T., \& Gavin, M. (2015). What drives cat-owner behaviour? First steps towards limiting domestic-cat impacts on native wildlife. Wildlife Research, $42(3), 257-265$. 
McDonald, R. I., Kareiva, P., \& Forman, R. T. (2008). The implications of current and future urbanization for global protected areas and biodiversity conservation. Biological Conservation, 141(6), 1695-1703.

McHugh, M. L. (2012). Interrater reliability: the kappa statistic. Biochemia medica: Biochemia medica, 22(3), 276-282.

McKinney, M. L. (2002). Urbanization, Biodiversity, and ConservationThe impacts of urbanization on native species are poorly studied, but educating a highly urbanized human population about these impacts can greatly improve species conservation in all ecosystems. BioScience, 52(10), 883-890.

McPhearson, T., Pickett, S. T., Grimm, N. B., Niemelä, J., Alberti, M., Elmqvist, T., . . Qureshi, S. (2016). Advancing urban ecology toward a science of cities. BioScience, 66(3), 198-212.

McQueen, S., \& Lawrence, B. (2008). Diet of ship rats following a mast event in beech (Nothofagus spp.) forest. New Zealand Journal of Ecology, 214-218.

Mengak, M. T., \& Guynn Jr, D. C. (1987). Pitfalls and snap traps for sampling small mammals and herpetofauna. American Midland Naturalist, 284-288.

Morgan, D., Waas, J., \& Innes, J. (2009). An inventory of mammalian pests in a New Zealand city. New Zealand Journal of Zoology, 36(1), 23-33.

Morgan, D. K., Waas, J. R., Innes, J., \& Fitzgerald, N. (2011). Identification of nest predators using continuous time-lapse recording in a New Zealand city. New Zealand Journal of Zoology, 38(4), 343-347.

Morris, P., \& Morris, M. (1988). Distribution and abundance of hedgehogs (Erinaceus europaeus) on New Zealand roads. New Zealand Journal of Zoology, 15(4), 491-498.

Morriss, G. A., \& Warburton, B. (2014). Modifying the Victor® Easy Set® rat trap to improve the animal welfare of stoats and ship rats trapped in New Zealand. PloS one, 9(2), e86760.

Moss, K., \& Sanders, M. (2001). Advances in New Zealand mammalogy 1990-2000: hedgehog. Journal of the Royal Society of New Zealand, 31(1), 31-42.

Murphy, E. C., Clapperton, B. K., Bradfield, P. M., \& Speed, H. J. (1998). Effects of ratpoisoning operations on abundance and diet of mustelids in New Zealand podocarp forests. New Zealand Journal of Zoology, 25(4), 315-328.

National Vegetation Survey Databank. (2018). NVS names and codes. In C. N. names (Ed.): Manaaki Whenua Landcare Research. 
Nelson, L., \& Clark, F. W. (1973). Correction for sprung traps in catch/effort calculations of trapping results. Journal of Mammalogy, 54(1), 295-298.

Norbury, G., Hutcheon, A., Reardon, J., \& Daigneault, A. (2014). Pest fencing or pest trapping: a bio-economic analysis of cost-effectiveness. Austral Ecology, 39(7), 795807.

Norton, D. A., \& Roper-Lindsay, J. (2004). Assessing significance for biodiversity conservation on private land in New Zealand. New Zealand Journal of Ecology, 295305.

Nugent, G., Sweetapple, P., Coleman, J., \& Suisted, P. (2000). Possum feeding patterns: dietary tactics of a reluctant folivore. The brushtail possum: biology, impact and management of an introduced marsupial, 10, 23.

NZ Landcare Trust. (2016). Pest Control Guidelines. In N. L. Trust (Ed.).

O'Donnell, C. F., \& Hoare, J. M. (2012). Quantifying the benefits of long-term integrated pest control for forest bird populations in a New Zealand temperate rainforest. New Zealand Journal of Ecology, 131-140.

Parkes, J., \& Murphy, E. (2003). Management of introduced mammals in New Zealand. New Zealand Journal of Zoology, 30(4), 335-359.

Patric, E. F. (1970). Bait preference of small mammals. Journal of Mammalogy, 51(1), 179182.

Pech, R., \& Maitland, M. (2016). Conservation of native fauna in highly invaded systems: managing mammalian predators in New Zealand. Restoration Ecology, 24(6), 816820.

Peters, D. H., Schumacher, K., Schumacher, R. J., \& Baigent, D. W. (2014). Goodnature automatic traps for vertebrate pest control: field trials using new kill traps targeting animal pests in New Zealand. Paper presented at the Proceedings of the Vertebrate Pest Conference.

Pickerell, G. A., O'Donnell, C. F., Wilson, D. J., \& Seddon, P. J. (2014). How can we detect introduced mammalian predators in non-forest habitats? A comparison of techniques. New Zealand Journal of Ecology, 86-102.

Poutu, N., \& Warburton, B. (2005). Effectiveness of the DOC 150, 200, and 250 traps for killing stoats, ferrets, Norway rats, ship rats and hedgehogs. Landcare Research Contract Report LC0405/109 for the Department of Conservation. Wellington, Department of Conservation. 
R Development Core Team. (2018). R: A language and environment for statistical computing. Vienna, Austria: R Foundation for Statistical Computing.

Ramsey, D., Efford, M., Cowan, P., \& Coleman, J. (2002). Factors influencing annual variation in breeding by common brushtail possums (Trichosurus vulpecula) in New Zealand. Wildlife Research, 29(1), 39-50.

Rastandeh, A., Pedersen Zari, M., Brown, D., \& Vale, R. (2018). Analysis of Landform and Land Cover: Potentials for Urban Biodiversity Conservation against Rising Temperatures. Urban Policy and Research, 1-12.

Rayner, M. J., Hauber, M. E., Imber, M. J., Stamp, R. K., \& Clout, M. N. (2007). Spatial heterogeneity of mesopredator release within an oceanic island system. Proceedings of the National Academy of Sciences, 104(52), 20862-20865.

Reardon, J. T., Whitmore, N., Holmes, K. M., Judd, L. M., Hutcheon, A. D., Norbury, G., \& Mackenzie, D. I. (2012). Predator control allows critically endangered lizards to recover on mainland New Zealand. New Zealand Journal of Ecology, 36(2), 1.

Richardson, E., Pearce, J., Mitchell, R., Day, P., \& Kingham, S. (2010). The association between green space and cause-specific mortality in urban New Zealand: an ecological analysis of green space utility. BMC public health, 10(1), 240.

Roura-Pascual, N., Brotons, L., Peterson, A. T., \& Thuiller, W. (2009). Consensual predictions of potential distributional areas for invasive species: a case study of Argentine ants in the Iberian Peninsula. Biological Invasions, 11(4), 1017-1031.

Ruffell, J., Didham, R. K., Barrett, P., Gorman, N., Pike, R., Hickey-Elliott, A., . . . Armstrong, D. P. (2014). Discriminating the drivers of edge effects on nest predation: forest edges reduce capture rates of ship rats (Rattus rattus), a globally invasive nest predator, by altering vegetation structure. PloS one, 9(11), e113098.

Ruffell, J., Innes, J., Bishop, C., Landers, T., Khin, J., \& Didham, R. K. (2015a). Using pest monitoring data to inform the location and intensity of invasive-species control in New Zealand. Biological Conservation, 191, 640-649.

Ruffell, J., Innes, J., \& Didham, R. K. (2015b). Efficacy of chew-track-card indices of rat and possum abundance across widely varying pest densities. New Zealand Journal of Ecology, 39(1), 87-92.

Ruscoe, W. (2001). Advances in New Zealand mammalogy 1990-2000: house mouse. Journal of the Royal Society of New Zealand, 31(1), 127-134. 
Ruscoe, W. A., Elkinton, J. S., Choquenot, D., \& Allen, R. B. (2005). Predation of beech seed by mice: effects of numerical and functional responses. Journal of Animal Ecology, 74(6), 1005-1019.

Ruscoe, W. A., Goldsmith, R., \& Choquenot, D. (2001). A comparison of population estimates and abundance indices for house mice inhabiting beech forests in New Zealand. Wildlife Research, 28(2), 173-178.

Ruscoe, W. A., Ramsey, D. S., Pech, R. P., Sweetapple, P. J., Yockney, I., Barron, M. C., . . Warne, R. (2011). Unexpected consequences of control: competitive vs. predator release in a four-species assemblage of invasive mammals. Ecology Letters, 14(10), 1035-1042.

Ruscoe, W. A., Sweetapple, P. J., Perry, M., \& Duncan, R. P. (2013). Effects of spatially extensive control of invasive rats on abundance of native invertebrates in mainland New Zealand forests. Conservation Biology, 27(1), 74-82.

Russell, J. C., Innes, J. G., Brown, P. H., \& Byrom, A. E. (2015). Predator-free New Zealand: conservation country. BioScience, 65(5), 520-525.

Russell, J. C., Towns, D. R., \& Clout, M. N. (2008). Review of rat invasion biology: implications for island biosecurity. Science for conservation(286).

Sanders, M. D., \& Maloney, R. F. (2002). Causes of mortality at nests of ground-nesting birds in the Upper Waitaki Basin, South Island, New Zealand: a 5-year video study. Biological Conservation, 106(2), 225-236.

Shanahan, D. F., Mathieu, R., \& Seddon, P. J. (2007). Fine-scale movement of the European hedgehog: an application of spool-and-thread tracking. New Zealand Journal of Ecology, 160-168.

Shochat, E., Warren, P. S., Faeth, S. H., McIntyre, N. E., \& Hope, D. (2006). From patterns to emerging processes in mechanistic urban ecology. Trends in ecology \& evolution, 21(4), 186-191.

St Clair, J. J. (2011). The impacts of invasive rodents on island invertebrates. Biological Conservation, 144(1), 68-81.

Sweetapple, P., \& Nugent, G. (2011). Chew-track-cards: a multiple-species small mammal detection device. New Zealand Journal of Ecology, 153-162.

Sweetapple, P., \& Nugent, G. (2017). Chewcards: A guide to the interpretation of animal tooth impressions. In L. Research (Ed.). Christchurch, New Zealand. 
Sweetapple, P. J., \& Nugent, G. (2007). Ship rat demography and diet following possum control in a mixed podocarp-hardwood forest. New Zealand Journal of Ecology, 186-201.

Tompkins, D. M., \& Veltman, C. J. (2006). Unexpected Consequences Of Vertebrate Pest Control: Predictions From A Four-Species Community Model. Ecological Applications, 16(3), 1050-1061.

Towns, D., West, C., \& Broome, K. (2013). Purposes, outcomes and challenges of eradicating invasive mammals from New Zealand islands: an historical perspective. Wildlife Research, 40(2), 94-107.

Towns, D. R., Atkinson, I. A., \& Daugherty, C. H. (2006). Have the harmful effects of introduced rats on islands been exaggerated? Biological Invasions, 8(4), 863-891.

Towns, D. R., Simberloff, D., \& Atkinson, I. A. (1997). Restoration of New Zealand islands: redressing the effects of introduced species. Pacific Conservation Biology, 3(2), 99124.

Warburton, B., Barker, R., \& Coleman, M. (2004). Evaluation of two relative-abundance indices to monitor brushtail possums in New Zealand. Wildlife Research, 31(4), 397401.

Watts, C., Thornburrow, D., Cave, V., \& Innes, J. (2014). Beetle community changes following pest mammal control at two biodiversity sanctuaries in Wellington, New Zealand. Journal of the Royal Society of New Zealand, 44(2-3), 61-87.

Watts, C. H., Armstrong, D. P., Innes, J., \& Thornburrow, D. (2011). Dramatic increases in weta (Orthoptera) following mammal eradication on Maungatautari-evidence from pitfalls and tracking tunnels. New Zealand Journal of Ecology, 35(3), 261.

Weihong, J., Veitch, C., \& Craig, J. L. (1999). An evaluation of the efficiency of rodent trapping methods: the effect of trap arrangement, cover type, and bait. New Zealand Journal of Ecology, 45-51.

Wellington City Council. (2004). Pest management plan: plan for the management of weeds and pest animals (187723222X). Retrieved from

Wilson, D. J., Lee, W. G., Webster, R. A., \& Allen, R. B. (2003). Effects of possums and rats on seedling establishment at two forest sites in New Zealand. New Zealand Journal of Ecology, 147-155. 
Wilson, K. A., Underwood, E. C., Morrison, S. A., Klausmeyer, K. R., Murdoch, W. W., Reyers, B., . . McBride, M. F. (2007). Conserving biodiversity efficiently: what to do, where, and when. PLOS biology, 5(9), e223.

Woolley, C. K., Hartley, S., Heezik, Y. v., Hitchmough, R. A., Innes, J. G., Shanahan, D. F., . . Nelson, N. J. (2018). Reviewing the past, present and potential lizard faunae of New Zealand cities. Victoria Univeristy of Wellington. Wellington, New Zealand.

World Health Organisation. (2016). Global health observatory data. Retrieved from https://www.who.int/gho/urban_health/en/

Wright, J. (2011). Evaluating the Use of 1080: Predators, Poisons, and Silent Forests.

Yom-Tov, Y., Yom-Tov, S., \& Moller, H. (1999). Competition, coexistence, and adaptation amongst rodent invaders to Pacific and New Zealand islands. Journal of Biogeography, 26(5), 947-958.

Zhu, L., Sun, O. J., Sang, W., Li, Z., \& Ma, K. (2007). Predicting the spatial distribution of an invasive plant species (Eupatorium adenophorum) in China. Landscape Ecology, 22(8), 1143-1154. 


\section{Appendix A1}

\section{Appendices for Chapter 2}

Table A1.1: Consistency of chew card interpretations between initial and cross-check identifiers for the complete dataset of cards.

\begin{tabular}{lccccccc}
\hline \hline Species & a & b & c & d & Accuracy & Kappa & $\boldsymbol{p}$ \\
\hline Rat & 137 & 17 & 10 & 835 & 0.973 & 0.8944 & 0.25 \\
Mouse & 119 & 7 & 29 & 844 & 0.964 & 0.8479 & $<0.001$ \\
Hedgehog & 9 & 2 & 5 & 983 & 0.993 & 0.7165 & 0.45 \\
Possum & 78 & 3 & 11 & 907 & 0.986 & 0.91 & 0.06 \\
Mustelid & 1 & 0 & 2 & 996 & 0.998 & 0.4992 & 0.48 \\
No Marking & 573 & 47 & 3 & 55 & 0.9289 & 0.8508 & 0.01 \\
\hline \hline
\end{tabular}

Table A1.2: Consistency of tracking card interpretations between initial and cross-check identifiers for the complete dataset of cards.

\begin{tabular}{lccccccc}
\hline \hline Species & a & b & c & d & Accuracy & Kappa & $\boldsymbol{p}$ \\
\hline Rat & 148 & 8 & 8 & 1504 & 0.9904 & 0.9434 & 1.00 \\
Mouse & 251 & 15 & 9 & 1393 & 0.9856 & 0.9458 & 0.31 \\
Hedgehog & 254 & 15 & 4 & 1395 & 0.9886 & 0.9572 & 0.02 \\
Possum & 13 & 17 & 9 & 1629 & 0.9844 & 0.4923 & 0.17 \\
Mustelid & 1 & 0 & 0 & 1667 & 1 & 1 & NA \\
No Marking & 580 & 34 & 133 & 921 & 0.8999 & 0.7918 & $<0.001$ \\
\hline \hline
\end{tabular}




\section{Appendix A2 \\ Appendices for Chapter 3}

\section{A2.1: Does season and monitoring duration have an influence on the disturbance of cards}

One of the limitations of the use of chew cards and tracking tunnels in mammal monitoring studies is the disturbance of devices from weather or other animals. As devices use attractive baits such as peanut butter or rabbit-based pastes, it is common for larger animals to also be attracted to the site. Animal disturbance seems like it would be less common in forest monitoring studies and is rarely reported as a factor in results. However, in an urban environment, disturbance from people and larger domestic mammals, such as cats and dogs, has been notably common in the study. Therefore, assessing the association of season and monitoring duration on tracking card disturbance was applicable to further understand the results that were obtained from chapter 2. It is hypothesised that more disturbance events occurred in spring, and that this potentially influenced why chew cards had a higher presence of species in spring compared with tracking tunnels, as in all other instances, tracking tunnels demonstrated a higher percentage of presence.

\section{Methods}

GLMM's were performed on tracking tunnel presence data to assess if the interaction between season and monitoring duration had an influence on the number of disturbance events occurring over monitoring periods. Disturbance was recorded with a 1 if tunnels had been significantly moved out of place, or if tunnels were incapable of recording species presence.

\section{Results}

Separately, season and monitoring duration have a significant influence on the disturbance of tracking tunnels. Disturbance was reportedly greater in autumn than in spring $(z=-2.331$, $\mathrm{df}=1911, p=0.019)$, with disturbance events increasing with monitoring duration $(z=3.506$, $p<0.001)$. The combined effect of season and night also reported a significant influence on 
disturbance $(W=6.934, \mathrm{df}=1, p=0.008)$. Notably, there is a decrease in disturbance between 6-night autumn and spring cards $(z=-3.388, \mathrm{df}=1911, p=0.004)$. However, disturbance of tunnels did not appear to influence the presence of species at sites. 


\section{A2.2: Example of vegetation survey datasheet}

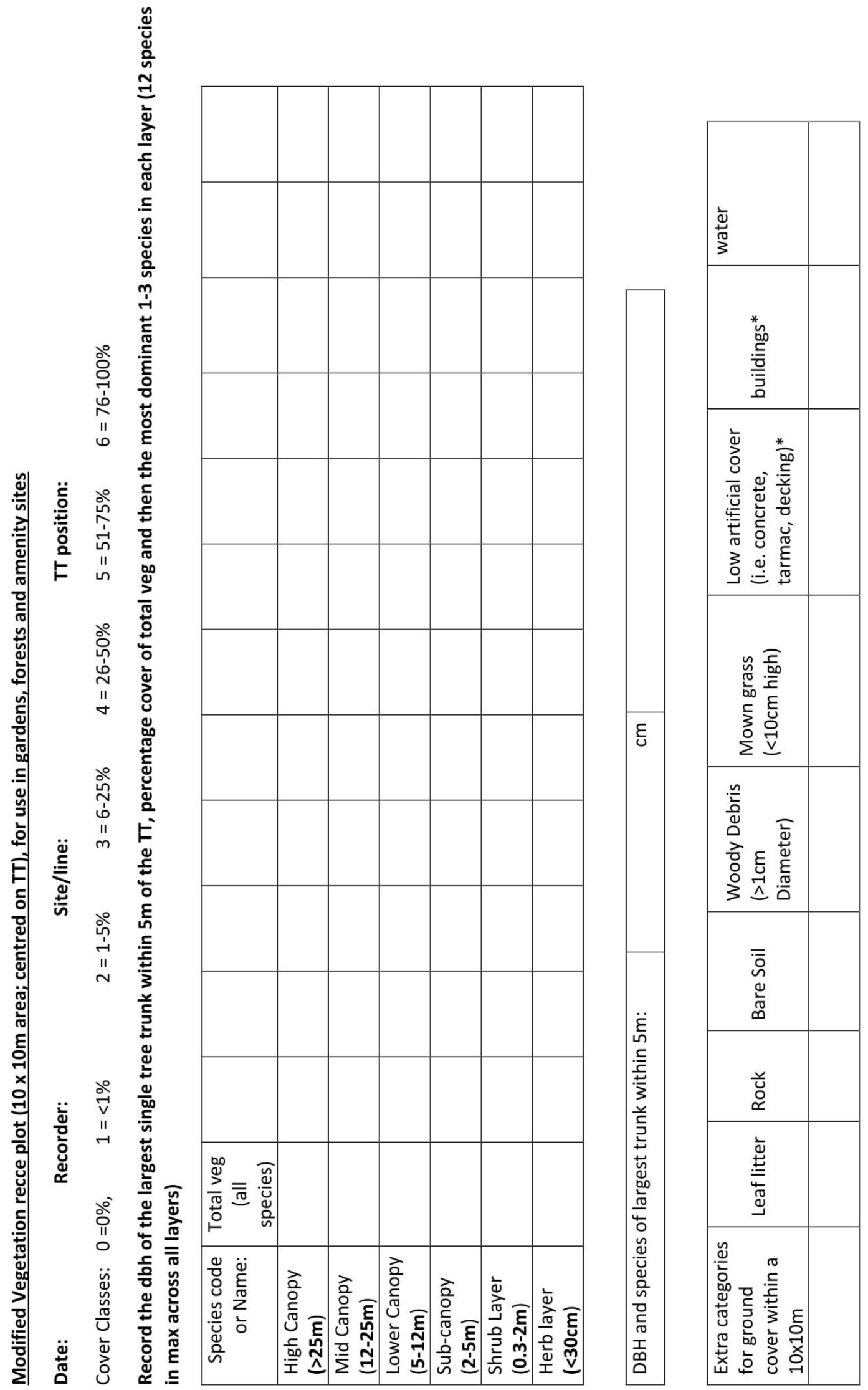




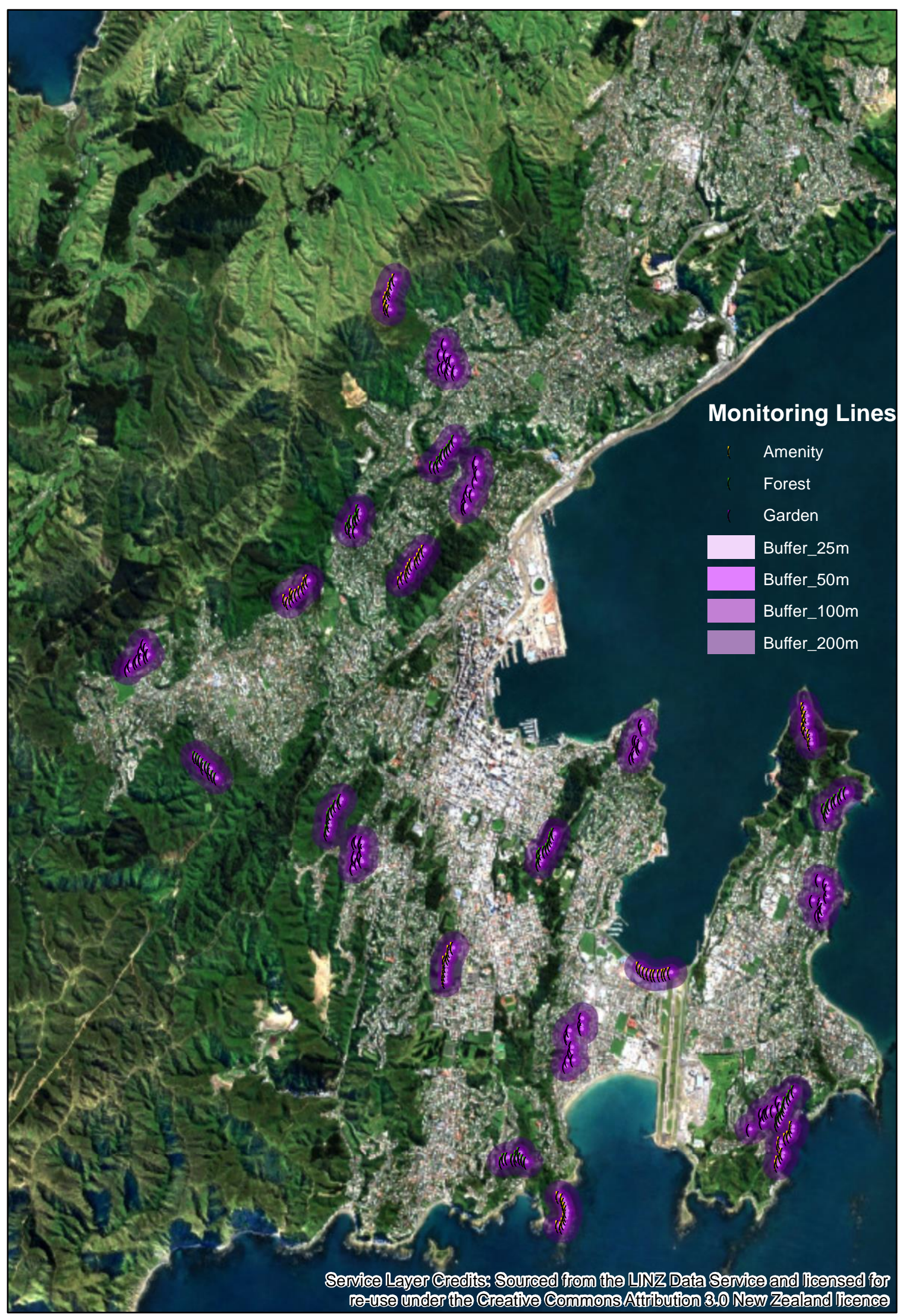

Figure A2.3: Map of the buffer zones created around the 240 mammal monitoring stations to assess trap density in Wellington. Buffers measure a $25 \mathrm{~m}, 50 \mathrm{~m}, 100 \mathrm{~m}$ and $200 \mathrm{~m}$ radius around stations. 


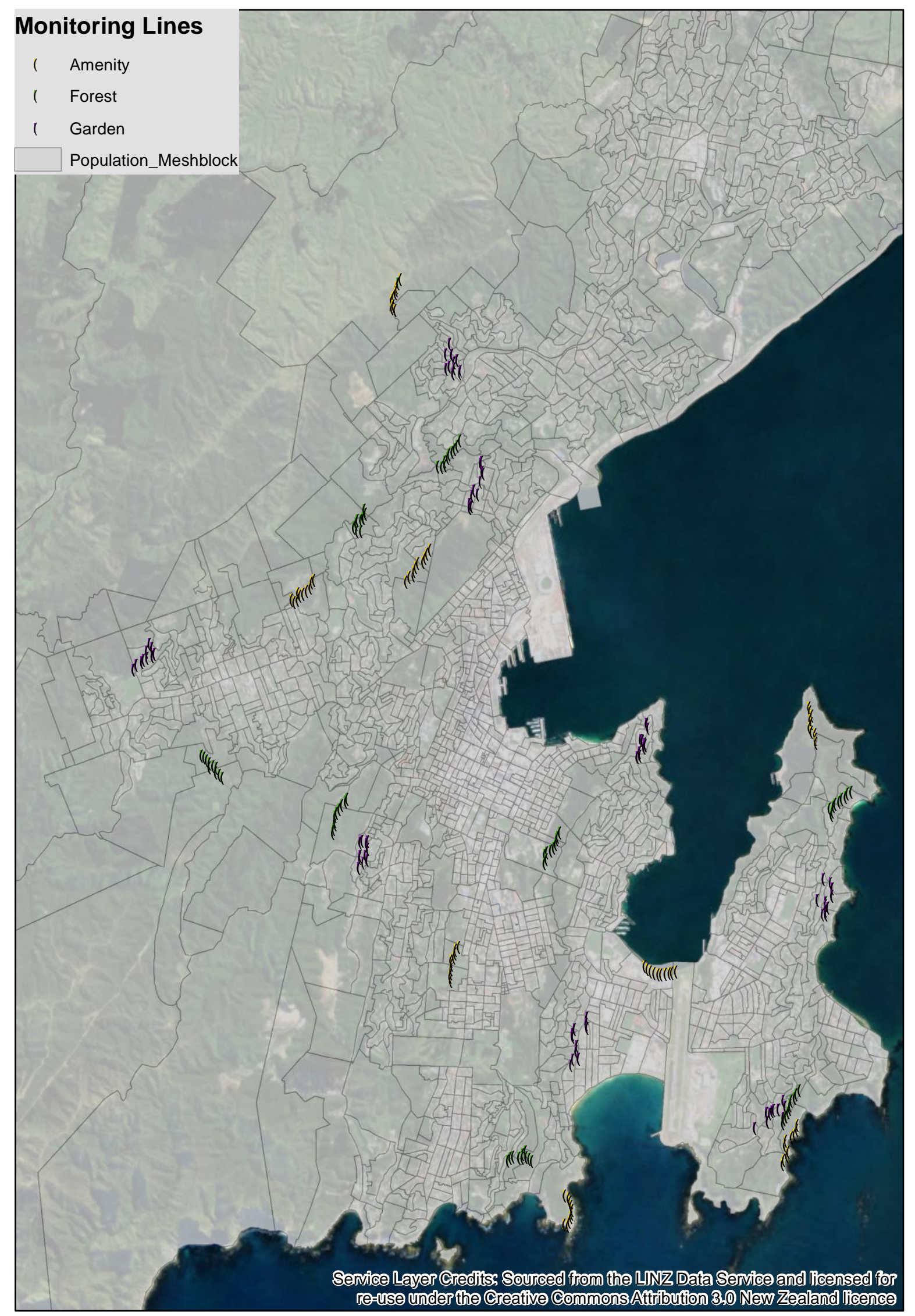

Figure A2.4: Map of the mesh blocks used to estimate human population within the 240 monitoring stations in Wellington. 


\section{Land cover}

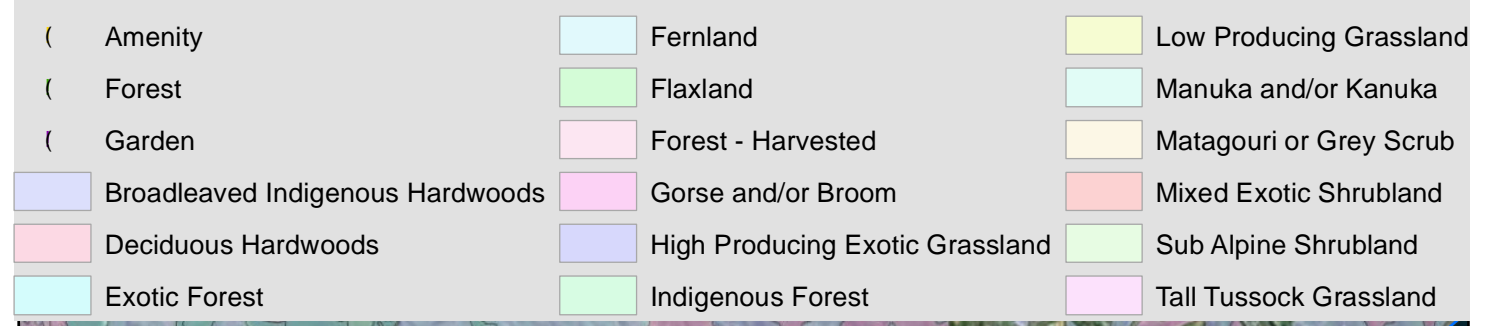

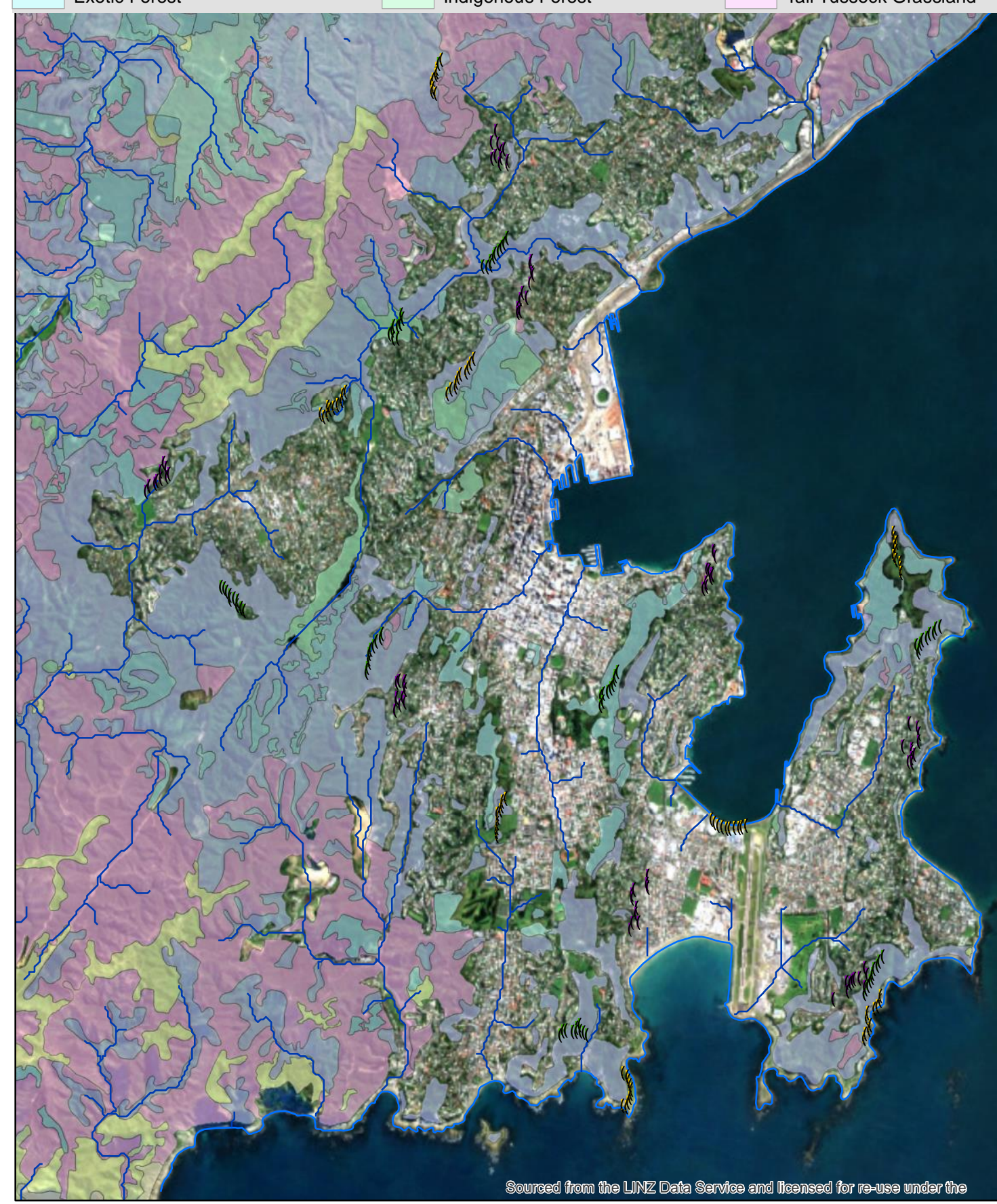

Figure A2.5: Map of the various vegetation fragment land cover layers used in the analysis assessing the influence of sites and their proximity to areas of vegetation. The vegetation categories represent those determined in the Land Cover Database, 2013, and are not representative of the vegetation types occurring in residential backyards. Urban areas are uncategorised and this information was not available in the database. 
Table A2.1: Spearman correlations between combinations of the six vegetation tiers used in GLMM models.

\begin{tabular}{|c|c|c|}
\hline Vegetation & $S$ & $p$ \\
\hline Tier1 + Tier2 & 15165000 & $<0.001$ \\
\hline Tier1 + Tier3 & 19730000 & 0.12 \\
\hline Tier1 + Tier4 & 21856000 & $<0.001$ \\
\hline Tier1 + Tier5 & 17727000 & 0.40 \\
\hline Tier1 + Tier6 & 16745000 & 0.05 \\
\hline Tier2 + Tier3 & 20018000 & 0.06 \\
\hline Tier2 + Tier4 & 23188000 & 0.00 \\
\hline Tier2 + Tier5 & 19405000 & 0.25 \\
\hline Tier2 + Tier6 & 18785000 & 0.68 \\
\hline Tier3 + Tier4 & 14655000 & $<0.001$ \\
\hline Tier3 + Tier5 & 16943000 & 0.08 \\
\hline Tier3 + Tier6 & 16404000 & 0.02 \\
\hline Tier4 + Tier5 & 17187000 & 0.14 \\
\hline Tier4 + Tier6 & 19120000 & 0.41 \\
\hline Tier5 + Tier6 & 16503000 & 0.02 \\
\hline
\end{tabular}


Table A2.2: Spearman correlations between the six vegetation tiers and their relationship with distances from environmental variables used in GLMM models.

\begin{tabular}{lcc}
\hline \hline Distance to coast & $\mathrm{S}$ & $p$ \\
\hline Tier 1 & 16632000 & 0.03 \\
Tier 2 & 19499000 & 0.21 \\
Tier 3 & 15781000 & $<0.001$ \\
Tier 4 & 16110000 & 0.01 \\
Tier 5 & 15702000 & $<0.001$ \\
Tier 6 & 16567000 & 0.03 \\
\hline \hline & & \\
\hline \hline Distance to stream & $\mathrm{S}$ & $p$ \\
\hline Tier 1 & 19499000 & 0.21 \\
Tier 2 & 19849000 & 0.09 \\
Tier 3 & 19424000 & 0.24 \\
Tier 4 & 22464000 & $<0.001$ \\
Tier 5 & 20891000 & $<0.001$ \\
Tier 6 & 21394000 & $<0.001$ \\
\hline \hline & & \\
\hline \hline Distance to vegetation & $\mathrm{S}$ & $p$ \\
\hline Tier 1 & 19121000 & 0.41 \\
Tier 2 & 21188000 & $<0.001$ \\
Tier 3 & 22535000 & $<0.001$ \\
Tier 4 & 20960000 & $<0.001$ \\
Tier 5 & 23535000 & $<0.001$ \\
Tier 6 & 20838000 & $<0.001$ \\
\hline \hline
\end{tabular}


Table A2.3: GLMM table reporting the influence of various landscape and microhabitat variables on the three alternative models for rat detections.

\begin{tabular}{|c|c|c|c|}
\hline a) Rat $25 \mathrm{~m}$ & Chisq & df & $\operatorname{Pr}(>$ Chisq $)$ \\
\hline (Tier1 + Tier2) & 0.162 & 1 & 0.69 \\
\hline$($ Tier3 + Tier $4+$ Tier5+ Tier6) & 1.223 & 1 & 0.27 \\
\hline $\mathrm{I}(\log 10($ dist2veg +1$))$ & 0.075 & 1 & 0.78 \\
\hline $\mathrm{I}(\log 10($ dist2stream $))$ & 3.212 & 1 & 0.07 \\
\hline $\mathrm{I}(\log 10($ dist 2 coast $))$ & 2.070 & 1 & 0.15 \\
\hline Habitat & 4.168 & 2 & 0.12 \\
\hline I(sqrt(hpopulation)) & 0.310 & 1 & 0.58 \\
\hline Season & 14.533 & 1 & $<0.001$ \\
\hline Traps_25m & 1.021 & 1 & 0.31 \\
\hline Trap_type 25 & 4.208 & 6 & 0.65 \\
\hline b) Rat $100 \mathrm{~m}$ & Chisq & $\mathrm{df}$ & $\operatorname{Pr}(>$ Chisq $)$ \\
\hline (Tier1 + Tier2) & 0.324 & 1 & 0.57 \\
\hline$($ Tier3 + Tier4 + Tier5+ Tier6) & 0.861 & 1 & 0.35 \\
\hline $\mathrm{I}(\log 10($ dist2veg +1$))$ & 2.319 & 1 & 0.13 \\
\hline $\mathrm{I}(\log 10($ dist2stream $))$ & 0.024 & 1 & 0.88 \\
\hline $\mathrm{I}(\log 10($ dist2coast $))$ & 2.259 & 1 & 0.13 \\
\hline Habitat & 6.738 & 2 & 0.03 \\
\hline I(sqrt(hpopulation)) & 0.121 & 1 & 0.73 \\
\hline Season & 16.938 & 1 & $<0.001$ \\
\hline Traps_100m & 2.942 & 1 & 0.09 \\
\hline Trap_type 100 & 5.168 & 7 & 0.64 \\
\hline c) Rat $200 \mathrm{~m}$ & Chisq & $\mathrm{df}$ & $\operatorname{Pr}(>$ Chisq $)$ \\
\hline$($ Tier1 + Tier2) & 0.188 & 1 & 0.66 \\
\hline (Tier3 + Tier4 + Tier5+ Tier6) & 1.313 & 1 & 0.25 \\
\hline $\mathrm{I}(\log 10($ dist2veg + 1) $)$ & 1.960 & 1 & 0.16 \\
\hline $\mathrm{I}(\log 10($ dist2stream $))$ & 0.083 & 1 & 0.77 \\
\hline $\mathrm{I}(\log 10($ dist2coast $))$ & 3.029 & 1 & 0.08 \\
\hline Habitat & 3.813 & 2 & 0.15 \\
\hline I(sqrt(hpopulation)) & 0.328 & 1 & 0.57 \\
\hline Season & 13.860 & 1 & $<0.001$ \\
\hline Traps_200m & 0.102 & 1 & 0.75 \\
\hline Trap_type200 & 4.078 & 6 & 0.67 \\
\hline
\end{tabular}


Table A2.4: GLMM table reporting the influence of various landscape and microhabitat variables on the three alternative models for mouse detections.

\begin{tabular}{lccc}
\hline \hline a) Mouse 50m & Chisq & df & $\operatorname{Pr}(>$ Chisq $)$ \\
\hline (Tier1 + Tier2) & 1.095 & 1 & 0.30 \\
$($ Tier3 + Tier4 + Tier5+ Tier6) & 2.258 & 1 & 0.13 \\
I(log10(dist2veg + 1)) & 0.669 & 1 & 0.41 \\
I(log10(dist2stream)) & 0.714 & 1 & 0.40 \\
I(log10(dist2coast)) & 1.436 & 1 & 0.23 \\
Habitat & 5.299 & 2 & 0.07 \\
I(sqrt(hpopulation)) & 0.166 & 1 & 0.68 \\
Season & 35.435 & 1 & $<0.001$ \\
Traps_50m & 1.005 & 1 & 0.32 \\
Trap_type & 3.813 & 6 & 0.70 \\
\hline \hline
\end{tabular}

\begin{tabular}{lccc}
\hline \hline b) Mouse 100m & Chisq & df & Pr(>Chisq) \\
\hline (Tier1 + Tier2) & 1.030 & 1 & 0.31 \\
(Tier3 + Tier4 + Tier5+ Tier6) & 2.140 & 1 & 0.14 \\
I(log10(dist2veg + 1)) & 0.743 & 1 & 0.39 \\
I(log10(dist2stream)) & 0.714 & 1 & 0.40 \\
I(log10(dist2coast)) & 1.448 & 1 & 0.23 \\
Habitat & 5.152 & 2 & 0.08 \\
I(sqrt(hpopulation)) & 0.222 & 1 & 0.64 \\
Season & 34.822 & 1 & $<0.001$ \\
Traps_100m & 0.267 & 1 & 0.61 \\
Trap_type & 3.766 & 6 & 0.71 \\
\hline \hline & & & \\
\hline \hline c) Mouse 200m & Chisq & df & Pr(>Chisq) \\
\hline (Tier1 + Tier2) & 1.161 & 1 & 0.28 \\
(Tier3 + Tier4 + Tier5+ Tier6) & 2.147 & 1 & 0.14 \\
I(log10(dist2veg + 1)) & 0.612 & 1 & 0.43 \\
I(log10(dist2stream)) & 0.713 & 1 & 0.40 \\
I(log10(dist2coast)) & 1.738 & 1 & 0.19 \\
Habitat & 6.042 & 2 & 0.05 \\
I(sqrt(hpopulation)) & 0.121 & 1 & 0.73 \\
Season & 33.529 & 1 & $<0.001$ \\
Traps_200m & 1.397 & 1 & 0.24 \\
Trap_type & 3.189 & 6 & 0.78 \\
\hline \hline
\end{tabular}


Table A2.5: GLMM table reporting the influence of various landscape and microhabitat variables on the three alternative models for hedgehog detections.

\begin{tabular}{lccc}
\hline \hline a) Hedgehog 25m & Chisq & df & $\operatorname{Pr}(>$ Chisq $)$ \\
\hline (Tier1 + Tier2) & 0.131 & 1 & 0.72 \\
$($ Tier3 + Tier4 + Tier5+ Tier6) & 0.002 & 1 & 0.97 \\
I(log10(dist2veg + 1)) & 0.076 & 1 & 0.78 \\
I(log10(dist2stream)) & 0.365 & 1 & 0.55 \\
I(log10(dist2coast)) & 0.731 & 1 & 0.39 \\
Habitat & 3.057 & 2 & 0.22 \\
I(sqrt(hpopulation)) & 2.738 & 1 & 0.10 \\
Season & 9.783 & 1 & $<0.001$ \\
Traps_25m & 0.893 & 1 & 0.34 \\
Trap_type & 4.595 & 6 & 0.60 \\
\hline \hline
\end{tabular}

\begin{tabular}{lccc}
\hline \hline b) Hedgehog 50m & Chisq & df & $\operatorname{Pr}(>$ Chisq $)$ \\
\hline (Tier1 + Tier2) & 0.161 & 1 & 0.69 \\
$($ Tier3 + Tier4 + Tier5+ Tier6) & 0.038 & 1 & 0.84 \\
I(log10(dist2veg + 1)) & 0.009 & 1 & 0.92 \\
I(log10(dist2stream)) & 0.177 & 1 & 0.67 \\
I(log10(dist2coast)) & 0.610 & 1 & 0.43 \\
Habitat & 0.529 & 2 & 0.77 \\
I(sqrt(hpopulation) $)$ & 4.299 & 1 & 0.04 \\
Season & 10.155 & 1 & $<0.001$ \\
Traps_50m & 0.031 & 1 & 0.86 \\
Trap_type & 4.142 & 6 & 0.66 \\
\hline \hline
\end{tabular}

\begin{tabular}{lccc}
\hline \hline c) Hedgehog 100m & Chisq & df & $\operatorname{Pr}(>$ Chisq $)$ \\
\hline (Tier1 + Tier2) & 0.119 & 1 & 0.73 \\
$($ Tier3 + Tier4 + Tier5+ Tier6) & 0.010 & 1 & 0.92 \\
I(log10(dist2veg + 1)) & 0.030 & 1 & 0.86 \\
I(log10(dist2stream)) & 0.158 & 1 & 0.69 \\
I(log10(dist2coast)) & 0.594 & 1 & 0.44 \\
Habitat & 0.382 & 2 & 0.83 \\
I(sqrt(hpopulation)) & 4.496 & 1 & 0.03 \\
Season & 8.961 & 1 & $<0.001$ \\
Traps_100m & 0.260 & 1 & 0.61 \\
Trap_type & 4.333 & 6 & 0.63 \\
\hline \hline
\end{tabular}




\section{Appendix 3}

\section{Appendices for Chapter 4}

Table A3.1: Results for the Pearson correlation between the total number of catches and the total number of traps within a trap group.

\begin{tabular}{lcccc}
\hline \hline & $\boldsymbol{t}$ & $\mathbf{d f}$ & $\boldsymbol{p}$ & $\boldsymbol{R}$ \\
\hline Rat & 4.8309 & 13 & $<0.001$ & 0.8014 \\
Mouse & 3.8946 & 13 & 0.0018 & 0.7338 \\
Hedgehog & 2.6434 & 13 & 0.0203 & 0.5913 \\
Stoat & -0.5341 & 13 & 0.6023 & -0.1465 \\
Weasel & -0.2125 & 13 & 0.835 & -0.0588 \\
Total & 4.5351 & 13 & $<0.001$ & 0.7828 \\
\hline \hline
\end{tabular}

Table A3.2: Linear model results for the association between the total number of catches and the total number of traps within a trap group. $R^{2}$ values represent the adjusted $R^{2}$ reported in the model summary.

\begin{tabular}{lccccc}
\hline \hline Trap Number & Estimate & Std. Error & z value & $\operatorname{Pr}(>|\mathbf{z}|)$ & $\boldsymbol{R} \mathbf{2}$ \\
\hline Rat & 0.9804 & 0.2029 & 4.831 & $<0.001$ & 0.6147 \\
Mouse & 0.8974 & 0.2304 & 3.895 & 0.0018 & 0.503 \\
Hedgehog & 0.0518 & 0.0196 & 2.643 & 0.0203 & 0.2996 \\
Stoat & -0.0011 & 0.0021 & -0.534 & 0.602 & -0.0538 \\
Weasel & -0.0004 & 0.0018 & -0.212 & 0.835 & -0.0732 \\
Total & 1.9280 & 0.4251 & 4.535 & $<0.001$ & 0.5829 \\
\hline \hline
\end{tabular}


Table A3.3: GLMM table reporting the differences between associations of season and area on hedgehog catches. Highlighted variables are the comparisons between residential and reserve sites across the same season.

\begin{tabular}{|c|c|c|c|c|}
\hline Variables & Estimate & Std. Error & $\mathrm{z}$ value & $\operatorname{Pr}(>|\mathbf{z}|)$ \\
\hline Autumn Residential - Autumn Reserve & -0.78452 & 0.20104 & -3.902 & 0.002 \\
\hline Spring Reserve - Autumn Reserve & -0.65364 & 0.27912 & -2.342 & 0.255 \\
\hline Spring Residential - Autumn Reserve & -1.04386 & 0.23133 & -4.512 & $<0.001$ \\
\hline Summer Reserve - Autumn Reserve & 0.9178 & 0.19266 & 4.764 & $<0.001$ \\
\hline Summer Residential - Autumn Reserve & -0.08804 & 0.20829 & -0.423 & 1.000 \\
\hline Winter Reserve - Autumn Reserve & -0.43055 & 0.25001 & -1.722 & 0.655 \\
\hline Winter Residential - Autumn Reserve & -2.48961 & 0.35506 & -7.012 & $<0.001$ \\
\hline Spring Reserve - Autumn Residential & 0.13088 & 0.27407 & 0.478 & 1.000 \\
\hline Spring Residential - Autumn Residential & -0.25935 & 0.20319 & -1.276 & 0.900 \\
\hline Summer Reserve - Autumn Residential & 1.70232 & 0.1856 & 9.172 & $<0.001$ \\
\hline Summer Residential - Autumn Residential & 0.69648 & 0.17236 & 4.041 & 0.001 \\
\hline Winter Reserve - Autumn Residential & 0.35397 & 0.24237 & 1.46 & 0.816 \\
\hline Winter Residential - Autumn Residential & -1.70509 & 0.33661 & -5.065 & $<0.001$ \\
\hline Spring Residential - Spring Reserve & -0.39023 & 0.29735 & -1.312 & 0.886 \\
\hline Summer Reserve - Spring Reserve & 1.57144 & 0.27018 & 5.816 & $<0.001$ \\
\hline Summer Residential - Spring Reserve & 0.5656 & 0.27959 & 2.023 & 0.447 \\
\hline Winter Reserve - Spring Reserve & 0.22309 & 0.3137 & 0.711 & 0.996 \\
\hline Winter Residential - Spring Reserve & -1.83597 & 0.40112 & -4.577 & $<0.001$ \\
\hline Summer Reserve - Spring Residential & 1.96167 & 0.2185 & 8.978 & $<0.001$ \\
\hline Summer Residential - Spring Residential & 0.95582 & 0.20873 & 4.579 & $<0.001$ \\
\hline Winter Reserve - Spring Residential & 0.61331 & 0.2686 & 2.283 & 0.286 \\
\hline Winter Residential - Spring Residential & -1.44575 & 0.35684 & -4.052 & 0.001 \\
\hline Summer Residential - Summer Reserve & -1.00585 & 0.19359 & -5.196 & $<0.001$ \\
\hline Winter Reserve - Summer Reserve & -1.34835 & 0.24007 & -5.616 & $<0.001$ \\
\hline Winter Residential - Summer Reserve & -3.40741 & 0.34684 & -9.824 & $<0.001$ \\
\hline Winter Reserve - Summer Residential & -0.34251 & 0.24874 & -1.377 & 0.858 \\
\hline Winter Residential - Summer Residential & -2.40157 & 0.34037 & -7.056 & $<0.001$ \\
\hline Winter Residential - Winter Reserve & -2.05906 & 0.38036 & -5.413 & $<0.001$ \\
\hline
\end{tabular}

